
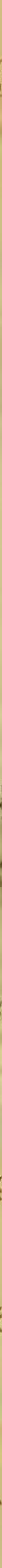
I-wille

DAv

Seationed Intsrosry 

(Aus dem Zoologischen Institut der Universität Jena.)

$196 d$

\section{Untersuchungen über den}

\section{anatomischen Bau der Lungenschnecke}

\section{Stenogyra decollata L.}

\section{Inaugural-Dissertation}

zur

Erlangung der Doktorwürde

$-10$.

der

Hohen philosophischen Fakultät der Universität Jena

vorgelegt von

Johannes Wille

aus Gera-Reuß

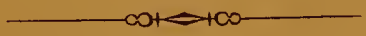

Druck von Ant. Kämpfe in Jena 1915 

QL (Aus dem Zoologischen Institut der Universität Jena.)

$\sqrt{30.4}$

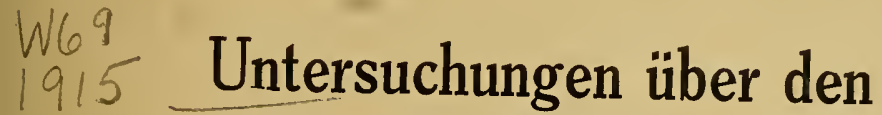

\section{anatomischen Bau der Lungenschnecke}

Moll. Stenogyra decollata

Division of Molluets.

Inaugural-Dissertation

Sectional Library

zur

Erlangung der Doktorwürde

der

Hohen philosophischen Fakultät der Universität Jena

vorgelegt von

Johannes Wille

aus Gera-Reuß"
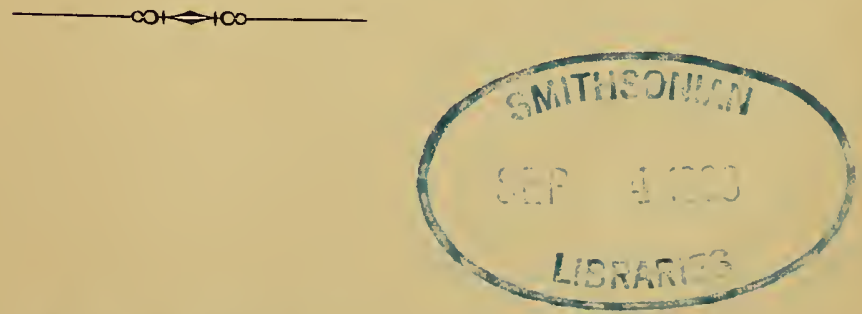

Druck von Ant. Kämpfe in Jena

1915 
Genehmigt von der philosophischen Fakultät der Universität Jena auf Antrag des Herrn Professor Dr. Plate.

J en a, den 28. Juli 1914.

Prof. Dr. Rein.

d. Zt. Dekan.

Abdruck aus der „Jenaischen Zeitschrift", Bd. LIII, Heft 4. 1915. 


\section{Meinen lieben Eltern}

in Dankbarkeit gewidmet. 



\section{Inhaltsverzeichnis.}

Vorbemerkung $\cdot$ Seite

orbemerkung • • . . . . . . . . . . . . . . . . . . . . . . . 1

I. Äußere Körperform und Lebensweise . . . . . . . . . . 2

II. Das Integument und seine Differenzierungen . . . . . . . . . 3

III. Schale und Dekollation . . . . . . . . . . . . . . . 8

IV. Muskulatur und Bindegewebe . . . . . . . . . . . . . 14

V. Nervensystem und Sinnesorgane . . . . . . . . . . . . . . . 19

VI. Darmkanal . . . . . . . . . . . . . . . . . . . . 29

VII. Lunge, Niere und Blutkreislauf . . . . . . . . . . . . 50

VIII. Geschlechtssystem . . . . . . . . . . . . . . . . . 60

IX. Zusammenfassung der wichtigsten Ergebnisse . . . . . . . . . 79

Literaturverzeichnis . . . . . . . . . . . . . . . . . . . . . . . . . . .

Erklärung der Figuren . . . . . . . . . . . . . . . . . . . 85 



\section{Vorbemerkung.}

Die merkwürdige Erscheinung der Dekollation, wie sie sich bei Stenogyra decollata L. und einigen anderen Pulmonaten findet, ist bisher noch nicht Gegenstand eingehender Untersuchungen gewesen. Da auch die anatomischen Verhältnisse von Stenogyra noch verschiedenes Neue boten, so schlug mir mein hochverehrter Lehrer, Herr Prof. Dr. L. Plate, vor, diese Form zu bearbeiten.

Bisher haben folgende Autoren über Stenogyra decollata in kürzeren Bemerkungen berichtet: Wiggmann (allgemein); JoHNston, Simroth (Dekollation); von Jhering, Amaudrut, Nabias, H. DE LACAZE-Duthiers (Nervensystem); AmaUdrut (Muskulatur); Semper (Niere); Dubrueil, A. Schmidt (Geschlechtsorgane).

Für das Material, welches Herr Prof. Plate in Rovigno gesammelt hatte, und welches er mir überließ, sowie für das große Interesse und liebenswürdige Entgegenkommen, mit dem er mir die ersten Anleitungen zu meiner Arbeit gab, spreche ich ihm meinen besten Dank aus. Besonders fühle ich mich verpflichtet, meinem hochverehrten Lehrer, Herrn Prof. Dr. J. MeIseNHEIMER, ergebenst zu danken, der mir mit vielen Anregungen und unermüdlichem Interesse bei der Vollendung dieser Arbeit zur Seite stand. Ebenfalls danke ich Herr Privatdozenten Dr. A. HASE, der mich stets mit Rat und Tat unterstützte. Ferner spreche ich dem Leiter der K. K. Zoologischen Station zu Triest, Herrn Prof. Dr. C. J. CoRI, meinen verbindlichsten Dank aus für die freundliche und bereitwillige Übersendung einer großen Zahl lebender Stenogyren. 
Die Untersuchungen wurden vorgenommen an Totalpräparaten und an Schnittserien, die durch das ganze Tier oder durch die einzeln herauspräparierten Organe geführt wurden. Das lebende Material wurde einesteils zur Beobachtung der Dekollation verwandt, anderenteils für feinere Untersuchungen fixiert. Als Fixierungsmittel bewährte sich Sublimat-Alkohol-Eisessig (1 Teil abs. Alkohol, 2 Teile Sublimat und einige Tropfen Eisessig). Als Entkalkungsflüssigkeit benutzte ich das Salpetersäure-Alkoholgemisch nach ОRTH. Zu den Färbungen wurde bei Hämalaun- oder Hämatoxylinvorfärbung Nachfärbung mit vaN GIESONschem Pikrinsäure-Säurefuchsingemisch $(1000: 25)$ oder Nachfärbung mit Eosin angewandt. Bei der Identifizierung der Drüsen gab Bismarckbraun, bei Radulafärbungen Ammoniumrubinpikrat gute Resultate. Bei der Färbung von Totalpräparaten bewährte sich Alaunkarmin.

\section{I. Äußere Körperform und Lebensweise.}

Die Schale von Stenogyra decollata ist hoch turmförmig mit zahlreichen (4-12) Windungen, welche nur langsam an Größe zunehmen. Der Mündungsrand ist einfach, ohne Zähne oder Falten. Die Schalenoberfläche ist einfarbig gelblich, glänzend und ganz fein gerippt, parallel zu den Anwachsstreifen. Die Schale ist sehr dünn und durchscheinend. Die Umgänge sind ganz wenig gewölbt; der letzte Umgang nimmt ein Viertel bis ein Drittel der Gehäuselänge ein. Die Mündung steht fast senkrecht und ist spitzeiförmig. Mundsaum mit einer schwachen Lippe versehen. An den Nähten feine Streifungen wie Kerben. Die Kolumella ist hohl. Die Schalen sind rechtsgewunden.

An allen älteren Tieren sind die oberen Windungen abgebrochen und ein neuer, an der Kolumella mit runder Kuppe beginnender Apex gebildet. Junge Tiere, bei denen die Dekollation noch nicht eingetreten ist, haben einen stumpfen Scheitel. Diese Verhältnisse werden uns später genauer beschäftigen.

Die Länge der Gehäuse schwankt je nach dem Alter des Tieres und der Dekollation zwischen 1,5 und $3,5 \mathrm{~cm}$ bei vier bzw. neun Windungen.

In der äußeren Körperform gleicht Stenogyra den von Helix her bekannten Verhältnissen.

Die Fußsohle ist weißlich, die übrigen Teile des Integuments schwärzlich. Die von Herrn Prof. Plate in Rovigno gesammelten Exemplare waren dunkler als die Triester Tiere. 
Die merkwürdige Erscheinung der Dekollation veranlaßte es, daß das Tier schon lange bekannt war. LINNÉ beschreibt unser Tier als Helix decollata. Von da an hat der Genus-Name versehiedene Wandlungen durchgemacht, wie Bulimus dec., Buliminus dec., bis die Art jetzt in die Gattung Stenogyra Shuttleworth gerechnet wird. Risso setzt sie hier noch in die Untergattung Rumina. Der von A. Sснміdт vorgeschlagene Name Sira decollata fand keine Verbreitung.

Das Verbreitungsgebiet von Stenogyra decollata liegt in den Mittelmeerländern, und die Schnecke ist jetzt auch in Nordamerika in Charleston anzutreffen, wo sie eingeschleppt ist. Sie kommt ziemlich gemein in Gärten, wie auch in der freien Natur vor.

Wie ich an meinen lebenden Tieren beobachten konnte, bildet die Nahrung Pflanzenkost; Salat und Kohlblätter wurden besonders gern von den Tieren verzehrt. Daneben verschlucken sie aber große Mengen von Erde. Dies bereitete bei der Anfertigung von Schnittserien große Schwierigkeiten; infolgedessen wurden die Tiere vor der Fixierung einige Tage lang mit feuchtem Fließpapier gefüttert, bis die Fäzes keine Erdteile mehr enthielten.

Das Tier verkriecht sich am Tage meist unter Steine, oder es bohrt sich in die Erde ein. Hierbei sieht dann bloß der Apex ein wenig über dem Erdboden hervor.

Mitte November verkrochen sich die Tiere sämtlich in die Erde, ohne daß von ihnen noch etwas zu sehen war. Gräbt man die Tiere aus, so findet sich ein dünnes häutiges Epiphragma an der Mündungsöffnung. $\mathrm{Da}$ mehrere Epiphragmen hintereinander abgeschieden wurden, konnte ich nicht feststellen.

Die lebenden Tiere, die ich aus Triest gesandt bekam, wurden in einem großen, mit einer Erdschicht bedeckten Käfig gehalten, der im Freien aufgestellt wurde. In die Erde wurde Gras ausgesät und aus einigen Kalksteinen Verstecke und Schlupfwinkel gebaut. Die Tiere fühlten sich anscheinend sehr wohl und munter in unserem Klima. Gestorben ist kein einziges.

\section{Das Integument und seine Differenzierungen.}

Den ganzen Körper überzieht ein einschichtiges Epithel, dessen Höhe in den einzelnen Körperteilen verschieden ist. Hohes Zylinderepithel findet sich in der vorderen Kopfregion, niedrigeres bekleidet den Fuß und die übrigen nicht von der Schale bedeckten Körperteile. Der spiralig eingerollte Eingeweidesack führt kubisches 
Epithel als Integument. Dieses zeigt schwache Erhöhung an den Außenrändern zwischen den Nähten und auf dem obersten, an die konkave Scheidewand angrenzenden Umgang. Nach der Kiolumella $\mathrm{zu}$ wird es sehr niedrig, und ist hier ein Plattenepithel. An der Anheftungsstelle des Kolumellarmuskels an die Schale zeigt das Epithel eine besondere Differenzierung, die wir dort besprechen. Eine Cuticula findet sich an allen außerhalb der Schale gelegenen Körperteilen, besonders stark entwickelt am Kopf. Der Fuß zeigt auf seiner gesamten Sohlenfläche, aber nicht an den Seitenteilen deutliche Flimmern (Textfig. 1). Den Epithel schließen sich nach innen als Stütze fibrilläres Binde-

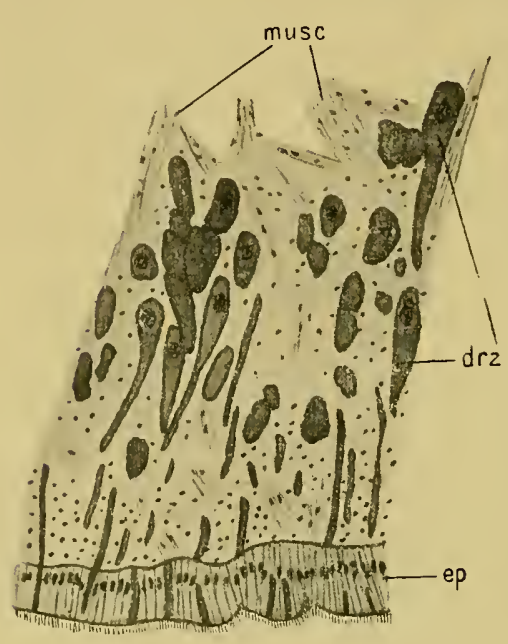

Textfig. 1. Schnitt durch die Fußsohle. Vergr. $225: 1$. gewebe und zahlreiche Muskelfasern an. Das Pigment tritt in verzweigten Bindegewebszellen auf. Spärlich verteilt ist es in der Sohle und im Mantelrand, gänzlich fehlt es an der Mundöffnung an Papillen, die das Mundrohr umstellen.

Charakteristisch für die Schneckenhaut ist der große Reichtum an Drüsenzellen. Sie sind stets einzellig und ragen mehr oder weniger tief bauchig in das Unterhautbindegewebe hinein (Textfig. 1, Taf. 1, Fig. 6). Ihr Sekret entleeren sie nach außen durch einen zwischen den Epithelzellen gelegenen Fortsatz, Wir unter scheiden Schleimdrüsen (schldrz Taf. 1, Fig. 6), Kalkdrüsen $(k d r z)$ und Eiweißdrüsen (eidrz). Alle drei zeigen einen basalständigen. sich dunkel färbenden Kern, um den sich das Protoplasma zusammenzieht, während der übrige Teil der Zelle von Sekret erfüllt ist, oder wenn dieses ausgestoßen ist, leer erscheint. Mit Hämalaun und van Greson färben sich die Schleim- und Kalkdrïsenzellen blau, die Eiweißdrüsenzellen gelb, mit Bismarckbraun die Kalkdrüsen brann. Bei den Eiweißdrüsen (eidrz Taf. 1, Fig. 6) erscheint das Sekret in einen homogenen Tropfen zusammengezogen, bei den Schleimdrüsen (schldrz) ist es grobschaumig und gleichmäßig in der Zelle verteilt; die Kalkulrüsenzellen $(k d r z)$ endlich führen in dem wabigen Inhait noch kleine 
rundliche Granula. Die Verteilung der einzelnen Drüsenarten auf dem Körper ist eine ganz bestimmte. Zunächst ist der von der Schale ständig bedeckte Teil des Körpers gänzlich frei von Drüsen. An der Fußsohle liegen nur Schleimdrüsen, die hier besonders tief gelagert sind und in langen Ausführgängen ihr Sekret nach außen entleeren (Textfig. 1). Sie zeigen hier an der Fußsohle meist einen mittelständigen Kern, während sonst die Schleimdrüsen, z. B. im Mantelsaum basalständige Kerne haben. An den Seitenteilen des Fußes und der Oberseite des Fußes finden sich neben den hier kurzen Schleimdrüsen die Eiweißdrüsen. In großer Menge finden sich im Mantelrand alle drei Arten von Drüsenzellen (Taf. 1, Fig. 6). Hier zeigen sie auch ganz bedeutende Größen. BEck beschreibt bei unseren einheimischen Buliminen eine Nackendrüse an der Verwachsungslinie des Mantels mit dem Nackenintegument. Bei Stenogyra finden sich an dieser Stelle zwar auch zahlreiche große Drüsenzellen, allein zu einer scharfen Differenzierung in einen abgeschlossenen Drüsenkomplex ist es noch nicht gekommen.

Manteldrüse. Dagegen erwähnt Fr. Wiegmans ein Drüsenorgan am Mantelrand von Stenogyra decollata: „Auf der Innenseite des Mantelrandes sitzt ein auch bei Sten. octona beobachtetes, gegen das Pneumostom sich erstreckendes und vermutlich dort öffnendes Drüsenorgan. Ob dasselbe mit der anderwärts zuweilen vorkommenden Analdrüse homolog ist, muß einstweilen unentschieden bleiben." Diese Manteldrüse nimmt die mittlere Partie des Mantelwulstes ein (mtldr Taf. 1, Fig. 1). Sie beginnt links neben dem Atemloch im Atemgang und läuft nach links bis wenig über die Medianlinie des Tieres hinüber. Dabei nimmt sie einen Teil des oberen linken Mantellappens (ol. $m l l)$ ein. Sie hat weder einen Ausführgang, noch liegt sie auf der Innenseite des Mantelrandes. Die Manteldrüse stellt vielmehr einen Komplex einzelliger Drüsen dar, die durch lange Fortsätze ihr Sekret nach außen auf den Mantelwulst und in den Atemgang hinein entleeren. Histologisch setzt sich die Drüse aus zweierlei Drüsenzellen zusammen (Taf. 1, Fig. 2): helleren. bläulich sich färbenden, die Außenseite Einnehmenden ( $v h d r z)$ und dunkleren braunen, nach hinten gelegenen Zellen ( $h d d r z)$. Diese letzteren finden sich einzeln eingesprengt auch noch vorn zwischen den hellen Zellen. Beide Zellsorten zeigen einen großen runden zentral gelegenen Kern mit einem Nucleolus. In den dunklen Kernen der hinteren Zellen findet sich das Chromatin in großen Mengen, so daß der Kern 
beinahe homogen schwarz erscheint. Die vorderen Zellen zeigen dagegen eine losere Verteilung des Chromatins in ihren Kernen, so daß hier der etwas kleinere Kern heller ist. Das Plasma bildet in den hinteren Zellen ein feinmaschiges Wabenwerk, in das die braunen bis gelben Sekretgranula verteilt sind. Dieses Sekret ergießen die Zellen in langen Fortsätzen $(a g)$, die homogen hellgelb aussehen, nach außen. Dabei schlingen sich die langen Fortsätze durch die hellen Zellen hindurch. Diese letzteren zeigen in ihrem Innern ein feines hellblau bis violett mit Hämalaun und van Gieson-Färbung erscheinendes Wabenwerk, in dem sich kleine, ebenso gefärbte Granulationen vorfinden. Das Epithel des oberen Mantellappens, welches sonst Flimmern trägt (Taf. 1, Fig. 1), zeigt diese im Bereiche der Drüse nicht; vielmehr ist das Epithel hier ein einfaches niedrig zylindrisches (ep Taf. ,1 Fig. 2). Die Manteldrüse stellt also eine besondere Differenzierung der einzelligen Hautdrüsen vor. Die Anal- oder Rektaldrüsen dagegen, mit welchen WIEGMANN diese Manteldrüse analogisieren will, sind Ausstülpungen und Blindsäcke des Enddarms. Die Bedeutung der Manteldrüse liegt wahrscheinlich darin, daß sie die aus der Kloake kommenden Abfallstoffe geschmeidig macht und sie so im Grunde des Atemganges nach außen befördert. Da die gleiche Aufgabe des Schlüpfrigmachens der Fäzes den eben erwähnten Analdrüsen zukommt, so hätten wir es bei unserer Manteldrüse mit einem Gebilde $\mathrm{zu}$ tun, welches den Anal- oder Rektaldrüsen nicht homolog, sondern analog wäre.

Fußdrüse. Die Fußdrüse liegt als langgestreckter, runder, weißlicher Schlauch im oberen Muskelgewebe des Fußes in der Mittellinie. Eine besondere bindegewebige Umhüllung, die sich scharf gegen die Fußmuskulatur abhebt, findet sich nicht. Nach hinten endet die Drüse blind eine Strecke vor der Schwanzspitze, nach vorn öffnet sie sich zwischen den inneren Lippen und dem Fußrand (Taf. 1, Fig. 19). Die Drüse wird durchzogen ron einem Kanal, den die Drüsenzellen paketförmig anfangs nur oben und unten, weiter hinten ringförmig, aber hauptsächlich auf der Unterseite umgeben. Der Querschnitt dieses Drüsenkanals erfährt in seinem Verlaufe mannigfache Veränderungen. An der Mündung stellt er eine längliche horizontale Spalte dar, die im ersten Drittel sich elliptisch abrundet. Weiter nach hinten nähert er sich mehr und mehr der Kreisform, wobei das Dach drei in das Kanallumen vorspringende Falten trägt; von diesen ist die mittelste am stärksten ausgebildet (vac Taf. 1, Fig. 4). Die einzelnen 
Drüsenzellen zeigen je nach ihrer Lage in der Drüse verschiedene Struktur und Farbreaktion, die folgenden Angaben der Färbung beziehen sich alle auf Hämalaun van Gieson-Färbung. Am Dach finden sich anfangs dunkelblaue Zellen ( $d d r z$ Taf. 1, Fig. 3), die in einem homogenen dunklen Inhalt kleine blau gefärbte Sekretkörnchen führen. Der runde Kern liegt zentral und ist chromatinreich. Zwischen diesen Zellen finden sich hellgelb gefärbte Drüsenzellen $(h d r z)$, die eine äußerst feine Netzstruktur aufweisen. Ihr Kern ist stark braun färbbar, elliptisch und zentral gelegen. Diese beiden Zellarten ergießen durch Fortsätze zwischen den Epithelzellen des Daches hindurch ihr Sekret in den Gang. Diese Zellen lagern sich zahlreich übereinander und bilden ein ziemlich breites Polster anı Dach des Ganges. Nach hinten hin erniedrigt sich dieses immer mehr, so daß wir in der Mitte nur noch eine Lage von Drüsenzellen an der Oberseite antreffen. Die Zellen finden sich dann auch in den Faltenscheiteln der Wülste am Dach (wu Taf. 1, Fig. 4). Diese Drüsenzellen, die bis zum blinden Ende des Ganges am Dach sich vorfinden, färben sich anders, als die an Anfang gelegenen, nämlich rotbraun ( $d r z$ Taf. 1, Fig. 4). Ihr Protoplasma ist wandständig und blasig und zeigt meist eine große Vakuole (vac). Der große runde Kern ist basal oder seitlich gelegen. Nach dem Ende des Ganges zu werden die Drüsenzellen des Daches von denen der Unterseite umgriffen. Die Zellen der Unterseite ähneln anfangs den Schleimdrüsenzellen der Fußsohle (drz Textfig. 1), mit denen sie an der Mündung der Fußdrüse nach unten hin am vorderen Fußsaum in Verbindung treten. Sie zeigen also eine blaue Farbreaktion und ein grobmaschiges schaumiges Protoplasma und runde Kerne. Bald treten aber an Stelle dieser Zellen von den Seiten her sich eindrängend Drüsenzellen, die die gleiche schaumige Struktur haben, aber sich violett färben. Ihr Kern liegt zentral und weist einen Nucleolus auf. Aber auch die violetten Zellen schwinden wieder und es finden sich dann ungefähr in der hinteren Hälfte der Drüsenunterseite blaugefärbte Zellen ( $d r z$ Taf. 1, Fig. 5). Diese haben um den zentral gelegenen runden Kern, der ein Kernkörperchen führt, einen braunen Protoplasmahof mit ganz feiner Körnelung. Das Übrige der Zelle wird eingenommen von sich stark blaufärbenden, schaumigen Sekreten. Hier zeigen auch die Epithelzellen der Unterseite (ep Taf. 1, Fig. 5) schaumigen Inhalt, der sich stark bläut; ihr Kern läßt sich dadurch nicht immer nachweisen. Alle diese beschriebenen Drüsenzellen ergießen ihre 
Sekrete durch melir oder weniger lange Fortsätze durch die Interzellularen des Epithels des Drüsengangs in diesen. Das Epithel des Ganges zeigt an der Unterseite stets Flimmern (ep Taf. 1, Fig. 5), es ist hier zylindrisch. An den Seiten wird es bedeutend niedriger und geht am Dach, wieder höher werdend, in ein nicht flimmerndes Zylinderepithel über ( $c p$ Taf. 1, Fig. 3, 4). Das flimmernde Epithel der Unterseite des Ganges setzt sich an der Vorderseite des Fußrandes direkt in das Flimmerepithel der Fußsohle fort.

\section{Schale und Dekollation.}

Stenogyra decollata zeigt die merkwürdige Erscheinung, daß die Schale an der Spitze abgebrochen ist (Taf. 1, Fig. 7, 8, 9, 12). Diesen Vorgang, der bei allen älteren Tieren regelmäßig eintritt, bezeichnet man als Dekollation; er findet sich auch noch bei anderen Formen in der Ordnung der Pulmonaten.

Wenn das Tier im Embryonalstadium sich befindet, wird die Schale natürlich nicht als abgebrochener Stumpf angelegt. Infolgedessen zeigen junge einjährige Tiere eine hoch turmförmige, vollkommen ganze Schale mit einem normalen Apex (Taf. 1, Fig. 7 a). Am Ende des ersten Jahres, meist aber erst im zweiten tritt dann die erste Dekollation auf, der dann normalerweise jährlich eine neue folgt. Diese tritt, wie ich an meinem lebenden Material beobachten konnte, meist im Juni auf, also zu einer Zeit, wo die Schnecke den Ansatz neuer Schalensubstanz an Mantelrande hauptsächlich vollendet hat.

Im folgenden wollen wir die einzelnen Stufen der Dekollation betrachten, nämlich den Ansatz neuer Schalensubstanz an der untersten Windung, das Hinabgleiten des Tieres in diese, das Abscheiden eines neuen Apex und das Abbrechen der oberen leeren Umgänge.

- Im Frühjahr setzt das Tier am unteren Schalenrand ein neues Stück Schale an; meist ist dieser neuangesetzte Schalenteil ziemlich groß und beträgt ein bis ein und einhalb Umgänge. In Vergleich hierzu setzt Helix ein viel kleineres Stück neuer Schalensubstanz im Frühjahr an. Durch dieses bedeutende Wachstum der Schale wird das ganze Gehäuse für den Weichkörper des Tieres zu groß, da dieser nicht so schnell an Größe zunimmt, wie neue Schalenteile angesetzt werden. Zugleich sind die neu angefügten unteren Umgänge an Durchmesser größer als die. oberen, fassen also an Volumen viel mehr. 
Die Schnecke rutscht dann mit ihrem Weichkörper aus den oberen Windungen in die unteren hinab, bis sie diese gänzlich bis zum vorderen Rande ausfüllt. Die oberen Umgänge stehen dann leer. Bei dem Vorgang des Hinabgleitens muß der Weichkörper des Tieres, der durch den Kolumellarmuskel an der Spindel befestigt ist, sich zunächst von seiner ursprünglichen Lage loslösen, an der Spindel abwärts gleiten und sich weiter unten von neuem befestigen. Infolge der bestimmten Verhältnisse der Kolumellarmuskelanheftung, die uns später noch beschäftigen, dürfte das dem Tier keine allzugroßen Schwierigkeiten bereiten.

Die oberste Windung des Weichkörpers der Schnecke, also die leizte Spirale des Lebersacks, ragt nun ohne Bedeckung in den oben entstandenen Hohlraum innerhalb der Schale. Sie verhält sich hier genau so, wie ein verletzter, von der Schale entblößter Teil des Schneckenkörpers. Ein solcher verletzter Teil zeigt bekanntlich die Erscheinung der Schalenregeneration, indem er, genau seiner Gestalt sich anpassend, nach außen eine Kalkschicht als Wundverschluß abscheidet. Techow hat bei Gasteropoden die Erscheinung der Schalenregeneration einem eingehenderen Studium unterzogen. Die regeneratorischen Vorgänge, welche sich an Gehäusen finden, denen am Mündungsrand Schalenteile entnommen wurden, kommen für unseren Fall nicht in Betracht. Wir haben nur den Ersatz von Schalenteilen zu berücksichtigen, die mitten aus dem Gehäuse oder am Spindelpol entfernt wurden. Techow fand nun, daß sich an diesen Stellen zunächst ein weißliches organisches Häutchen bildet, welches allmählich durch Kalkanlagerung immer mehr verstärkt wird, so daß zuletzt ein vollkommener Wundverschluß gebildet ist. Die Regenerate entsprechen aber in ihrem Bau durchaus nicht der normalen Schale. Ein ähnliches Verhalten, wie das eben geschilderte, findet sich nun auch an der obersten unbedeckten Windung von Stenogyra. Auch sie bildet eine Kalkschicht, die einen genauen Abguf der oberen Leberwindung darstellt. Dieser neugebildete Apex der Schale unterscheidet sich auch in seinen Strukturverhältnissen, wie wir später sehen werden, von dem gewöhnlichen Bau der Schale. Der neugebildete Apex ist eine konkave Scheidewand (kkvw Taf. 1, Fig. 8), die innen an der Kolumella mit rundlicher Kuppe, die zuweilen auch etwas spitz auslaufen kann, dem Unterrand des obersten Umgangs aufsitzt, sich an der inneren Seite an die Kolumella anschließt, nach außen 
spiralig an dem Außenrand emporsteigt, bis sie die Naht der Windung erreicht (Taf. 1, Fig. 8, 12). Hier schließt sie sich dann dem oberen Rande des ursprünglichen Gehäuses an. Die Scheidewand bildet also eine vollständige Bedeckung des darunter liegenden Leberumgangs. Die Bildung des neuen Apex halte ich also für einen regeneratorischen Vorgang. Die einzelnen Stadien des regeneratorischen Prozesses lassen sich hier nicht genau verfolgen, da ja doch diese Scheidewand im Inneren der Schale abgesondert wird.

Vor dem Hinabgleiten des Weichkörpers in die unteren Windungen bohrt sich die Schnecke vorher in die Erde ein, wobei sie - wie gewöhnlich am Tage - nur mit ihrem Apex aus der Erde hervorsieht. So verbleibt sie einige Zeit; kommt dann das Tier wieder aus seinem Loch hervor, so sind die oberen Windungen weißlich und zeigen damit an, daß sie vom Tier verlassen sind. Es hat sich dann die konkave Scheidewand schon gebildet, die anfangs noch dünn ist, und erst in den nächsten Tagen die Dicke des ausgebildeten Zustandes erreicht.

Bei Tieren, die kurz vor dem Hinabgleiten und dem damit eng verbundenen Abscheiden der konkaven Wand standen, war das Bindegewebe besonders in der Gegend der Leber stark mit Kalkgranulation angefüllt (Taf. 1, Fig. 17). Diese übermäßigen Kalkansammlungen bringe ich in Verbindung mit der Abscheidung des neuen Apex.

Die oberen vom Tier verlassenen und durch die konkave Scheidewand jeder Verbindung mit dem Weichkörper beraubten Schalenteile zeigen eine weißliche Farbe. Diese kommt nur durch Lichtbrechung zustande, nicht etwa durch eine innere Anlagerung von Substanz. Die oberen Windungen der Schale werden vom Tier noch einige Zeit als nutzloser und hinderlicher Balast mit herumgeschleppt, bis sie dann zerfallen. Zuerst tritt stets in der Windung, welche direkt über der Scheidewand liegt, und dort gerade im Scheitel der Außenwand, ein Riß auf (Taf. 1, Fig. 9). $\mathrm{Da}$ es gerade diese Windung und diese Stelle ist, wo zuerst eine Zerstörung auftritt, erklärt sich dadurch, daß gerade diese Stelle mechanischen Einflüssen am meisten ausgesetzt ist. Denn jeder Druck oder Stoß, den das Tier an seiner oberen Spitze beim Graben in der Erde oder auch beim Kriechen erhält, pflanzt sich nach unten im Gehäuse fort. Dabei können die mit dem Weichkörper in Verbindung stehenden Schalenteile dies bequen aushalten, während im oberen Teile dort, wo bewohnter und verlassener Teil sich berühren, die Gefahr des Zerbrechens am größten ist. 
Wir müssen bei allen diesen Vorgängen, die der Abscheidung der konkaven Scheidewand zeitlich folgen, aber noch eins berücksichtigen: den oberen Schalenteilen fehlt jede Verbindung mit dem Tier. Sie sind also in der gleichen Lage wie leere Gehäuse, deren Schnecken gestorben sind. Wie diese im Freien liegend allmählich der Verwitterung anheimfallen, genau so werden die obersten Schalenteile von den zersetzenden Einflüssen der Erde, der Luft und des Regens angegriffen. Da die Schale von Stenogyra an und für sich schon sehr dünn ist, so führt hier der Verwitterungsproze $\beta$ sehr schnell dazu, daß die Schale brüchig und morsch wird. Der zunächst entstehende Riß verbreitert sich, und es entsteht nun eine breite Spalte, durch die hindurch Wasser bequem eindringen kann. So werden dann auch die inneren Teile des verlassenen Gehäuses, besonders aber die Spindel. den zersetzenden äußeren Einflüssen ausgesetzt. Man braucht dann die oberen Windungen bloß leise anzustoßen, und sie brechen ab. Dieser Vorgang spielt sich in der Natur so ab, daß das Tier bei seinem häufigen Bohren im Erdboden, wenn die oberen Windungen morsch genug geworden sind, diese verliert. Dann stehen die äußeren Ränder noch kraterartig nach oben (Taf. 1, Fig. 12) ebenso bleibt auch noch ein Stumpf der Spindel stehen. Mit der Zeit brechen ja hier auch noch Teile ab, aber niemals findet man, daß der durch die Scheidewand neugebildete Apex ganz glatt von den alten Schalenteilen gesäubert ist. Das Abbrechen der verlassenen Schalenteile geschieht also rein mechanisch.

Blainville leitet nach einer Anmerkung Johnstons das Absterben und Zerbrechen des Gewindes davon her, daß die innere Oberfläche der verlassenen Windungen mit einer sehr zerbrechlichen glasigen Rinde überzogen werde. Eine solche glasige Schicht findet sich bei Stenogyra nicht.

Wir sahen also, daß der Prozeß der Dekollation eingeleitet wird durch ein übermäßiges Ansetzen neuer Schalenwindungen, wodurch dann das Gehäuse für das Tier zu groß wird, und dieses die oberen Teile der Schale verläßt und nicht mehr ausfüllt. - Diesen Vorgang finden wir auch bei anderen Formen, ohne daß aber eine Entscheitelung des Gewindes darauf folgte. Nach JoHnston sondern diese Schnecken in dem oberen dünnen und zerbrechlichen Teile der Schale Kalk ab, wodurch diese Teile dann mit einer wandständigen dicken Kalkschicht versehen oder gänzlich mit Kalk ausgefüllt werden. Sімroth gibt an, daß andere Schnecken statt dieser Erscheinung eine zweite innere Schale absondern, so 
daß wir dann doppelte, ineinander geschachtelte Gehäuse erhalten. Das Resultat bei diesen Vorgängen aber ist immer, daß die oberen unbewohnten und für das Tier nutzlosen Teile verstärkt und dadurch vor Abbrechen geschützt werden. Dabei müssen sie aber für das Tier eine bedeutende Last bilden und dieses sehr in seiner Bewegungsfreiheit hindern. Dagegen scheint das Abwerfen der nutzlosen verlassenen Schalenteile, wie es unsere Stenogyra decollata zeigt, eine zweckmäßigere Einrichtung zu sein.

Die feinere Struktur der Schale läßt sich am besten an Dünnschliffen studieren, die senkrecht $\mathrm{zu}$ den Anwachsstreifen und senkrecht zur Außenfläche geführt wurden (Taf. 1, Fig. 10). $\mathrm{Zu}$ äußerst liegt das Periostrakum (perostr), welches ein schmales organisches Häutchen darstellt, das homogen erscheint. Nach innen folgen dann das Ostrakum (ostr) und das Hypostrakum (hypostr), welche beide noch einzelne Schichten wieder unterscheiden lassen. Dem Periostrakum folgt nach innen zunächst eine halbe Kalkschicht (1), die nur spärlich Anwachsstreifen erkennen läßt, dafür aber eineZusammensetzung aus senkrecht zur Schalenoberfläche stehenden Säulchen aufweist. An diese Schicht schließt sich weiterhin eine zweite viel mächtigere an (2), die gelbbraun erscheint. Sie zeigt in größeren Abständen senkrecht zur Oberfläche gestellte Streifungen. ferner eine Längsstreifung parallel zur Oberfläche und noch eine ganz feine diagonale Felderung. Sie setzt sich aus senkrecht zur Oberfläche gestellten Blättchen zusammen und verursacht die hellbraune Färbung der Schale. Nach innen folgen zwei weitere Schichten $(3,4)$, die der Struktur nach gleichartig gebaut sind, von denen aber die äußere (3) dunkler ersclieint als die innere (4). Beide Schichten setzen sich aus Bänderı zusammen, die in der Längsrichtung verlaufen, sie zeigen also die Stalaktitenstruktur Biedermanns. Diese vier eben erwähnten Schichten bilden das Ostrakum. Zu innerst liegt unter den Ostrakum das Hypostrakum (hypostr), welches sich aus zwei Schichten zusammensetzt. Die oberste von diesen beiden (5) besteht aus feinen Kristallnadeln, die senkrecht zur Oberfläche angeordnet sind. Die zweite, innerste Hypostrakumschicht (6) weist dagegen nur Längsstreifen parallel der Außenfläche auf, sie hat also blätterige Struktur.

Die nach dem Hinabgleiten des Tieres oben abgeschiedene Wand zeigt einen anderen Bau als die übrige Schale. Dies läßt sich auch am besten an Dünnschliffen erkennen, die senkrecht zur Außenfläche geführt wurden (Taf. 1, Fig. 11). Zunächst fehlt diesem neugebildeten Apex das Periostrakum, ebenso fehlen die 
vier Schichten des Ostrakums. Der Schliff zeigt nur zwei Schichten, die in ihrem Bau den Schichten 5 und 6 des Hypostrakums der übrigen Schale gleichen. Während in den übrigen Schalenteilen das Hypostrakum nur eine geringe Mächtigkeit besitzt, zeigen oben am neugebildeten Apex die beiden Schichten eine derartig starke Entwicklung, daß die Schale hier genal so dick ist, wie in den übrigen Seitenwänden. Die obere Schicht (5) hat hier eine etwas dunklere Färbung wie die untere (6); im übrigen weist sie die Zusammensetzung aus senkrecht zur Oberfläche angeordneten Kristallnadeln auf, während die untere nur Längsstreifung parallel der Außenfläche zeigt. Wir können also die beiden Schichten der konkaven Scheidewand als verdickte Schichten 5 und 6 des Hypostrakums auffassen.

TECHOw fand bei seinen Regenerationsversuchen, daß die Schalenregenerate nicht den Bau der normalen inneren Blätterschicht, also des Hypostrakums besitzen, sondern ein unregelmäßiges scholliges Gefüge. Dies trifft für Stenogyra also nicht zu, vielmehr zeigt der Querschliff durch den neugebildeten Apex die beiden Hypostrakalschichten in dem für sie charakteristischen Bau. Flächenschliffe, an denen hauptsächlich ТЕсноw die Untersuchungen anstellte, gelangen an der sehr zerbrechlichen Schale von Stenogyra nur unvollkommen, doch bestätigten sie auch die Übereinstimmung des Baues von konkaver Scheidewand und Hypostrakalschicht. Ich glaube also, daß dadurch, daß die oben an der Spitze abgeschiedene Wand sich nur aus den beiden hypostrakalen Schichten aufbaut, die oben erwähnte Annahme bestätigt wird, daß wir bei der Bildung des neuen Apex einen regeneratorischen Vorgang vor uns haben.

Das Epiphragma, das im Winter abgeschieden wird, ist eine weißliche dünne Membran. Besonders starke Kalkeinlagerungen wie bei Helix finden sich nicht in ihm.

Wie Moynier DE VILLEPRIX nachwies, geht das Ansetzen neuer Schalenwindungen vom Mantelrand aus. Hier verläuft rings um den ganzen Mantelsaum eine Furche, die Mantelfurche ( $u$ Taf. 1, Fig. 1). Die niedrigen Epithelzellen dieser Region bilden das Periostrakum. Weiterhin schließt sich an diese Mantelfurche nach hinten ein Polster von hohen Zylinderzellen an, welchen drüsige Funktion zukommt. Dieses Drüsenpolster (drp) färbt sich mit vaN GIESON stets intensiv braun und hat basalständige Kerne. Von dieser Zellgruppe und den nach hinten immer niedriger werdenden Epithelzellen werden die Schichten des Ostrakums 
abgeschieden. Das kubische Epithel des Eingeweidesacks stellt endlich die Bildungsstätte des Hypostrakums dar. Diese Funktion kommt dann besonders auch den obersten Windungen zu, die, wie wir sahen, den neuen Apex abscheiden. Hierbei zeigt jedoch das Epithel der oberen Umgänge keine Differenzierungen gegenüber dem sonstigen Verhalten. Eine Veränderung des Epithels, wie sie TEchow unter regenerierenden Stellen fand, läßt sich nicht konstatieren.

Um die Frage zu entscheiden, ob in der Schale von Stenogyra decollata der kohlensaure Kalk als Kalkspat oder Aragonit abgelagert ist, wandte ich die Kobaltprobe an. Da die gepulverte Schale nach Kochen mit Kobaltnitratlösung und nachfolgender Filtration violett gefärbt war, so ist der Kalk als Aragonit in der Schale abgelagert.

\section{Muskulatur und Bindegewebe.}

Unter der äußeren Epithelbedeckung liegen zahlreiche, sich untereinander verflechtende Muskelstränge. Sie bilden einen Hautmuskelschlauch, bei dem die bindegewebigen Elemente stark zurücktreten (Taf. 1, Fig. 18). Es finden sich die Muskelfasern zu Gruppen vereinigt, die in den drei Richtungen des Raumes verlaufen, also longitudinale, vertikale und transversale Bündel. Außer diesen drei Richtungen können aber auch einzelne Stränge diagonal verlaufen. Zwischen den einzelnen Muskelbündeln findet sich spärliches Bindegewebe $(b d g w)$, in welches dann und wann Kerne eingestreut sind.

Als selbständiges Muskelsystem treffen wir den Kolumellarmuskel im Innern des Körpers an. Er stellt ein starkes Muskelband dar, das oben an der Kolumella sich anheftet, in Spiralwindungen nach unten steigt und am Kopf mit seinen Anhängen und am Fuß inseriert. Der Beginn des Muskels liegt in der dritten Windung des Schneckenkörpers unter dem Magen an der Kolumella. Mit einer einheitlichen, breiten in die Länge gestreckten Platte windet er sich hier um diese herum. Unter der Eiweißdrüse und Lungenhöhle schlingt er sich dann in Spiralen nach unten und begibt sich unterhalb des Darmrohrs in die Leibeshöhle. In seinem Verlaufe teilt sich der Kolumellarmuskel in zwei Hauptbündel (Textfig. 2). Von ihnen begibt sich das eine in die rechte, das andere in die linke Seite des vorderen Körpers. 
Das linke Muskelbündel spaltet zunächst nach innen von seiner Oberseite einen breiten Muskel $l I \mathrm{ab}$; er folgt der Medianlinie des Körpers, tritt durch den Schlundring und inseriert bogenförmig in mehrere Bündel zerteilt an der Unterseite des Pharynx. Er bildet also den Pharynxretraktor. Nach vorn von seiner Abgangsstelle sondert sich nach unten ein Muskel $l I I$ ab, der sich in zwei Bündel teilt. Das innere, nach der Mitte zu gelegene lII a dringt unterhalb des Schlundrings in die Fußmuskulatur, das äußere $l I I b$ weiter vorn unter dem Pharynx in den Hautmuskelschlauch ein. Das ganz links gelegene Muselbündel $l I I I$, das nun schon bedeutend an Stärke abgenommen hat, entsendet nach oben aus seiner Mitte den Retraktor für den Augententakel $l I I I a$, der vom Cerebralganglion her den großen Tentakelnerv aufnimmt und ihn röhrenförmig umschließt. Der Muskel lIII spaltet sich schließlich in einen nach innen verlaufenden dünnen Strang $l I I I b$, der in den linken kleinen Tentakel tritt und dessen Retraktor darstellt, und in einen breiteren Muskel $l I I I c$, der an der vorderen Kopfseite in der Gegend zwischen großem und kleinem Tentakel inseriert. Beim rechten Hauptmuskelbündel sind die Insertionsstellen die gleichen, dagegen ist die Abspaltung der einzelnen Bänder vom Hauptstamm auf der rechten Seite eine andere. Ferner findet sich hier auch

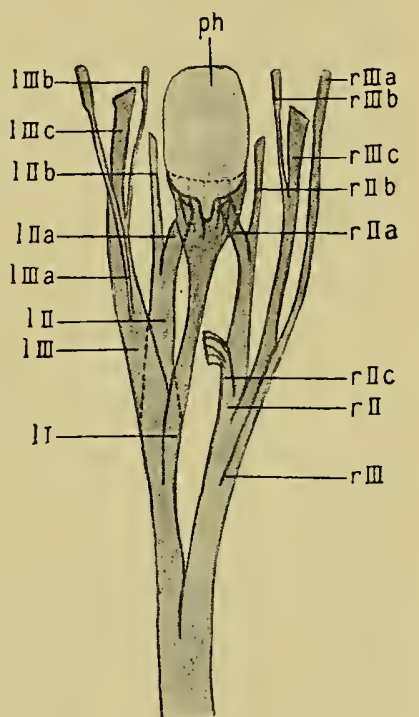

Textfig. 2. Kolumellarmuskel. Vergr. $5: 1$. nicht der Pharynxretraktor, dieser kommt vielmehr nur der linken Seite zu und ist also gleichsam ein unpaarer Muskel. Auf der rechten Seite finden wir auch einen solchen unpaaren Strang, dem auf der rechten Seite kein Muskelbündel entspricht. Es ist dies der Muskel $r I I c$, der sich ganz nach innen von dem breiten Muskel $r I I$, welcher sonst mit dem linken Muskel $l I I$ korrespondiert, absondert und sich mit einem oder zwei Ästen in den Schwanz des Fußes begibt.

Neben dem Kolumellarmuskel finden wir noch an den einzelnen Teilen des Darmtraktus Muskelsysteme, die dort betrachtet werden sollen. 
Der Penis hat einen bandartigen dünnen Rückziehmuskel. Dieser inseriert an seiner äußersten Spitze und begibt sich nach oben und hinten in die Mittellinie des Lungendaches. Hier befestigt er sich an der Stelle, wo dieses von der Kopfarterie durchbohrt wird. Er vereinigt sich also nicht, wie A. SchmidT mitteilt, mit dem Kolumellarmuskel.

Die Muskeln bestehen aus den kontraktilen Muskelfasern. Diese sind langgestreckte Zellen, die einen runden bis ovalen, zuweilen einen eckigen Querschnitt haben. Der kleine Kern ist rundlich, manchmal auch unregelmäßig gestaltet und braucht nicht immer in der Mitte der Faser zu liegen, sondern rückt oft so stark seitlich, daß er scheinbar aus der Zelle hinausragt. Die Muskelfasern werden umschlossen von einer bindegewebigen Faserschicht (bdgw Taf. 1, Fig. 14, 16, 18), die runde spärliche Kerne enthält. Eine Querstreifung der Muskeln fand ich in keiner meiner Schnittserien. Ich schließe mich daher der Ansicht Mertons an, daß die Querstreifung nur eine vorübergehende Erscheinung ist, hervorgerufen durch die Tätigkeit des Muskels, und daß sie dann nach Aufhören derselben wieder verschwindet.

An der Anheftungsstelle des Kolumellarmuskels an der Schale zeigt das Körperepithel und auch der histologische Bau des Muskels besondere Verhältnisse (Textfig. 3, Taf. 1, Fig. 13, 14). Während das Epithel in der Gegend der Kolumella ein Plattenepithel ist ( $e p^{\prime}$ Taf. 1, Fig. 13), wird es, je mehr es sich der Muskelanheftung nähert, höher und bildet an der Anheftungsstelle selbst eine hohe Epithelschicht $(e p)$. Zugleich werden die Kerne größer und elliptisch ( $e p$ Taf. 1, Fig. 14); deutliche Zellgrenzen kann man nicht in der Gegend der Anheftungsstelle feststellen. Unter dem Plattenepithel (epp' Taf. 1, Fig. 13), also dort, wo der Kolumellarmuskel noch nicht herangetreten ist, liegen geringes Bindegewebe und wenige schwache Längs- und Quermuskelstränge, wie sie sich stets als Stütze des Epithels des Eingeweidebruchsackes vorfinden. Tritt der Hauptmuskel nun an das Epithel heran (musc Taf. 1, Fig. 13, 14), so findet sich außer der Erhöhung des Epithels $(e p)$ eine starke Vermehrung des Bindegewebes $(b d g w)$. Dieses vereinigt sich mit den bindegewebigen Fasern, die die einzelnen Muskelfasern des Hauptmuskels umgeben. Wir finden also ein bindegewebiges Gerüstwerk, welchem kolumellarwärts das hohe Körperepithel aufliegt $(e p)$. Dieses zeigt keine Basalmembran, sondern das Bindegewebe dringt teilweise zwischen die Epithelzellen ein. Dann folgen die spär- 
lichen Längs- und Quermuskeln, die sich auch sonst unter dem Körperepithel des Eingeweidesacks finden und die hier in den kolumellarwärts gelegenen Teil des reichlichen Bindegewebes ( $b d g$ w) eingelagert sind. Nach innen folgen dann weiter die Muskelfasern des Kolumellarmuskels (musc), die sich teilweise mit den eben erwähnten Muskelfasern verflechten und so in das vordere Bindegewebe eindringen. Der Hauptteil des Kolumellarmuskels liegt aber weiter nach innen und wird hier von bindegewebigem Gerüstwerk fest umsponnen. Durch Schrumpfungen bei der Fixierung entstehen zwischen den Muskelfasern einerseits und den Bindegewebszellen und ihren Fortsätzen andererseits kleine Lücken. Die Muskelfasern selbst treten also nicht an die Schale heran, sondern ihre Befestigung wird durch das reichliche Bindegewebe bewirkt, welches eng mit dem Epithel verbunden ist. Dieses wieder legt sich fest der Spindel an. Die Muskelfasern laufen auch nicht senkrecht zur Kolumella, wie es der Fall sein müßte, wenn sie das Epithel durchdringend an der Schale sich anheften würden, sondern sie sind parallel zur Kolumella gerichtet.

Paravicini hat die Anheftung des Spindelmuskels bei Helix pomatia untersucht und findet, daß die Anheftungsstelle sich zusammensetzt aus glatten Muskelfasern, reichlichem Bindegewebe, einer Schicht Zylinderepithel und einer hoinogenen Membran. Diese letztere soll, ohne daß PARavicini hierfür einen Grund angibt, mit der Schalensubstanz fest verwachsen sein. Andererseits soll die Zylinderepithelschicht aus dem Bindegewebe hervorgehen, was er auch nicht näher begründet. Diese Erklärung der hohen Epithelschicht halte ich für unwahrscheinlich. Denn alle Teile des Körpers sind von einschichtigem Epithel bedeckt, also doch auch die Stelle, wo der Schalenmuskel sich anheftet. Dieses erhöht sich hier und so läßt sich das Vorhandensein des Zylinderepithels viel leichter erklären, als durch die Annahme einer besonderen Differenzierung des Bindegewebes. Was die homogene Membran Paravicinis betrifft,' so läßt sich diese an Präparaten erkennen, die entkalkt wurden, ohne daß vorher die Schale von dem Muskel gelöst wurde. Die Membran (perostr Textfig. 3) liegt hier eine Strecke von dem Epithel entfernt. Diese Strecke entspricht der Dicke der Schale. Dem Epithel selbst liegt direkt keine Membran an. Zugleich zeigt sich, daß die Membran ringförmig geschlossen ist. Daraus geht hervor, daß sie die innere Auskleidung der hohlen Kolumella darstellt, also daß sie das Periostrakum ist. Das Epithel tritt niemals mit dieser Membran 
in Verbindung, denn dazwischen liegt ja die anorganische Schalensubstanz des Hypostrakum und des Ostrakum. Die homogene Membran Paravicinis hat demnach mit der Anheftung des Schalenmuskels nicht das geringste zu tun.

Bindegewebe. Das Bindegewebe umhüllt das Nervensystem und die Gefäße und bildet zwischen den Eingeweiden feine durch-

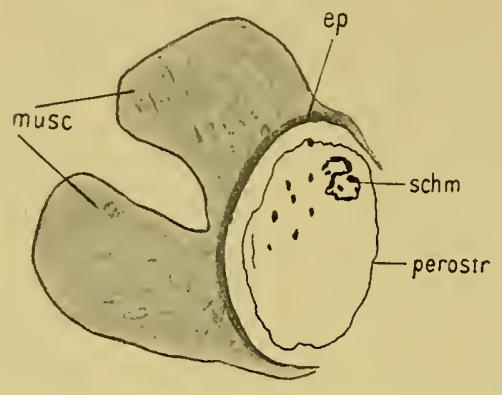

Textfig. 3. Schnitt durch die Anheftungsstelle des Kolumellarmuskels bei einem entkalkten Exemplar. Vergr. 28: 1 .

sichtige Häutchen. Ferner findet es sich in den oberen Windungen, wo es die einzelnen Leberläppchen umhüllt, und am äußeren Hautmuskelschlauch als innere Lage unter dem Epithel.

Die Bindesubstanz setzt sich aus verschiedenen Zellelementen zusammen. Es finden sich große blasige Zellen mit kleinen wandständigen Kernen und geringen Plasmaresten in der Umgebung der Gefäße und am Schlundring. Ferner finden sie sich zwischen der äußeren Körperwand und den Lebertubuli in den oberen Windungen als dünne Schicht. Hier besonders finden sich in diesen Zellen starke kalkige Ansammlungen ( $k k z$ Taf. 1, Fig. 17), hauptsächlich an solchen Tieren, die kurz vor der Abscheidung der konkaven Scheidewand stehen. Diese Kalkkörner erscheinen bei durchfallendem Licht als dunkle amorphe Konkretionen, bei auffallendem Licht als helle weiße Klumpen. Außer dieser Sorte von Kalkzellen finden sich kleine Bindegewebszellen, die ganz fein verteilte Kalkkörnchen führen, die sich leicht blau färben ( $k k z$ Taf. 1, Fig. 16). Sie sind hauptsächlich in der Muskulatur (musc) anzutreffen, besonders reich an ihnen ist der Penisretraktor. Neben diesen Kalkzellen findet sich eine andere Art von Bindegewebszellen, die in ihrem Innern kleine, wachsartig glänzende, ungeschichtete Kügelchen haben. Diese „Körnchenzellen" Brocks ( $k z$ Taf. 1, 2, Fig. 17, 30, 31) finden sich im ganzen Körper verteilt, besonders häufig sind sie im Lungendach vorhanden. Schlieflich wäre noch der faserigen Bindegewebselemente zu gedenken, wie sie sich in den Falten des Nieren- und Ösophagusepithels finden. Auch der Pfropf, welcher das Innere der Radulapapille ausfüllt, zeigt gleichmäßig faseriges Bindegewebe (Taf. 1, Fig. 15), ohne daß sich vesikulöses Gewebe zwischen 
die Bindegewebsfasern einlagerte, wie Merton dies für Gasteropoden beschreibt. Die Bindegewebszellen, welche in dem Hautmuskelschlauch liegen, führen das Pigment in braunen und schwarzen Körnchen. Auch am Schlundring und an dem primären und sekundären Harnleiter finden sich Pigmenteinlagerungen im Bindegewebe.

\section{Nervensystem und Sinnesorgane.}

Das Nervensystem ist schon des öfteren Gegenstand der Untersuchung verschiedener Forscher gewesen. v. IHERING gibt als erster eine Abbildung und sehr eingehende Beschreibung desselben in seiner vergleichenden Anatomie des Nervensystems und Phylogenie der Mollusken. Seine Darstellungen wurden dann wesentlich verbessert durch Amaudrut in „Sur les systèmes nerveux de quelques Mollusques pulmonés" und durch einige Bemerkungen von Wiegmann. Ferner gab LaCaze-Duthiers eine Beschreibung der Viszeralganglien. Von der Darstellung v. InERINGS weichen meine Befunde bedeutend ab. Desgleichen bekam ich teilweise andere Resultate als Amaudrut.

Das Nervensystem liegt als geschlossener Ring um den vorderen Abschnitt der Speiseröhre. Seine Lage ist nicht fest an eine bestimmte Stelle gebunden, sondern ändert sich je nach dem Kontraktionszustande des Tieres. Bei-stark zusammengezogenen Tieren befindet es sich direkt an der Mundöffnung in der Gegend des Kiefers, also am Anfang des Pharynx, während es bei ausgestreckten Tieren hinter dem Pharynx am Beginn des Ösophagus liegt. Dieses ist die normale Lage.

Der ganze Schlundring ist dicht eingehüllt von Bindegewebe, welches in der Gegend der Cerebralganglien Pigment führt. Dieses Bindegewebe geht auch auf die Nerven über. Besonders der Nerv, der in den Augententakel eintritt, ist von stark pigmentiertem Bindegewebe umgeben. Außerdem laufen noch zwei, zuweilen auch drei bindegewebige Brücken vom Cerebralganglion zur muskulösen Röhre des Tentakels und zụr seitlichen Körperwand.

Der Schlundring zerfällt in die für die Pulmonaten typischen Ganglien: ein Paar Cerebralganglien, ein Paar Pedalganglien, ein Paar Pleuralganglien, ein Paar Parietalganglien, ein unpaares Abdominalganglion und ein Paar Bukkalganglien. Die Lagerung der Ganglien untereinander, wie auch die Verbindung durch Kommissuren und Konnektive ist die von Helix her bekannte. 
Infolge der bindegewebigen Umhüllung ist am Cerebralganglion von Einzelheiten zunächst nicht viel zu erkennen. Bei der Betrachtung von oben sehen wir eine trapezförmige Platte (Textfig. 7) mit ihrer längsten Seite nach vorn dem Mundrohr aufliegen. Die Cerebralganglien liegen stets dorsal vom Schlund in Gegensatz zu allen anderen ventral gelegenen Ganglien. Unter sich sind sie durch eine kurze Kommissur verbunden (c.c Textfig. 4). Eine commissure sub-cérébrale, wie sie Amaudrut für Bulimus und für unsere Stenogyra angibt, findet sich nicht. Durch vorsichtiges Abpräparieren des Bindegewebes und durch Schnittserien läßt sich feststellen, daß die Cerebralganglien mehrere Lappen bilden (Textfig. 4). Diese sind anders als bei Helix gestaltet; das Bild, welches v. Inering von ihnen gibt, ist äußerst ungenau. $\mathrm{Da}$ die Lappen in engem Zusammenhang mit dem Austritt der Nerven

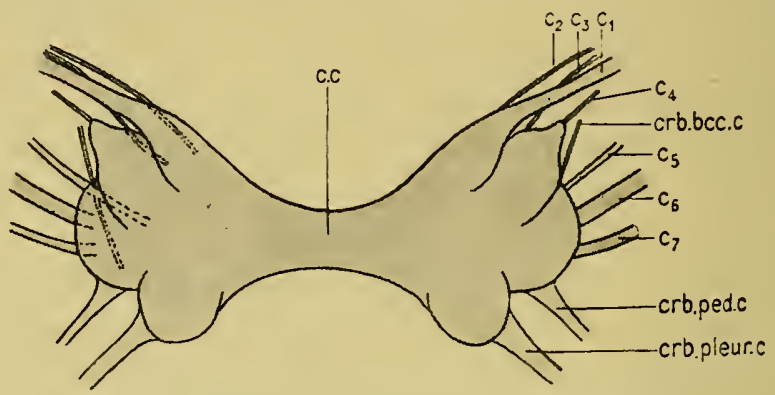

Textfig. 4. Cerebralganglion. Die Nerven der linken Seite sind bis zu ihrem Ursprung auf der Unterseite punktiert. Vergr. 16:1.

stehen und teilweise durch diese hervorgerufen werden, so betrachten wir beide gemeinsam. Ganz nach außen und oben liegt ein birnförmiges Gebilde, welches einen ganz feinen Nerven $\left(c_{4}\right)$ an seiner äußersten Spitze entsendet. Von diesem Lappen nach innen zu und den ersteren teilweise übergreifend liegt ein schmälerer, aber tiefer eingreifender Komplex. Dieser Lappen setzt sich nach außen zunächst in den Tentakelnerv $\left(c_{1}\right)$ fort. Dieser tritt an den Muskel des großen Tentakels heran, der sich röhrenförmig um iln schließt. An der Spitze des Fühlers bildet der Nerv ein großes Ganglion, nachdem er kurz vorher noch einen dümnen Nerven zum Auge abgegeben hat. Neben dem Tentakelnerven $\left(c_{1}\right)$ entspringen unterhalb an diesem Lappen noch zwei dünne Nerven $\left(c_{2}\right.$ und $\left.c_{3}\right)$. Diese beiden Nerven und der Nerv $\left(c_{4}\right)$ vereinigen sich mit einer der oben erwähnten bindegewebigen Brücken zu einem Strang, in welchen auch noch ein Gefäß ein- 
tritt. Auf der linken Seite läuft dieser Strang nach vorn zur seitlichen Körperwand und innerviert diese in der Gegend des großen Tentakels. Auf der rechten Seite ist der Verlauf des Stranges der gleiche, nur sondert sich ein Nerv mit einem Gefäß davon ab, welcher nach unten an den Penis herantritt. Es findet sich also kein gesondert entspringender, unpaarer Penisnerv der rechten Seite, vielmehr bildet dieser eine Abspaltung des Nerven $\left(c_{3}\right)$. Den hinteren Komplex der Cerebralganglien nehmen zwei rundliche Lappen ein, die oben durch eine kurze Furche voneinander getrennt sind. Der mehr nach vorn gelegene von diesen beiden Lappen entsendet von seiner Unterseite eine Reihe von Nerven. Am weitesten nach vorn entspringt der Nerv $\left(c_{5}\right)$ und schließt sich dem Rückenziehmuskel lIIIc, rIIIc (Textfig. 2) an und innerviert die Gegend der Körperwand, wo dieser Muskel inseriert, also zwischen großem und kleinem Tentakel. Nach hinten von ihm folgt der starke Nerv $\left(c_{6}\right)$. Er läuft nach unten und geht neben dem Pharynx nach vorn. Hier teilt er sich in zwei Äste, von denen der stärkere in den kleinen Fühler geht, während der schwächere den benachbarten Lippententakel innerviert. Der nach hinten folgende, dünne Nerv $\left(c_{7}\right)$ geht wie der vorhergehende nach unten und läuft ihm immer parallel, aber unter dem Pharynx nach vorn, wo er die Unterseite der Mundöffnung mit Nerven versorgt. Weit nach innen an der Unterseite entspringt noch das lange dünne Cerebrobuccalkonnektiv (crb. bcc.c), welches unterhalb der drei vorhergehenden Nerven gerade nach vorn zu den Buccalganglien verläuft. Schließlich geht seitlich nach hinten und unten von diesem vorderen der beiden runden Lappen das starke Cerebropedalkonnektiv $(c r b . p c d . c$.) ab. Der hintere rundliche Lappen, der zugleich der am weitesten nach hinten gelegene Teil des Cerebralganglions ist, entsendet nur das kräftige Cerebropleuralkonnektiv (crb. pleur. c). Der Statocystennerv verläuft dicht neben dem Cerebropedalkonnektiv, doch gelang es mir nicht, ihn infolge seiner Kleinheit $\mathrm{zu}$ isolieren.

Unterhalb der Einmündung des Ösophagus in den Pharynx liegen die Buccalganglien (Textfig. 10). Sie sind rundliche ovale Gebilde, die unter sich durch die Buccalkommissur verbunden sind (bcc.c Textfig. 5). An ihrem vorderen äußeren Ende geben sie das sehr lange Cerebrobuccalkonnektiv (crb. bcc.c) ab. Außerdem entsenden sie noch einen starken und vier dünnere Nerven. Neben dem Austritt der Cerebrobuccalkommissur entspringt der Nerv $\left(b_{1}\right)$, der sich zur mittleren Pharynxpartie begibt. Ganz 
vorn, etwas mehr nach innen, entspringen zwei dünne Nerven $\left(b_{2}\right.$ und $\left.b_{3}\right)$, die die Einmündung der Speicheldrüsengänge, die Nalepaschen Drüsen, kurz, die ganze obere Pharynxwand innervieren. Am hinteren Ende der Buccalganglien, ziemlich weit an der Unterseite, nimmt der starke Nerv $\left(b_{4}\right)$ seinen Ursprung. Er läuft direkt nach unten und verzweigt sich hier auf der Radulapapille und der unteren Pharynxpartie. Nach innen von ihm geht ein ganz feiner Nerv $\left(b_{5}\right)$ ab, der sich nur eine ganz kurze Strecke weit nach hinten und unten verfolgen ließ.

Unter dem Schlundrohr liegt der Komplex der Pedalganglien, Pleuralganglien, Parietalganglien und das Abdominalganglion. Die Pedalganglien liegen am weitesten nach vorn von dieser ganzen

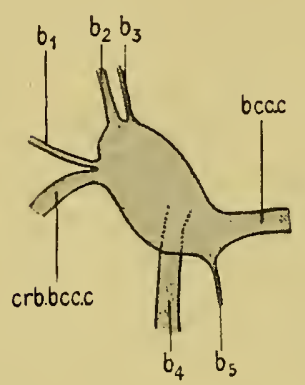

Textfig. 5. Linkes Bukkalganglion. Vergr. $24: 1$.

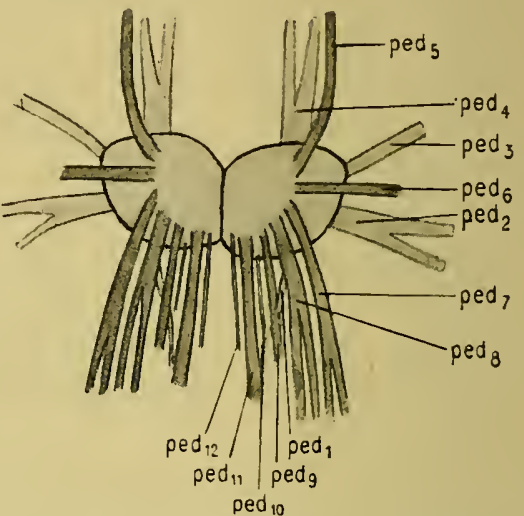

Textfig. 6. Pedalganglion von unten. Vergr. $16: 1$.

Gruppe und etwas unterhalb der Pleuralganglien (Textfig. 7). Sie haben eine eiförmig rundliche Gestalt und zeigen nie Einkerbungen. In ihrer Mittellinie legen sich beide eng aneinander. Auf Schnitten sieht man, daß die Pedalganglien durch zwei Kommissuren miteinander verbunden sind, eine vordere kräftige in der Mitte der Ganglien gelegene, und eine hintere dünnere, mehr der Basis genäherte. Auf der nach hinten gekehrten Seite liegen den Pedalganglien die Statocysten (stat Textfig. 7) als helle Pünktchen auf.

Die Pedalganglien geben zahlreichen Nerven den Ursprung. Von der Oberseite zunächst entspringen vier Nervenpaare (Textfig. 6, 7). Nach vorn läuft ein Nerv (ped 4), welcher sich in zwei Äste teilt und die Mündung der Fußdrüse nebst dem vorderen Fußteil innerviert. Seitlich gehen jederseits zwei Nerven ab, 
von denen der vordere ( $p \in d$ 3) ungeteilt bleibt, während der hintere ( $p e d$ 2) sich in zwei Stränge spaltet. Beide Nerven innervieren die Seitenteile des Fußes, auf der rechten Seite innerviert der Nerv (ped 3) auch noch das Geschlechtsatrium. Nach hinten verläuft noch ein dünner Nerv (ped I), der die Oberseite des hinteren Fußteils mit Nerven versorgt. Auf der Unterseite der Pedalganglien entspringen die Nerven aus der Mitte in einer Linie, die einen nach vorn offenen Halbkreis bildet (Textfig. 6). Alle diese Nerven der Unterseite innervieren die Sohlenfläche des Fußes. Thre Zahl ist nicht immer konstant; ich zählte sieben bis neun, da manchmal einer der dünnen Nerven (ped ro, ped I2) fehlte, oder auch neben den stärkeren Nerven noch ein dünner Nerv mehr entsprang. Nach vorn begibt sich stets der starke Nerv (ped 5) und ebenso seitlich (ped 6), die sich sofort in die Fußmuskulatur einsenken. Alle übrigen nach hinten gerichteten Nerven (ped 7 bis ped I2) laufen anfangs über und neben der Fußdrüse parallel der Fußarterie, bis sie

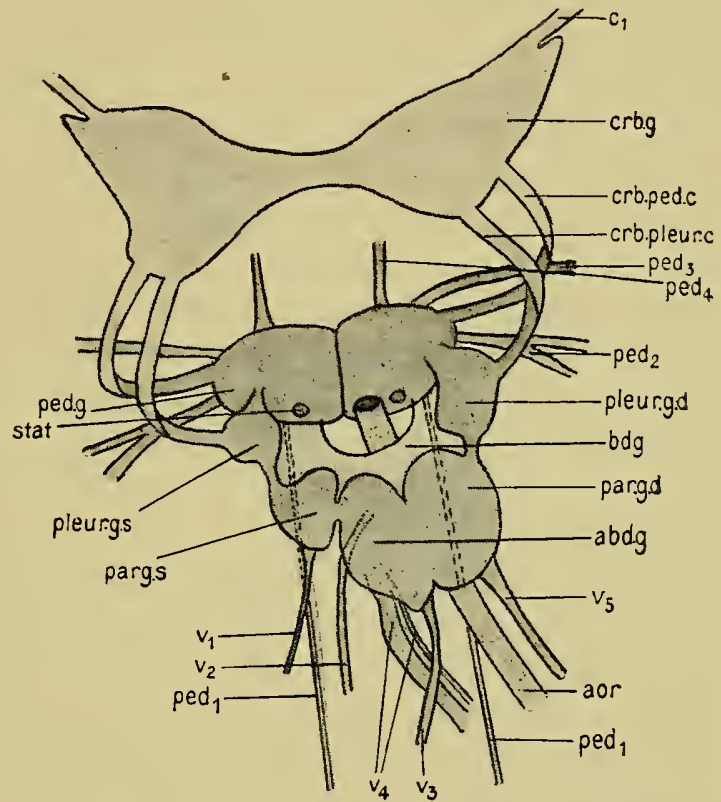

Textfig. 7. Der ganze Schlundring. Die Cerebralganglien mit bindegewebiger Umhüllung. Vergr. 16:1. sich in gewissen

Abständen in die FuBmuskulatur nach unten begeben. Am stärksten entwickelt sind die Nerven (ped 7, ped 8, ped II). Von diesen spalten sich die beiden ersteren bald nach dem Austritt aus dem Ganglion in je zwei Stämme.

Nach hinten schließt sich an die Pedalganglien der viszerale Komplex an, der aus fünf Ganglien besteht (Textfig. 7). Während die beiden Pleuralganglien und das linke Parietalganglion scharf gegeneinander abgesetzt sind und deutliche Konnektive unter sich 
zeigen, sind das unpaare Abdominalganglion und das rechte Parietalganglion eng miteinander verschmolzen; nur noch eine einschnürende Furche läßt diese Verschmelzung erkennen. In ihrer Größe sind die paarigen Ganglien jeder Seite voneinander verschieden. Das linke Pleural- und Parietalganglion (pleur.g. $s$ par.g.s) ist klein und rundlich, und beide sind unter sich durch ein verhältnismäßig langes Konnektiv verbunden. Dagegen ist das rechte Pleuralganglion (pleur.g.d) bedeutend größer, und besonders das rechte Parietalganglion $(p a r . g . d)$ ist fast dreimal so groß als das linke. Infolge dieser Größenzunahme ist das Pleuralparietalkonnektiv der rechten Seite sehr kurz und andererseits ist das rechte Parietalganglion eng mit dem Abdominalganglion $(a b d . g)$ verschmolzen, während das linke Parietalganglion immer noch ein kurzes, allerdings breites Konnektiv zum Abdominalganglion entsendet. Die Gestalt des Abdominalganglions ist eine eiförmige, nach hinten sich verjüngende, während das fast gleich große rechte Parietalganglion die Gestalt eines Ellipsoids hat. v. IHERING beschreibt und zeichnet in dem viszeralen Komplex der eben beschriebenen fünf ungleichen Ganglien sechs Ganglien, die alle fast gleiche rundliche Gestalt und Größe zeigen. Alle Forscher, die nach ihm das Nervensystem von Stenogyra decollata untersuchten, wie Amaddrut und Wiegmann, stellten die Beobachtung v. IHerings als Irrtum fest.

Von den Pleuralganglion jeder Seite (pleur. g. s und pleur.g.d) geht nach oben das sehr lange Cerebropleuralkonnektiv (crb.pleur.c), nach vorn das kurze Pedalpleuralkonnektiv und nach hinten das Pleuroviszeralkonnektiv aus. Ein Nerv entspringt nicht aus diesem Ganglion. Amaudrut beschreibt einen Nerven, doch hat er wahrscheinlich ein feines Blutgefäß, welches unter diesem Ganglienpaar jederseits läuft, damit verwechselt.

Aus dem linken Parietalganglion (par.g.s) geht ein langer Nerv $\left(v_{1}\right)$ hervor; er begibt sich über sämtliche Muskelbündel der linken Seite hinweg nach oben und innerviert die linke Seite des Mantelwulstes. Das Abdominalganglion $(a b d . g)$ gibt den Ursprung für drei kräftige Nervenstämme. An der Unterseite des Ganglions weit nach vorn entspringt der Nerv $v_{2}$. Er folgt dem Verlauf des linken Muskelbandes und läßt sich bis in die Gegend des Herzens verfolgen. Hier gibt er mehrere Äste an den hinteren Teil der Lungenhöhle und die linke Körperwand ab. Aus der Mitte des Abdominalganglions auch an seiner Unterseite entspringt der kräftige Nerv $\left(v_{4}\right)$, der sich gleich nach seinem 
Austritt aus dem Ganglion in einen stärkeren und einen dünneren Ast teilt. Beide Äste ziehen unter dem Nerven $v_{3}$ und der Arterie hindurch nach rechts. Hier gibt der stärkere Ast Nerven an den Spermovidukt ab. Beide Nerven begeben sich dann nach innen zum Columellarmuskel und steigen mit ihm nach oben. Dort innervieren sie Darm, Leber, Magen und die hinteren Teile des Geschlechtsapparates. Nach hinten rechts von dem Zipfel tritt aus dem Abdominalganglion als letzter ein Nerv $\left(v_{3}\right)$ aus, der sich anfangs parallel der Aorta, dann aber unter derselben hinweg und über die Muskelbündel nach rechts oben begibt und Teile der Lungenhöhle innerviert. Mit dem Abdominalganglion eng verbunden liegt nach rechts das rechte Parietalganglion (par.g. $d$ ), das den Nerv $v_{5}$ entsendet. Dieser überschreitet die rechten Muskelbündel und auch den Spermovidukt und innerviert die rechte Seite des Mantelwulstes mit dem Atemloch.

Die histologische Struktur des Nervensystems unseres Tieres ist die gleiche wie bei Helix und entspricht genau den Angaben von Nabias. Wir finden die großen Ganglienzellen mit den elliptischen, chromatinreichen Kernen, die meistens einen oder mehrere Nucluoli zeigen. Ihre bedeutendste Größe erreiçhen sie im Abdominal- und rechten Parietalganglion. Diese ,cellules ganglionnaires proprement dites" bilden die äußere Umhüllung der Ganglienknoten und werden nach innen zu immer kleiner, bis sie ganz aufhören und ihren Fortsätzen, den Nervenfasern, Platz machen, die sich vielfach durchflechtend und durchkreuzend im Zentrum der Ganglien die sogenannte Punktsubstanz bilden. An der Bildung dieser Punktsubstanz ist außerdem noch das intranervöse Bindegewebe, die Neuroglia, beteiligt, welche auch die Ganglienzellen umhüllt. Schließlich finden sich noch als listologischer Bestandteil der Ganglien die „cellules chromatiques", kleinere Zellen mit sehr wenig Protoplasma, aber mit chromatiureichen Kernen. Die Verteilung dieser histologischen Elemente in den einzelnen Partien des Cerebralganglions ist eine ähnliche wie bei Helix. So finden sich die Ganglienzellen als äußere Umhüllung bei den beiden nach hinten gelegenen Lappen. Die „cellules chromatiques" liegen in großer Menge in dem birnförmigen Gebilde, welches an seiner Spitze den Ner'v $c_{4}$ entsendet. Der von diesem nach innen gelegene Lappen, aus welchem die Nerven $c_{1}, c_{2}, c_{3}$ austreten, führt an seiner nach außen gelegenen Seite spärliche Ganglienzellen, sonst ist er ganz frei von solchen und nur von der Punktsubstanz erfüllt. Die anderen Ganglien haben 
alle einen mehr oder weniger gleiclımäßigen Belag von Ganglienzellen auf der Außenseite.

\section{Simnesorgane.}

Wie bei allen Landschnecken zeigt auch die nicht von der Schale bedeckte Hautdecke von Stenogyra decollata eine hohe Empfindlichheit gegen chemische, thermische und mechanische Reize. Besonders empfindlich sind der Mantelrand in der Gegend des Atemlochs, die Kopfgegend mit den Tentakeln und die Seitenteile des vorderen Fußabschnitts. Diese Teile werden auch zuerst beim geringsten Reiz unter die schützende Schale geborgen. Das hintere Fußstück und besonders die Oberseite des Schwanzes reagieren viel schwächer auf Reize.

Tentakel. Der Kopf zeigt in der Ausbildung der drei Tentakelpaare besondere Differenzierungen zur Reizperzeption (Taf. 1, Fig. 19). Das zu unterst gelegene Paar (a. Li), die Lippententakel, werden wir beim Darmsystem genauer kennen lernen. Sie ermangeln der Fähigkeit, sich ein- und auszustülpen und stellen jedlerseits von der Mundöffnung gelegene Platten dar, die durch eine Abzweigung des kleinen Tentakelnerven innerviert werden. Der große und der kleine Tentakel sind wie bei Helix ausstülpbare, hohle Röhren. Sie zeigen infolgedessen eigene Muskeln, die zum System des Kolumellarmuskels gehören. Die in sie eintretenden Nerven bilden gangliöse Anschwellungen. Im großen Tentakel, spärlicher auch im kleinen, finclen sich Drüsenzellen, die von Yung zuerst bei Helix festgestellt wurden. Einzeln oder meist zu Haufen vereinigt, liegen sie als flaschenförmige, mit Hämalaun und van GIESON braun bis dunkelviolett sich färbende Zellen im Bindegewebe neben den Muskelbündeln und in der Nähe der Tentakelganglien. Die Drüsen zeigen wabiges Protoplasma mit großen chromatinreichen Kernen. Ihr Sekret, welches sie nach innen in den Tentakel absondern, soll diesen bei dem häufigen Ein- und Ansstïlpen schlüpfrig erhalten.

Auge. An der Spitze des großen Tentakels in der Mitte der bogenförmigen Furche, die sich bei Stenogyra wie bei Helix findet, liegt das schwarze, punktförmige, durch das Epithel durchschimmernde Auge. Es ist eine geschlossene Blase, die annähernd Kugelform hat (Textfig. 8). Sie wird umschlossen von einer faserigen Bindegewebsschicht ( $b d g w)$, die sich auch auf den in die Blase eintretenden Sehnerven ausbreitet. An der Außenseite hat 
das Körperepithel $(e p$ ) über dem Auge eine besondere Differenzierung erfahren. Die Epithelzellen (pell. ext) sind niedriger geworden und haben klaren Inhalt. Zugleich haben die Zellkerne an Größe abgenommen und die hohe Cuticula (cut) hat sich erniedrigt. Unter dieser sogenannten pellucida externa folgt dann die hier sehr dünne bindegewebige Schicht (bdgw) der Augenblase. An dieser selbst unterscheiden wir eine größere, pigmentierte Zone, die Retina, und eine kleinere pigmentfreie, die Pellucida interna, und die im Innern gelegene kugelförmige homogene Linse. Die Retina zeigt wie gewöhnlich bei den Pulmonaten Pigmentzellen und unpigmentierte Sehzellen. Die Pigmentzellen sind kegelförmig gestaltet, und zwar richten sie ihr breites Ende nach dem Innern der Blase. Nach außen zu werden sie dünner, und ihr schwarzes, körnig verteiltes Pigment (pigm) nimmt an Dichtigkeit ab. In dem nach außen gerichteten schmalen Drittel liegt der elliptische, sich stark färbende Kern $\left(k \epsilon^{\prime}\right)$. Den Raum zwischen den Pigmentzellen

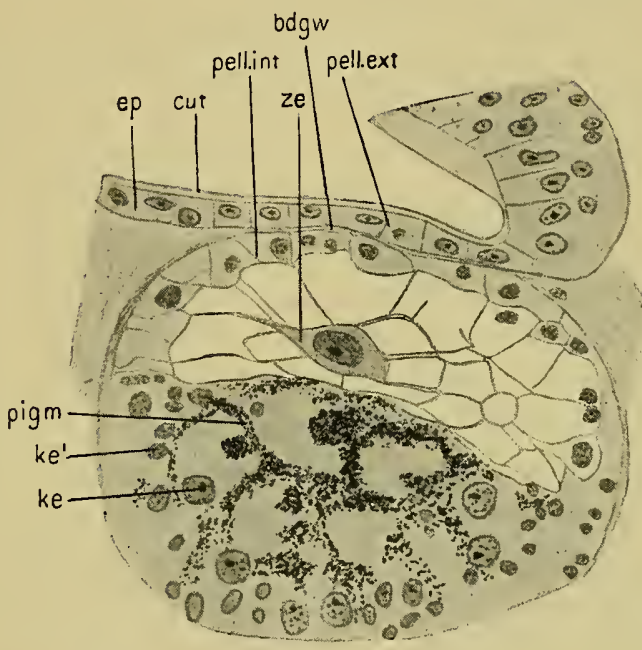

Textfig. 8. Das Auge seitlich in der Sagittalebene angeschnitten. Vergr. 515: 1 . nehmen die unpigmentierten Sehzellen ein, die gerade umgekehrt ihr breiteres Ende nach der Peripherie gerichtet haben. Sie enthalten ein homogenes, sich schwach färbendes Protoplasma mit einem rundlichen Kern $(k e)$, der größer als der der Pigmentzellen und wie bei diesen im äußeren Drittel der Zellen gelegen ist. Nach der Peripherie zu bilden die Sehzellen Fortsätze, die mit den Fasern des auf der Basalseite der Augenblase sich ausbreitenden Sehnerven in Verbindung treten. Nach dem Augeninnern zu drängen sich die Sehzellen, indem sie ganz scbmal werden, zwischen den breiten Pigmentzellen durch und tragen dann auf dem etwas verbreiterten, aber wenig vorgewölbten Ende einen fächerförmig gestellten Stiftchensaum. 
Dieser Retina, die den größeren und inneren Teil der Augenblase einnimmt, sitzt wie eine Kugelhaube die pigmentfreie Zone oler Pellucida interna (pell. int) nach außen auf. Sie wird von kubischen Zellen gebildet, die einen klaren, hellen Inhalt fülıren. Ihr kleiner rundlicher Kern ist basal gelegen. BECK fand im Auge unserer einheimischen Buliminen in der Pellucida interna eigenartige Zellen und gibt von diesen Verhältnissen ein treffendes Bild, auf rlas ich verweise (Jen. Zeitschr. f. Naturw. Bd. XLVIII 1912, Taf. 10, Fig. 49). Auch bei Stenogyra lassen sich diese Zellen nachweisen (ze Textfig. 8). „Sie liegen in einer Reihe nebeneinander, die der Grenzlinie zwischen Retina- und Pellucida internazellen parallel läuft und stets auf der Seite des Auges, welche beim etwas eingestülpten Fühler der Pellucida externa und dem daran anschließenden äußeren Tentakelepithel am meisten genähert ist" (BECK), d. h. also in der größeren Hälfte des Tentakels, da durch die bogenförmige Furche der Fühler in zwei ungleiche Hälften geteilt wird. Von den benachbarten Pigmentund Sinneszellen sind sie stets durch eine oder auch mehrere Pellucidazellen getrennt. Charakteristisch für diese Zellen $(z e)$ ist zunächst ihre bedeutende Größe gegenüber den umgebenden Pellucidazellen. Ferner enthalten sie Protoplasma, das sich mit Hämalaun und van Gieson blau färbt, und einen großen Kern mit spärlichen Chromatinkörnern und einem großen Nucleolus. Der Kern liegt auch höher in der Zelle als die Kerne in den benachbarten Pellucidazellen, so daß ein Flächenschnitt durch die Pellucidaschicht uns Textfig. 8 liefert. Es ist hier der Kern der Zelle ze getroffen, während die benachbarten Pellucidazellen, die basalständige Kerne haben, in dieser Höhe keine Kerne führen. Die Zahl der Zellen ist wechselnd; sie schwankt zwischen fünf und acht, sie ist also größer als bei unseren einheimischen Buliminen, wo Beck im Maximum sechs fand. Der Annahme von BEck, daß diese Zellen drüsiger Natur sind, stimme ich bei. Vielleicht haben sie Bedeutung für die Abscheidung des Glaskörpers.

Statocyste. Die Statocysten liegen als kleine, bläschenförmige Gebilde den Pedalganglien auf ihrer inneren, der Viszeralkette zu gerichteten Seite auf (stat Textfig. 9). Sie stellen von oben betrachtet zwei kreisrunde Bläschen dar, die aber im Querschnitt eine zusammengedrückte ellipsoide Form zeigen (Textfig. 9). Außen wird die Statocyste umgeben von faserigem Bindegewebe (bdgw), darauf folgt nach innen das Epithel. Dieses setzt sich aus großen Zellen mit langen Fortsätzen (rze) und aus kleineren 
kubischen Zellen (synze) zusammen. Die erstere Art, die sogenannten Riesenzellen ( $r z e)$ haben blasiges Protoplasma und einen großen chromatinarmen Kern, der einen Nucleolus enthält. Sie haben lange seitliche Fortsätze, mit denen sie teilweise die kleinen kubischen Zellen überdecken. Diese finden sich in der Literatur als Syncytialzellen (synze) bezeichnet und sind viel zahlreicher als die Riesenzellen. Ihr Protoplasma ist feinkörnig und der kleine Kern hat neben einigen Chromatinkörnern ein Kernkörperchen. Des öfteren wird der Beziehung Erwähnung getan, die sich zwischen den Syncytial- und Riesenzellen findet. Um jeden Riesenkern liegen die Syncytialzellen in stern- oder kranzförmiger Anordnung. Bei Stenogyra ist diese Anordnung nicht scharf ausgeprägt, eine bestimmte Lagebeziehung zwischen Riesenzellen und Syncytialzellen findet sich nicht. Das von Flüssigkeit erfüllte Lumen der Statocystenblase enthält die Statolithen oder Otokonien. Sie sind sehr zahlreich vorhanden und zeigen eine scheibenförmig elliptische Form (stat Textfig. 9). Die Statolithen finden sich in allen Größen, von den kleinsten bis $\mathrm{zu}$ ziemlich großen vor, wobei dann die größeren stets konzentrische Schichtung um einen zentralen Kern haben. Neben diesen einfachen Formen finden sich auch Statolithen, die aus zwei oder vier zusammengesetzt sind und dann zwei

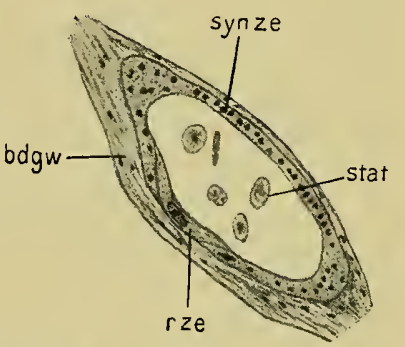

Textfig. 9. Schnitt durch die Statocyste. Vergr. $225: 1$. bzw. vier zentrale Kerne führen. Der größte Durchmesser der Statocyste war $105 \mu$.

\section{Darmkanal.}

Die Aufnahme und Verarbeitung der Nahrung und die Abgabe der Abfallstoffe findet durch den Darmkanal statt, der sich als ein in den ganzen Körper durchziehendes Rohr darstellt. Der Aufnahme und mechanischen Zerkleinerung dienen die Mundöffnung und der Pharynx, der chemischen Vérarbeitung und der Resorption der Ösophagus und der Magen mit ihren Anhangsdrüsen und der Mitteldarm, der Abführung der Abfallprodukte der Mittel- und Enddarm mit der Kloake.

Mundöffnung. An der Vorderseite des Kopfes beginnt der Darmkanal mit der Mundöffnung (Taf. 1, Fig. 19). An Tieren, 
die in Wasser erstickt wurden, sind die umgebenden Papillen und Wülste wie beim lebenden Tiere ausgestreckt. An der Oberseite begrenzen die Mundöffnung fünf große Papillen ( $p a$ Taf. 1, Fig. 19 und 20), die sich von den übrigen Warzen der Haut durch ihre Anordnung und Größe, besonders aber durch das Fehlen von Pigment unterscheiden. Seitlich folgen dann ein oder Zwei kleinere Wülste ( $p a$ Taf. 1, Fig. 19 und 20). Die Unterseite wird eingenommen von zwei mächtigen, weit nach innen hinein sich erstreckenden Wülsten, die man in der Literatur wohl auch als innere Lippen bezeichnet findet (i. Li Taf. 1, Fig. 19, 20, Taf. 2, Fig. 22, 23). Dadurch, daß diese zwischen sich eine starke Einbuchtung bilden und weit nach innen vorspringen, erscheint die Mundöffnung von außen, makroskopisch betrachtet, wie auch besonders im Schnitt als eine T-förmige Spalte (Taf. 1, Fig. 19 , Textfig. 11a). Nach außen von den inneren stehen die eigentlichen äußeren Lippen oder die Lippententakel ( $a$. Li Taf. 1, Fig. 19, 20, 22) als breite, sich nach innen zur Mundöffnung nicht fortsetzende, papillentragende Gebilde. Alle diese Organe haben die Funktion des Tast-, Geschmacks- und Geruchssinnes im besonderen Maße zu eigen.

Kiefer. An der Oberseite folgt auf die erwähnten fünf großen Papillen der Kiefer (Taf. 1, Fig. 19, 20). Er ist ein halbmondförmig gebogenes, dunkelbraun gefärbtes, chitiniges Gebilde. Daß sich zu seiner weiteren Festigung kohlensaurer Kalk in ihm ablagert, konnte ich nicht feststellen. Gebildet wird er von dem darunter liegenden Zylinderepithel genau so, wie die übrige chitinige Cuticula der Mundhöhle. So zeigt der Kiefer Radialstreifung und Längsstreifung, entsprechend den Anwachsstreifen. Nach linten geht er allmählich in die starke Cuticula der Mundhöhle (cut. Textfig. 11a) über, nach vorn aber bricht er scharf gegen die dünne, heller gefärbte Cutislage der Papillen ab. Bei jungen Tieren laufen über den Kiefer zahlreiche vorspringende Querleisten, so daß der Kiefer fein gerippt erscheint, bei älteren Tieren sind sie wahrscheinlich infolge Abnutzung nicht mehr vorhanden. Da der Kiefer einer Eigenmuskulatur entbehrt, so bedarf er einer Stütze. Diese erhält er in der starken muskulösen Platte, die an der Oberseite des ganzen Pharynx gelegen ist (mu. pl Taf. 1 , Fig. 20, Taf. 2, Fig. 22, 23, Textfig. 11a). Sie legt sich in starker Breite und Mächtigkeit direkt dem Epithel an, auf welchem der Kiefer gebildet wird, und erstreckt sich von dieser Stelle. nach hinten allmählich schwächer werdend, bis zur Austrittsstelle 
des Ösophagus aus dem Pharynx. Die Muskeln dieser Platte des Daches sind hauptsächlich dorsoventral gerichtet. Es finden sich aber auch zahlreiche Ringmuskeln und sehr spärlich Längsmuskelfasern.

Das Epithel, welches alle diese Teile der Mundöffnung auskleidet, ist ein Zylinderepithel mit runden, basalständigen Kernen. Es zeichnet sich überall durch eine mehr oder minder starke Cuticula aus.

Pharynx. Hinter dem Kiefer beginnt der Pharynx oder die Buccalmasse. Von außen stellt er ein birnförmiges Gebilde dar (Textfig. 10), welches von zahlreichen Muskelbündeln überzogen und durchdrungen wird und dessen dickeres Ende nach hinten gerichtet ist. Nach vorn geht er in die Körperwand des Kopfes über, während er nach hinten an seiner Oberseite den Ösophagus austreten läßt. Neben der

Ösophagusaustrittsstelle dringen jederseits die Speicheldrüisenkanäle in die Pharynxmuskulaturein, die, wie wir später sehen werden, erst weiter nach vorn ausmünden. Unterhalb des Ösophagus liegen dem Pharynx noch die paarigen Buccalganglien $(b c c . g)$ auf, bedeckt von einem dünnen

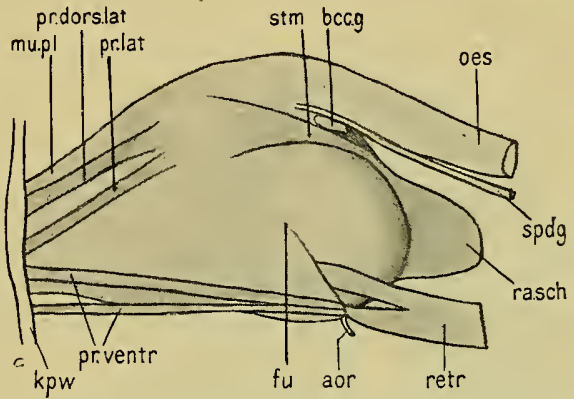

Textfig. 10. Pharynx mit seinen Muskeln von der Seite. Vergr. 12:1. transparenten Häutchen. Sie innervieren hauptsächlich die einzelnen Teile des Pharynx und stehen mit dem Cerebralganglion durch die Cerebrobuccalkonnektive, unter sich durch die Buccalkommissur in Verbindung. Am unteren hinteren Ende liegt eine rundliche Papille, die Radulascheide ( $r a . s c h$ ), welche den Bildungsherd der Radula enthält. Am hinteren Teile des Pharynx fällt noch eine jederseits an den Seitenteilen verlaufende, schwache Furche (fu) auf, an die sich nach hinten jederseits eine muskulöse Anschwellung anschließt.

Der innere Ban der Buccalmasse zeigt am Dach die erwähnte muskulöse Platte (mu. pl Taf. 1, Fig. 20, Taf. 2, Fig. 22, 23). Auf der Unterseite verlaufen die beiden unteren Wülste $(i . L i)$, die die innere Fortsetzung der inneren Lippen darstellen; sie bilden zwischen sich eine tiefe Furche, die sich nach hinten erweitert, um einem mächtigen, vom Boden aufsteigenden, halbkreisförmig 
nach vorn gebogenen Gebilde Platz zu machen. Dieser hohe Wulst ( $r a . \not p$ Taf. 1, Fig. 20, Taf. 2, Fig. 22, 23) wird gebildet
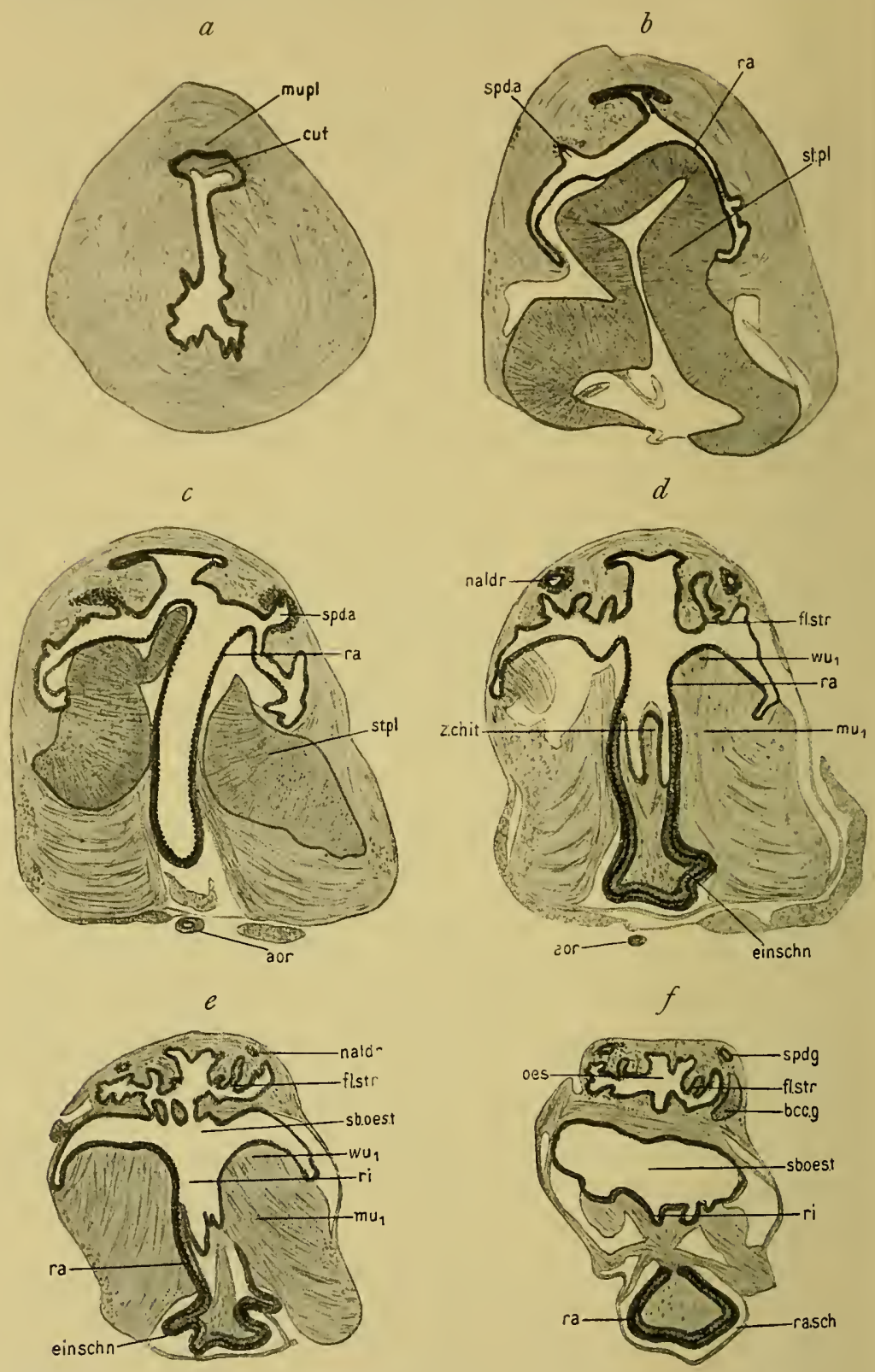

Textfig. 11. Schematische Querschnitte durch den Pharynx. Vergr. 19:1. vom Stützapparat der Radula und trägt auf seinem Scheitel den Teil der Radula, der jeweils an der Kantätigkeit am meisten be- 
teiligt ist. Etwas unterhalb des Scheitels des Radulapolsters nach vorne zu münden seitlich in der Rinne, welche die unteren Wülste mit dem Radulapolster bilden, jederseits die Speicheldrüsengänge mit einem länglichen Spalt ein ( $s p d$. a Taf. 1, Fig. 20, Textfig. $11 b, c, d$.). Hinter dem Scheitel des Radulapolsters geht nach hinten und oben der Ösophagus (oes Taf. 1, Fig. 20, Taf. 2, Fig. 22) ab, der zahlreiche Längsfalten bildet. Vor dem Eingang in den Ösophagus liegen einige vorspringende Falten ( fa Taf. 1, Fig. 20, Taf. 2, Fig. 22), die von den letzten Ausläufern der unteren Wülste $(i . L i)$ gebildet werden. Die Funktion dieser Falten liegt darin, daß bei der Kaubewegung der Zapfen z. chit Taf. 1, Fig. 20, Taf. 2, Fig. 23) gegen diese Falten sich emporschiebt und daß so ein Widerlager gebildet wird gegen den Rückfluß der zerriebenen Nahrung, die sich in der Subösophagaltasche befindet. Diese liegt unterhalb nach hinten von der Abgangsstelle des Ösophagus als ein breiter, niedriger Hohlraum ( $s b$. oes $t$ Taf. 1, Fig. 20, Textfig. 11e,f). Während das Dach dieser Tasche einfach gestaltet ist, zeigt der Boden zunächst zwei Wülste ( $w u_{1}$ Taf. 2, Fig. 23, Textfig. $11 d, e$ ), die sich an das halbkreisförmige Radulapolster ( $r a . p$ Taf. 2, Fig. 23) als nach hinten gerichtete Schenkel anschließen und noch mit der Radulamembran bedeckt sind. Diese Wülste werden aber nicht mehr von dem eigentlichen kompakten Stützapparat getragen wie der vordere Scheitel, sondern sie erhalten ihre Stütze von Muskelbündeln, die an dem eigentlichen Stützapparat unten ansetzen ( $m u_{1}$ Textfig. $\left.11 d, e\right)$ und von hier aus an diese Wülste von unten herantreten. So erhält der Radulascheitel hufeisenförmige Gestalt. Diese wird außerdem hervorgerufen von dem Zapfen (z. chit Taf. 1, Fig. 20. Taf. 2, Fig. 23, Textfig. 11 d), der sich zwischen die beiden Schenkel der Radula von hinten hineinschiebt und so das Innere des Hufeisens ausfüllt. An seiner Spitze trägt der Zapfen eine starke chitinige Haube. Dieser Zapfen setzt sich nach hinten in ein paariges muskulöses Polster (wu Taf. 2, Fig. 23) fort, das durch eine tiefe, nach hinten sich verflachende Rinne getrennt ist ( $r i$ Taf. 2, Fig. 23, Textfig. $11 e$ ). Diese beiden wulstförmigen Polster (wu) greifen auch nach vorn an die beiden Schenkel des hufeisenförmigen Radulapolsters $\left(w u_{1}\right)$ an und verbinden sich mit ihnen an der Furche ( $f u$ Taf. 2, Fig. 23). Die Radula setzt sich auf das paarige Polster (wu) nicht fort, sondern sie senkt sich von dem Scheitel des Stuitzapparates und der seitlichen Wulste $\left(w u_{1}\right)$ nach unten ein (Textfig. $11 \mathrm{c}$ ) und umgreift dabei den Zapfen (z. chit Text- 
fig. 11 d), der sich gleichsam zwischen die beiden Schenkel drängt Ehe die Radula in die Radulapapille eintritt, erleidet sie jederseits eine doppelte Einschnürung (einschn. Textfig. $11 d, e$ ).

Epithel des Pharynx. Am Anfang ist das Epithel wie an der Mundöffnung gebaut und überzieht das Dach wie die Wülste am Boden mit einer starken Cuticula (cut Textfig $11 a$ ), die besonders am Dach am mächtigsten ist zum Schutz gegen Verletzung durch die scharfen Radulazälnne. An der Unterseite legt sich nach innen zu die Radula mit ihrer Basalmembran dem Epithel auf (Textfig. 11 b). Dieses wird allmälılich niedriger und erscheint in der Umgebung und am Scheitel der darunterliegenden Zungenstützplatten (st. pl Textfig. $11 c$ ) als ein Plattenepithel. Dieses zeigt im Querschnitt zwischen den einzelnen Zellen unregelmäßig starke Partien von Kittsubstanz. Von der Fläche gesehen (Taf. 1, Fig. 21) haben die einzelnen Epithelzellen gezacktes Aussehen. Zwischen ihnen liegt in breiten Streifen, mit Hämalaun und vaN GIEson hellgelb sich färbende, interzellulare Kittsubstanz. Die feinkörnigen Protoplasmakörper der Zellen stehen untereinander durch feine plasmatische Stränge und Brücken in Verbindung, die sich meistens an die zackigen Fortsätze der Zellen anschließen. Jerle Zelle enthält einen länglichen, seltener, runden oder unregelmäßig gestalteten Kern. Diese Art des Epithels nimmt die oberste Spitze des Radulawulstes ein und erstreckt sich von da eine kurze Strecke nach vorn und etwas tiefer nach hinten in die absteigende Radularinne. Nach den Seiten wie auch nach hinten und vorn geht dieses Epithel in das gewöhnliche niedrige Epithel über. Die bestimmte Lage am Scheitel des Zungenwulstes läßt die Erklärung gerechtfertigt erscheinen, daß die besondere Differenzierung des Epithels in die gezackten Zellen mit der starken interzellularen Ablagerung an dieser Stelle sich ausgebildet hat, um dem starken Zug und Druck, der hier an der Spitze bei der raspelnden Kaubewegung an stärksten einwirkt, mit der nötigen Festigkeit entgegenzuwirken. Im weiteren Verlaufe unter der Radula erhöht sich allmählich das Epithel wieder, un in der Radulapapille wieder zu Zylinderepithel zu werden (ra. sch Textfig. $11 f$ ). Am Dach des Pharynx zeigt das Epithel geringere Differenzierungen. In der Mittellinie begleitet die starke Muskelplatte ein Zylinderepithel, das mit einer starken Cuticula ausgekleidet ist (cut Textfig. 11 a). Es erstreckt sich auch nach dem Schwinden der Muskelplatte noch eine kleine Strecke in den Ösophagus hinein. An den Seitenteilen schwindet 
allmählich die Cuticula. Sobald dann die Einmündung der Speicheldrüsengänge $(s p d$. a Textfig. $11 b, c)$ stattgefunden hat, zeigt nach hinten zu das Epithel jederseits Flimmerung, wobei aber die Speichelgänge wie auch ihre Einmündung frei von Flimmern sind. Dieses Flimmerepithel verläuft in zwei breiten Reifen ( $f$. str Textfig. $11 d, e, f)$ an den Seiten entlang nach hinten, wo es erst im Ösopliagus auf den Boden und später auch auf das Dach ïbergeht. Die flimmernde Region des Epithels zeigt eine starke Faltenbildung. Semper beschreibt bei Pulmonaten im Schlundkopf Flimmerung, doch scheint er mit seiner Bemerkung: „nirgends im Schlundkopfe mit Ausnahme eines Wulstes, der sich vom Schlunde aus an der oberen Wandung der Mundhöhle bis ziemlich weit nach vorn hinzieht, findet sich Flimmerung: etwas anderes zu meinen als den beschriebenen paarigen Flimmerstreifen unserer Stenogyra. Das Epithel, welches die Subösophagealtasche auskleidet, zeigt zylindrische Form und ist mit einer dünnen Cuticula bedeckt. Diese Cuticula vereinigt sich mit der Radulamembran auf dem Scheitel der Wülste (wn und wu Taf. 2. Fig. 23, Textfig. $11 d, e)$. Eine ganz bedeutende Dicke nimmt die Cuticula auf dem vorspringenden Zapfen an, der von der absteigenden Rinne der Radula umgriffen wird (z. chit Taf. 2, Fig. 23 und Textfig. $11 d$ ). Diese starke Bedeckung ist als Schutzmittel gegen die scharfen Züngenzähne zı erklären. Die Gestalt und Bedeutung des Epithels, welches sich der Radula von oben her anlegend in die Radulascheide eintritt, werden wir mit der Radula gemeinsam kennen lernen.

Innere Muskulatur des Pharynx. Am Boden des Pharynx befindet sich, wie wir sahen, die Radula, welcher die Funktion der Zerkleinerung der Nahrung zukommt. Um diese Aufgabe des Kauens zu erfüllen, bedarf sie zunächst eines Stützapparates, sodann aber eines bewegenden Muskelsystems. Den Stützapparat bilden die paarigen Stützplatten (st. pl Taf. 1, Fig. $20 \mathrm{u}$. Textfig. $11 b, c, 12,13$, die man infolge der Ähnlichkeit ihres histologischen Baues mit echtem Knorpelgewebe auch wohl als Zungenknorpel bezeichnet findet. In natürlicher Lage bilden sie eine von hinten unten nach vorn oben gerichtete, scheinbar einheitliche, nierenförmige Platte (st. pl Taf. 1, Fig. 20, Textfig. 12, 13). Bei mikroskopischer Betrachtung eines Schnittes zeigt sich aber (Textfig. $11 b, c)$, daß diese Platte aus zwei symmetrischen Hälften besteht, die nur im oberen Viertel fest miteinander verwachsen sind; im übrigen finden sich zwischen beiden symmetrischen Hälf- 
ten quere muskulöse Verbindungsfasern. Während die Stützplatte von vorn und unten gesehen eine fast gleichmäßig konvex gekrümmte Fläche hat (Textfig. 13), zeigt die Oberfläche, von hinten her betrachtet, oben einen schmalen vorspringenden Saum (vorspr. $s$ Textfig. 12). Dieser Saum setzt sich nach unten jederseits in eine wulstartige Anschwellung fort, so daß dann der untere Teil der Platte ein paariges Polster bildet. So erhält die Stützplatte in ihrem oberen Teil eine löffelartig gekrümmte Form, wie sie uns in der Radula wieder symmetrisch begegnet.

Die Stïtzplatte zeigt in ihrem histologischen Aufbau außen eine dünne Schicht faserigen Bindegewebes, dessen Stränge parallel zur Oberfläche verlaufen. Innen wird sie durchzogen von zahlreichen Muskelsträngen, die einzeln oder auch untereinander anastomosierend von vorn nach hinten, also senkrecht zur Ober-

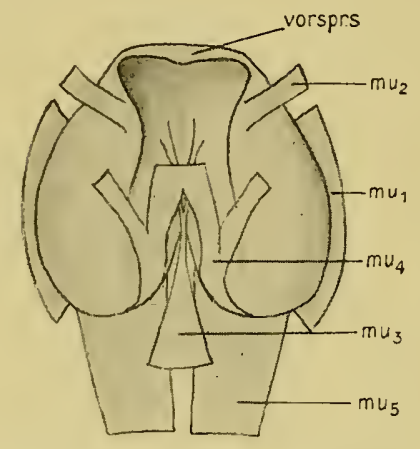

Textfig. 12. Radialstützplatte von hinten. Vergr. $12: 1$.

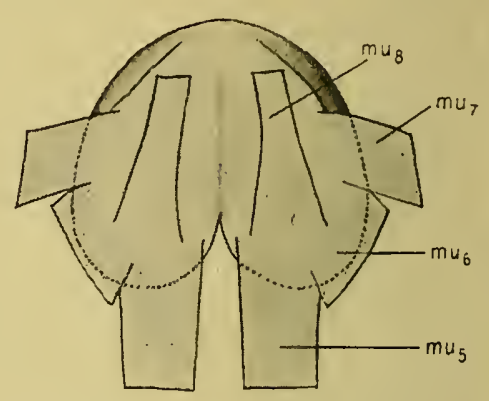

Textfig. 13. Radialstützplatte von vorne. Vergr. 12:1.

fläche einander parallel verlaufen. Querstreifung findet sich an diesen Muskelfasern bei Stenogyra decollata nicht. Sie sincl am zahlreichsten und dichtesten gelagert im obersten Teil der Platte, wo die beiden symmetrischen Hälften miteinander verwachsen sind und der Saum löffelartig vorspringt. Hier verdrängen sie fast ganz die Bindegewebszellen. Diese liegen zwischen den einzelnen Muskelfasern als große polygonale, blasige Zellen, die einen klaren Inhalt und runden Kern zeigen. Sie sind selten einzeln, meist in größeren Gruppen zwischen die Muskelbündel eingestreut. Amaudrut und Loisel untersuchten bei Pulmonaten das Muskelsystem der Radula und ihrer Stützplatte. Stenogyra dec. zeigt verschiedlene Abweichungen von der dort gegebenen Beschreibung. Wir unterscheiden zwei Muskelsysteme: die einen Muskel bewegen und befestigen die Radula, die anderen haben die Befestigung 
der Stützplatte zur Aufgabe. Diese letzteren sind bedeutend kräftiger und stärker als die anderen; von ihnen soll zunächst die Rede sein. Als mächtigster Muskel inseriert an der Stützplatte auf ihrer Hinterseite jederseits mu (Textfig. 12). Er nimmt drei Viertel des seitlichen Saumes ein und hat seinen Ursprung in der seitlichen Wand des Pharynx. An dieser entlang entsendet er noch einige kräftige Stämme nach oben und bildet hier die Stütze für die beiden seitlichen Schenkel des Radulapolsters ( $m u_{1}$ Taf, 2, Fig. 23). Auf der Hinterseite der Stützplatte inseriert dicht neben der Medianlinie jederseits ein dünner Muskel, der nach hinten unter den Bändern des Muskels $m u_{4}$ hindurch verläuft, wobei sich dann die paarigen Äste jeder Seite vereinigen. Als einheitlicher Muskel $m u_{3}$ zieht er dann nach hinten an die Radulapapille, die er als dünne Muskelschicht umgibt ( $m u_{3}$ Taf. 1, Fig. 20). An der Vorderseite der Stützplatte (Textfig. 13) inseriert unten jederseits ein breiter bandartiger Muskel $m u_{5}$, der unter der Platte hinweg nach hinten zieht ( $m u_{5}$ Taf. 1, Fig. 20). Hier hat er seinen Ursprung teils in den Pharynxretraktoren, teils geht er in die muskulöse Umhüllung der Radulapapille über. Seitlich von der Insertionsstelle dieses Muskels nach oben zu inserieren am Rande der Vorderseite der Platte die beiden Muskeln mu und $m u_{7}$ (Textfig. 13). $m u_{6}$ stellt eine Fortsetzung von $m u_{1}$ nach vorne $\mathrm{zu}$ dar und hat seinen Ursprung wie dieser in der benachbarten seitlichen Pharynxwand. Der dicke Muskel $m u_{7}$ verläuft weiter oben seitlich nach vorn in die Pharynxwand, wo er in die äußere Ringmuskulatur übergeht.

Das Muskelsysten, welches der Befestigung der Radulamembran dient, setzt sich aus dünnen, bandartigen Muskeln zusammen. An der Vorderseite der Stützplatte ungefähr in der Mitte der unteren Hälften hat ein bandartiger Muskel jederseits seinen Ursprung ( $m u_{z}$ Textfig. 13, Taf. 1, Fig. 20). Er inseriert am vordersten Ende der Radulamembran und hat die Aufgabe, diese bei der Kaubewegung nach vorne zu ziehen. Dies ist ihm dadurch möglich, daß seine Ursprungsstelle, wie überhaupt das unterste Ende der Stützplatte durch die erwähnten Muskeln $m u_{6}$ und $m u_{5}$ in der Pliarynxwand fixiert sind. Als Antagonist von $m u_{8}$ wirkt der paarige Muskel $m u_{4}$ (Taf. 1, Fig. 20, Textfig. 13). Er zieht die Radulamembran wieder nach hinten zurück, da seine Insertionsstelle an der absteigenden hinteren Radularinne liegt. Sein Urprung liegt an den unteren inneren Rändern der Anschwellungen der Stützplatte an ihrer Hinterseite. Von hier nach 
oben steigend teilt er sich in zwei Äste; die beiden inneren jeder Seite verwachsen in der Medianlinie und inserieren gemeinsam einheitlich, die äußeren Äste setzen ebenfalls nur etwas weiter nach den Seiten zu an der Radula an. Ein kurzes Muskelband $m_{2}$ (Textfig. 12) läuft auf der Hinterseite vom oberen Ende der Anschwellung jederseits nach oben seitlich an die Radulamembran.

Äußere Muskulatur des Pharynx. ÄuBerlich stellt der Pharynx, wie wir gesehen hatten, ein birnförmiges Gebilde dar, welches hinten jederseits eine Anschwellung zeigt (Textfig. 10). Vor dieser Anschwellung gehen seitlich und unten die Retraktormuskeln (retr) nach hinten ab, die nicht in einem einzelnen Bande, sondern in mehrere Bündel geteilt am Boden und an den Seitenteilen also in einem Bogen am Pharynx ansetzen. Sie gebören zu dem System des Kolumellarmuskels, und ihren Verlauf haben wir dort weiter verfolgt. Die seitlichen Anschwellungen werden von einer dünnen Muskelschicht bedeckt, die von der einen Seite nach der anderen zieht und dabei die Radulapapille und die ganze hintere Seite des Pharynx umgibt. Aus ihr sondert sich an den hinteren Seitenrändern je ein Bündel ab (st. m), welches eine Richtung von hinten unten nach vorn oben nimmt und sich bis über die Ösophaguseinmündung nach vorn erstreckt. Hier stößt es in der Medianlinie oben an die erwähnte muskulöse Platte $(m u$. $p l)$, seitlich setzt es sich an beiden Seiten in je zwei Muskelbänder fort, die nach vorn an die Kopfwand ziehen ( $p r$. dors. lat und $p r$. lat). Der obere Protractor dorsalis lateralis (pr. dors. lat) liegt jederseits neben der muskulösen Stützplatte (mu. pl). Das andere kräftigere Muskelbündel Protractor lateralis (pr. lat) zieht tiefer nach unten und begibt sich fast an der Unterseite des Pharynx in die vordere Körperwand. Zuweilen fand ich, daß dieser Muskel sich in zwei Stränge sonderte und dann zwei Muskeln nebeneinander in die Körperwand einliefen. Am unteren hinteren Teile des Pharynx entspringen an der Stelle, wo nach hinten die Retraktoren sich ansetzen, drei dünne Muskeln mit der Richtung nach vorn zu. Dieses System bezeichnen wir als die protractores ventrales $(p r . v)$. Der oberste ron ihnen geht in die seitliche Körperwand ungefähr dort, wo jedlerseits die Enden des halbmondförmigen Kiefers gelegen sind. Unterhalb von diesem, also an der Unterseite des Pharynx, laufen die beiden anderen Stämme dieses Systems in die untere Körperwand ein. Zwischen der Insertionsstelle der protractores ventrales und der der Retraktoren tritt unten in den Pharynx die Arterie (aor) ein. 
Unter allen äußeren Muskelbündeln befindet sich eine Ringmuskelschicht, deren Fasern von der dorsalen Muskelplatte jederseits nach unten ringförmig den Pharynx umgreifen. Sie tritt, wie wir sahen, mit einigen Muskeln, die an der Radulastützplatte inserieren und so zur inneren Pharynxmuskulatur gehören, in Verbindung.

Radula. Im binteren Teil des Pharynx liegt innen dem Epithel der Unterseite die Radula auf. Ihre Gestalt wird bedingt durch die darunterliegende Stüzplatte und die an dieser inserierenden Muskelsysteme, welche gemeinsam die Wülste (won und $w_{1}$, Taf. 2, Fig. 23) bilden. Vom Scheitel dieser Erhebung erstreckt sich die Radula noch ein wenig weiter nach vorn und unten und erscheint hier an ihrem vorderen Ende zerfranst. Dies erklärt sich dadurch, daß die abgenutzten Teile der Radula stïckweise sich loslösen. Vom Scheitel des Wulstes, der einen nach hinten offenen Halbkreis bildet, senkt sich dann die Radula, eine Rinne bildend und den konischen Zapfen (z. chit) umgreifend nach hinten und unten (Taf.1, Fig. 20, Taf. 2, Fig. 23, Textfig. $11 c, d$ ). Kurz vor dem Eintritt in die Radulascheide treten zwei Einschnürungen jederseits auf (einschn Textfig. 11d,e). Die Radula hat also vorne die Gestalt eines umgekehrten Löffels, nach hinten die einer Rinne mit einem an einer Stelle doppelt eingeschnürtem Rande. Die am hinteren unteren Teile der Pharynxmasse gelegene Papille, die Radulascheide ( $r a . s c h$ Textfig. 2, 11f), enthält den Bildungsherd der Radula.

Die Radula selbst besteht aus einer chitinigen dünnen Basalmembran, der die Zähne einzeln aufsitzen. Diese zeigen wieder eine Basal- oder Fußplatte (b.pl Textfig. 14) und den eigentlichen beim Kauen tätigen Zahnfortsatz. Die Zähne sind regelmäßig in Längs- und Querreihen angeordnet. An jeder Querreihe unterscheidet man einen mittleren oder Rhachiszahn, dann die seitlich davon gelegenen Lateralzähne und schließlich ganz nach außen die Marginalzähne. Der Rhachiszahn ( $r . z$ Textfig. 14) ist bei unserer Form äußerst klein und winzig; meist ist er dreispitzig, doch verschwinden auch die beiden seitlichen kleinen Spitzen, und dann ähnelt er einer einfachen dreieckigen Platte. Der Rhachiszahn sitzt am Hinterende seiner langen schmalen Basalplatte auf und nimmt nur ungefähr ein Drittel von ihr ein. Viel größer sind die Lateralzähne; sie besitzen eine lange Mittelspitze und zwei kleinere Seitenspitzen. Am Grunde der Spitzen befindet sich eine Kimme. Die Lateralzähne ragen nach hinten über ihre Basalplatte hinaus, während nach vorn $\mathrm{zu}$ in der Mitte sich die 
Spitze erhebt. Das Hinterende des vorhergehenden Zahnes greift in die so entstehende Lücke des nach hinten folgenden ein, so daß eine dachziegelartige Lagerung ensteht (Textfig. 16). Weiter nach den Seiten zu verlieren die Lateralzähne ihre typische Gestalt, indem die nach dem Rhachiszahn zu gelegene Seitenspitze allmählich immer kleiner wird. Ungefähr vom 22. Seitenzahn an ist die

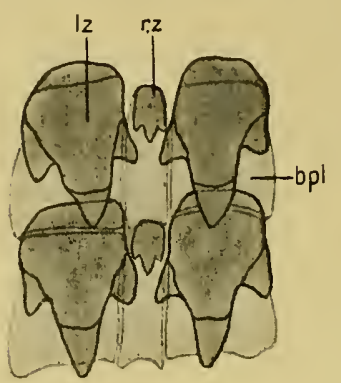

Textfig. 14. Rhachiszähne und erste Lateralzähne. Vergr. $338: 1$.

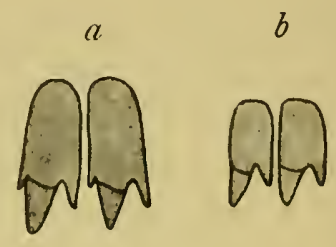

Textfig. 15. Marginalzähne. a 23. und 24. Zahn. $b$ Äußerste Zähne. Vergr. $338: 1$.

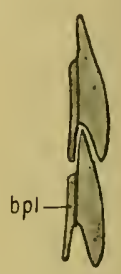

Textfig. 16. Sagittalschnittdurch 2 Lateralzähne. Vergr. $338: 1$.

Spitze derartig winzig, daß man die noch nach außen folgenden Zähne als Marginalzähne bezeichnen kann (Textfig. 15). Sie zeigen in deutlicher Ausbildung nur noch zwei Spitzen, nähmlich die größere Mittelspitze und die nach außen gelegene Seitenspitze. Das Auftreten von mehr als zwei Spitzen an den Marginalzähnen konnte ich nicht beobachten. Außerdem sind die Marginalzähne bedeutend kleiner als die Lateralzähne; die bei dem Rhachis- und Lateralzahn deutlich hervortretende Basalplatte läßt sich nach den Seiten $\mathrm{zu}$ immer schwieriger erkennen.

Die Zahl der Zähne einer Querreihe beträgt durchschnittlich 45-71, die einer Längsreihe 91-106. Wir können als die Zahnformel für Stenogyra decollata aufstellen:

$$
\frac{8-13 \cdot 14-22 \cdot 1 \cdot 14-22 \cdot 8-13}{91-106}
$$

Auffallende Unregelmäßigkeiten und Abnormitäten im Bau der Zähne fanden sich an den untersuchten Exemplaren nicht.

Der Bildungsherd der Radulazähne liegt am Ende der Radulapapille in Gestalt des Odontoblastenpolsters. Diese Odontoblasten sind hohe Zellen mit großen runden, chromatinarmen Kernen mit Nucleolus. Im Sagittalschnitt, der dieselben Verhältnisse wie bei Helix zeigt, erscheinen sie in der bekannten Fünf- oder Vierzahl, zuweilen auch noch in größerer Anzahl. Daher findet sich in 
der Literatur die irrige Annahme, daß zur Bildung eines Zahnes fünf, bzw. vier Zellen nötig seien. BECK stellte zuerst bei unseren einheimischen Buliminen fest, daß diese Zahl der Bildungszellen bei weitem nicht ausreicht, indem er Flächenpräparate von dem Odontoblastenpolster herstellte. Auf dem gleichen Wege zeigte sich bei unserer Stenogyra, daß mehr als fünf Odontoblasten an der Bildung eines Zahnes teilnehmen und daß besondere Verhältnisse bei der Bildung des Rhachiszahnes vorliegen. In den Flächenpräparaten (Textfig. 17) liegt nach vorn eine Reihe von breiten großen rechteckigen Zellen (1), die genau so breit sind wie je ein Zahn. Dabei ist jede Zelle der vorderen Reihe gegen die dahinterliegende Zellgruppe, die immer je einen Zahn bildet, um eine halbe Zellbreite seitlich verschoben. Ferner zeichnen sich die Zellen durch einen etwas größeren Kern und eine deutliche Zellmembran aus. Diese vorderste Zellreihe hat die Funktion, die basale Radularmembran abzuscheiden und daraus, daß sie an der eigentlichen Zahnbildung nicht teilnimmt, erklärt sich auch ihre seitliche Verschiebung. Nach hinten folgen dann die eigentlichen Bildungszellen der Zähne. Die folgende Zellreihe (2, Textfig. 17) hat die Basalplatte der Zähne zu bilden, und die noch weiter nach hinten gelegenen bauen dann die übrigen Teile des Zahnes auf. Bei den Flächenpräparaten treten dieZellgrenzen nicht scharf hervor. Trotzdem kehren stets bestimmte Verhältnisse in der Lage der Kerne wieder. Daraus schloß ich auf die Anordnung der Zellen und stellte das Schema des Odontoblastenpolsters (Text-

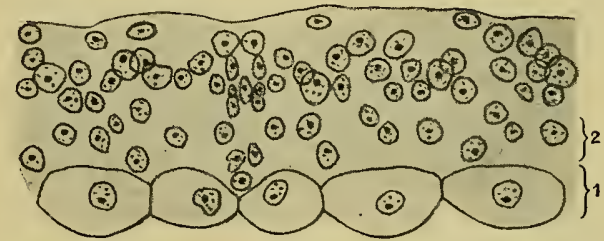

Textfig. 17. Odontoblastenpolster von der Fläche. Vergr. $338: 1$.

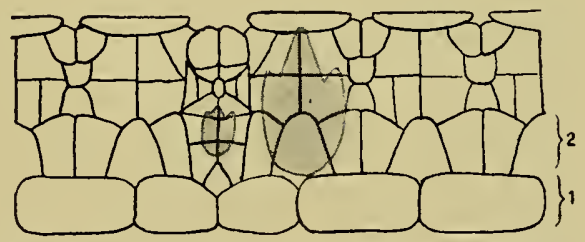

Textfig. 18. Schema der Odontoblastengruppen mit Zähnen. Vergr. 338:1. fig. 18) auf. Daraus geht hervor, das zur Bildung des Rhachiszahnes 16 , des ersten Lateralzahnes 12 , und der folgenden Lateralzähne je 13 Zellen nötig sind, wobei die vorderste Zellreihe nicht mitgerechnet ist, da sie als Bildnerin der Basalmembran am Bau des eigentlichen Zahnes nicht beteiligt ist. 
Die Frage, ob die Odontoblastengruppe des Rachiszahnes aus der Verschmelzung der Zellgruppen zweier Lateralzälne hervorgegangen ist, daß also der Rhachiszahn durch Verschmelzung zweier Lateralzähne entstand, worauf PLATE bei Aneithella berghi hinwies, lasse ich für Stenogyra unentschieden.

Dagegen schließe icls mich in der Frage, ob die Odontoblasten von hinten nach vorn mit dem von ihnen gebildeten Zahn mitwandern, und dabei von hinten her ersetzt werlen, während sie nach vorn zu den gewöhnlichen Epithelzellen werden, der Ansicht Rösslers an. Die Odontoblasten werden nämlich nach der Bildung eines Zahnes nicht durch neue, von hinten nachrücliende Zellen ersetzt, sondern die zahnbildenden Zellgruppen sind an ihrer Stelle fixiert und die Funktion der Zahnabscheidung kommt ihnen fortdauernd $\mathrm{zu}$. Übergänge zwischen Odontoblastenzellen und einfachen Epithelzellen müßten sich doch sonst vorfinden, und in keinem meiner Präparate ließen sich solche feststellen.

Im Grunde der Radulapapille schließt sich an das Odontoblastenpolster ein Epithel an, welches nach oben und dann nach vorn scharf umbiegt und sich von oben auf die Radula legt, um sich nach oben in den konischen Zapfen (z. chit Taf. 1, Fig. 20) mit seiner starken Cutislage fortzusetzen. Dabei zeigt das Epithel zunächst in der Gegend der Odontoblasten zylindrische Form ohne scharfe Zellgrenzen mit zerfaserten Enden, die an die in Bildung begriffenen Zähne herantreten. Weiterhin nach vorn werden die Zellen niedriger und umgeben die Zähne fest von allen Seiten her. Auf diese Weise bildet dieses obere Epithel einen Sperrapparat gegen $\mathrm{zu}$ starken Zug beim Kauen. Außer dieser epithelialen Sperrung halte ich aber auch die erwähnten Einschnürungen (einschn Textfig. $11 d, e$ ), die die ganze Radula in ihrem hinteren Teile erfährt, für einen wirksamen Schutz gegen einen zu starken Zug bei der Kaubewegung. Durch diese Einschnürung wird sich leicht verhindern lassen, daß ein starker Zug sich bis nach hinten zum Odontoblastenpolster fortsetzt und hier eine in Bildung begriffene Zahnreihe in ihrer Fertigstellung stört.

$\mathrm{Ob}$ das obere Epithel sich an der Zahnbildung beteiligt, ist der Gegenstand zahlreicher Untersuchungen gewesen. Da die Zähne nach dem Verlassen des Odontoblastenpolsters an ihrer oberen Seite noch eine Größenzunahme zeigen, so glaube ich, daß neben der Aufgabe des Sperrapparates die Abscheidung von Zahnsubstanz dem oberen Epithel zu eigen ist. 
Ösophagus. An der oberen Seite des Pharynx tritt nach hinten der Ösophagus aus (oes Taf. 1, Fig. 20, Taf. 2, Fig. 22, Textfig. 10, 19). Er ist ungefähr viermal so lang als der Pharynx. In zwei Windungen steigt er, sich dicht dem Kolumellarmuskel anlegend, nach oben, bis er schließlich in den Magen übergeht. Bei einigen meiner Exemplare bildet er ein einfaches dünnes Rohr, welches mit zahlreichen Querfalten, die besonders an der Decke entwickelt sind, ausgekleidet ist. Bei der Mehrzahl der Tiere dagegen fand ich, daß der Ösopbagus zunächst als dünnes Rohr aus dem Pharynx austritt, sich aber kurz danach unter den aufliegenden Speicheldrüsen stark erweitert und dann wieder enger wird (Textfig. 19). Diese Aufblähung nimmt, wenn sie vorhanden ist, die Hälfte der Gesamtlänge des Ösophagus ein, und zeigt Längsfalten wie die übrigen Teile des Ösophagus. Diese Anschwellung tritt bei Helix immer auf und wird als Magen bezeichnet. Unsere Stenogyra zeigt aber außerdem im weiteren Verlaufe des Darmes eine dem Magen der Buliminen entsprechende Anschwellung. Es wäre möglich, die Ösophaguserweiterung nur für einen bestimmten Kontrak-

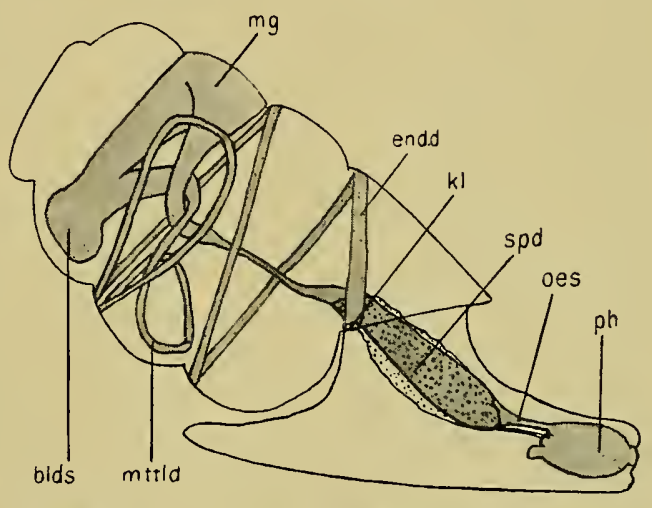

Textfig. 19. Schema des ganzen Darmtraktus. tionszustand zu halten, in dem sich die Tiere beim plötzlichen Absterben auszudehnen pflegen. Ich glaube jedoch, daß infolge der besonderen Beschaffenheit des Ösophagusepithels diese Erweiterung eine dem Helixmagen ähnliche Funktion besitzt und daß damit die Ösophagusanschwellung unserer Stenogyra ein dem Helixmagen analoges Gebilde darstellt.

Im Anfangsteil des Ösophagus ist das Epithel ein gleichmäßig flimmerndes, zylindrisches. Weiter nach hinten treten iedoch helle Zellen auf, die flaschenförmig gestaltet sind und einen runden, sich dunkelfärbenden Kern besitzen ( $d r z$ Taf. 2, Fig. 25). Ihr Protoplasma ist fädig zusammengezogen. Neben diesen ziemlich großen Zellen, die immer einzeln und in $\mathrm{Ab}$ ständen voneinander gelagert sind, liegen die gewöhnlichen zylin- 
drischen Flimmerzellen mit körnigem Protoplasma und elliptischen Kernen, die ein oder zwei Nucleoli besitzen. Ich halte die flaschenförmigen Zellen $(d r z)$ für sekretorische Schleimdrüsenzellen, die ihr Sekret durch die zwischen den Flimmerzellen befindliche Öffnung nach außen entleeren. Nach außen umgibt den Ösophagus, wie überhaupt das ganze Darmrohr, eine innere Längsmuskelschicht und eine äußere Ringmuskelschicht. In den hohen Falten, die in den Ösophagus vorspringen, findet sich auch spärlich faseriges Bindegewebe.

Speicheldrüsen. Dem Ösophagus liegen in seiner unteren Hälfte die großen Speicheldrüsen als zwei untereinander anastomosierende Lappen auf (spd Textfig. 19). Diese Anastomosen treten auf der Oberseite und Unterseite auf, so daß die Speicheldrüsen teilweise den Ösophagus ringförmig umgeben. Sie sind von weißlicher bis gelblicher Farbe und ganz unregelmäßig bei den einzelnen Individuen zerteilt und gelappt. Nach vorn setzen sich die Drüsen in zwei jederseits neben dem Ösophagus herlaufende Kanäle fort, die wie dieser durch den Schlundring hindurchgehen und sich auf der hinteren Oberseite des Pharynx in diesen einsenken, seitlich unterhalb von der Einmündungsstelle der Speiseröhre (Textfig. 10). Die Kanäle verlaufen zunächst noch eine Strecke innerhalb der Pharynxmuskulatur nach vorn und münden dann in der Rinne, die vom inneren Lippenwulst mit dem Radulapolster gebildet wird, vor dessen Scheitel in einem länglichen Schlitz aus (spd.a Taf. 1, Fig. 20). Während seines Verlaufes innerhalb der Pharynxmuskulatur wird der Ausführgang der Speicheldrüsen von einer Nebenspeicheldrüse rings umgeben, wie sie bei Helix von NALEPA gefunden wurde. Diese Drüsen sind äußerst klein und bei makroskopischer Präparation sehr schwer aufzufinden.

In den großen Speicheldrüsen von Helix finden sich nach PACAUT und Vigier fünf verschiedene Arten von Drüsenzellen, die untereinander Übergänge zeigen. Bei unserer Stenogyra sind an bemerkenswertesten die zahlreichen runden Schleimzellen, die eine schaumige Struktur zeigen und sich blau färben. In geringerer Anzahl sind Zellen vertreten, die runde helle Körnchen führen und mit den granulösen Zellen RiNa MoNTIs übereinstinımen. Außerdem finden sich noch transparente Zellen, die entweder ganz hell sind oder nur eine ganz schwach färbbare, blasige Struktur zeigen. Alle diese Drüsenzellen haben einen sich sehr stark färbenden, runden, großen Kern; meistens ist er zentral 
gelagert. Zwischen den drüsigen Zellen finden sich bindegewebige Stützzellen. Die Drüsenzellen geben ihr Sekret in ganz feine dünne Speichelkanäle $a b$, die mit einem Plattenepithel ausgekleidet sind. Diese vereinigen sich zu größeren Gängen, wobei sich das Epithel allmählich erhöht, bis es im gemeinsamen großen Speichelgang zu einem Zylinderepithel wird. Flimmern finden sich nirgends im Ausführungssystem der Speicheldrüsen, ebenso fehlen die bei Helix für den Hauptkanal beschriebenen vorspringenden Längsfalten. Sein Querschnitt ist vielmehr anfangs rundlich und wird innerhalb der Pharynxmuskulatur mehr elliptisch. Hier treten nun die NalePaschen Drüsen auf. Sie bestehen aus einem geschlossenen Komplex einzelner flaschenförmiger Drüsenzellen mit runden Kernen und feinkörnigem Protoplasma, das sich mit Hämalaun und v. Greson gelbraun färbt (Taf. 2, Fig. 24). Jede Zelle besitzt einen langen, schmalen ausführenden Fortsatz, der mit dem hellgelben Sekret angefült ist und sich mit denen der Nachbarzellen häufig verflechtend durch Interzellularen des Epithels in den Speichelgang ausmündet. Auf diese Weise sind die eigentlichen Drüsenzellen paketweise nach außen angeordnet, während nach innen rings um den Speicheldrüsengang die Zone ihrer Fortsätze liegt. Da sich diese sehr stark verflechten, kann man nicht immer deutlich die Zellgrenzen unterscheiden. In der Nähe der Mündung des Speichelkanals verlieren die NaLEPAschen Drüsen ihren geschlossenen Charakter. Sie gehen hier in einzelne Drüsenzellen über, die isoliert stehen und durch ihren langen Ausführgang ihr Sekret entleeren. Diese einzelnen Drüsenzellen finden sich auch noch an dem länglichen Spalt, durch den der Speichelgang in die Pharynxhöhle mündet.

Magen. Nachdem der Ösophagus bei seinem zweiten Umgang um die Kolumella unter der Eiweißdrüse vorbeigekommen ist, erweitert er sich allmählich zum Magen. Hierbei verdrängt er die nach außen gelegenen Teile des unteren Leberlappens und wird nun im dritten Umgang (von der Spitze her gezählt) außen sichtbar. Er nimmt von diesem die obere Hälfte und vom zweiten Umgang die untere Hälfte ein. Der Magen hat also die Ausdehnung einer ganzen Windung. In seinem hintersten am weitesten nach oben gelegenen Abschnitt bildet der Magen eine Einschnürung und hinter dieser eine blindsackartige Erweiterung, in die die Leberausführgänge einander gegenüberliegend einmünden (Textfig. 20, Taf. 2, Fig. 26). Von diesem Blindsack steigt dann 
in einem spitzen Winkel nach unten und innen der Mitteldarm hinab.

Im Inneren verlaufen an der Unterseite des Magens aus dem Ösophagus her Längsfalten, während sich an der Decke Querfalten finden (Taf. 2, Fig. 26). Der Magen stellt also ein gefaltetes Rohr dar, in dem sich keine besonders charakteristischen Reliefbildungen finden. Dagegen sind solche im Blindsack vorhanden und gehen von hier auf den Anfangsteil des Mitteldarms über. Zunächst zeigt der Blindsack Faltungen ähnlich wie der vordere Teil des Magens. Sobald aber die Lebergänge einmünden, finden sich zwei wulstförmige Falten, die stark in den Blindsack und weiterhin auch in den Mitteldarm vorspringen. Ton diesen beiden Falten beginnt die eine (wu Taf. 2, Fig. 26) hinter der

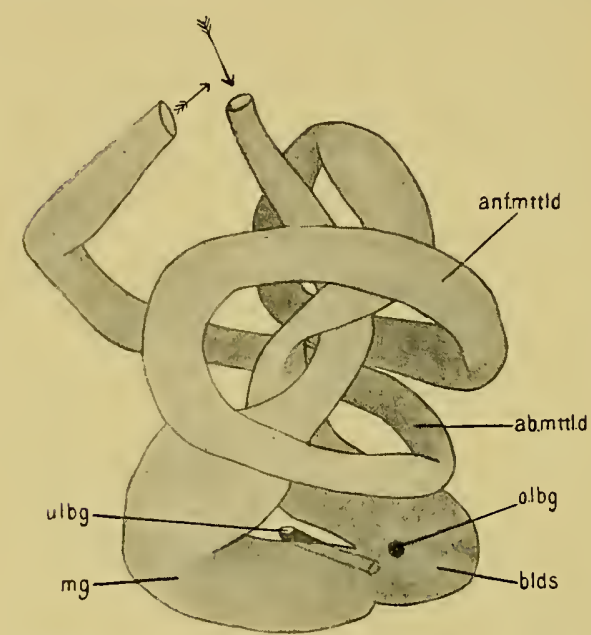

Textfig. 20. Magen und Mitteldarmschlingen. Vergr. $5: 1$.
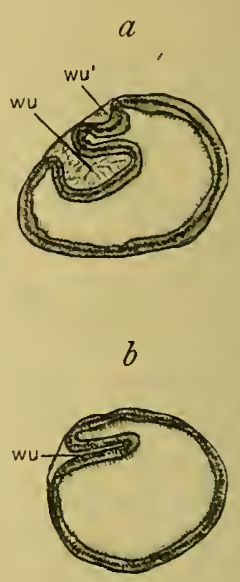

Textfig. 21. Querschnitte durch den Mitteldarm. Vergr. $19: 1$.

Einmündung des unteren Lebergangs $\left(u . L b . o^{\circ}\right)$; sie ist nicht allzu bedeutend und verstreicht bald im Verlaufe des Mitteldarmes (Textfig. 21). Dagegen ist der zweite Wulst (wи Taf. 2, Fig. 26, Textfig. 21) viel höher und kräftiger. Er setzt direkt an die Mündung des oberen Leberlappens $(0 . \mathrm{Lgg})$ nach hinten an und verläuft weit in den Darm hinein. Hierbei zeigt er zunächst dickwulstige Gestalt, weiterhin wird er aber schmäler und länger und stellt schließlich einen schmalen, ins Lumen vorspringenden Streifen dar (Textfig. 21). Solange beide Wülste nebeneinander herlaufen, schließen sie eine Rinne zwischen sich ein, späterhin bildet der bedeutend erhöhte Wulst (wu) allein diese Rinne mit der 
benachbarten Darmwandung. Auf die physiologische Bedeutung der Reliefbildungen des Blindsacks wies Bredermans hin. Diese besonderen anatomischen Einrichtungen „dienen speziell dem Zwecke, den flüssigen Inhalt des Magens, und eventuell darin aufgeschwemmte feste Partikel in das Innere der Leber zu leiten, resp. aus derselben wieder in denj Darm zu befördern". Diese Wülste und außerdem der scharfe Knick, mit dem der Mitteldarm sich an den Magen ansetzt, bilden einen Sperrapparat, der die eben erwähnte physiologische Funktion ermöglicht. Dazu kommt noch die starke Muskulatur, die den Blindsack umgibt und die durch ihre Kontraktion den im Magen befindlichen Inhalt in die Lebergänge preßt. Erwähnenswert ist noch, daß der untere Lebergang bedeutend schmäleren Querschnitt hat wie der obere. Auf diese Weise wird, da auch die Sperrung durch den höheren Wulst (wu) am oberen Leberlappengang bedeutender ist, mehr Mageninhalt zur Resorption in den oberen Leberlappen befördert werden als in den unteren. Die aus den Leberlappen wieder hinausbeförderten Massen gelangen in den Mitteldarm; hierbei kommen die festeren Bestandteile in die von den beiden Wulsten umschlossene Rinne. Hier werden sie zu den schmalen Schläuchen der Exkremente zusammengepreßt, während das größere Lumen des Darmes die flüssigen Partikel passieren. So stellt diese Rinne gleichsam ein Rohr für sich im Mitteldarm dar.

Das Epithel des Magens ist ein Zylinderepithel mit basalständigen elliptischen Kernen und schwachen Cuticularsaum. Im Blindsack tritt starke Flimmerung auf, die sich von da eine Strecke in den Mitteldarm weiter erstreckt. Der Blindsack zeichnet sich ferner dadurch aus, daß die Muskulatur bedeutende Verstärkung erfährt. Die beiden Wülste (z๗u und $\approx \iota_{1}$ Textfig. 21) haben als Stütze blasiges Bindegewebe unter dem Epithel. Der absteigende Ast des Mitteldarms ( $a b . m t t l . d$ Textfig. 19) zeigt nur noch ganz spärliche Flimmerung, die schließlich ganz schwindet. Erst ungefähr an der Stelle, wo der Darm als Enddarm in die Lungenhöhle eintritt, treffen wir wieder Flimmern an, aber nur auf der Unterseite. Im Vorderteil des Magens finden sich schleimbereitende, flaschenförmige Drüsenzellen nur äuserst spärlich, dagegen sind sie im Blindsack und im Mitteldarm in großer Menge vertreten. Ihr Sekret ist körnig und stark blau färbbar. Das Protoplasma der Magenepithelzellen ist feinkörnig und zeigt Längsstreifung; diese wird, wie EllermanN für Helix nachwies, durch starke Längsfaltung der Zelloberfläche hervorgerufen. 
Leber. Der Bau der Leber von Stenogyra weicht von dem gewöhnlichen Verhalten der Gasteropodenleber nicht ab. Sie zerfällt in zwei braun gefärbte Hauptlappen, einen vorderen unteren. der dem unteren Teile des Magens aufliegt, und in einen hinteren oberen, der die beiden obersten Windungen des spiralig eingerollten Eingeweidesacks einnimmt. Dieser Teil birgt in seinem Inneren nach der Columella zu die Zwitterdrüse. Die Leber ist eine zusammengesetzte azinöse Drüse, die sich in zahlreiche größere und kleinere Läppchen verästelt und deren Drüsenelemente stark verzweigte Follikel bilden. Dem Lebergewebe liegt außen das Körperepithel auf, welches an der Columella meist noch eine dünne Längsmuskelschicht unter sich führt. Zwischen Körperepithel und Lebergewebe liegt noch blasiges Bindegewebe, welches auch zwischen die eilnzelnen Tubuli dringt und so die Lappen und Läppchen verbindet.

Die Leberläppchen werden von drei verschiedenen Fornien von Drüsenzellen ausgekleidet, nämlich von Leber-oder Resorptionszellen, Ferment- oder Sekretzellen, Kalkzellen. - Die Leberzellen sind am zahlreichsten vorhanden; sie zeigen schmalzylindrische Gestalt und haben einen basalständigen elliptischen Kern. Zuweilen sind sie am inneren Ende kolbig verdickt und springen dann in das Lumen der Tubuli vor. Das Protoplasma ist körnig und enthält zahlreiche kleine Vakuolen, die sich gelb färbende Körner und Klümpchen enthalten. Diese Zellen häufen Glykogen und Fette an. Außer dieser Resorption von Nährstoffen fällt ihnen noch die Aufgabe der Exkretion von Abfallprodukten zu. Die Ferment- oder Sekretzellen stellen breite Zellen dar, für die eine große, fast die ganze Zelle erfüllende Vakuole charakteristisch ist. Der Kern ist unregelmäßig gestaltet und liegt an der Basis. In der klaren Vakuole liegen mehrere braune Sekretkugeln. Diese Zellen liefern in ihren Sekreten die verdauenden Enzyme oder Fermente. - Die Kalkzellen sind breite, nach dem Lumeninneren schmäler werdende Zellen, zeigen also die Gestalt des abgestumpften Kegels. Sie haben einen großen Kern mit einem Nucleolus und grobmaschiges Protoplasma, das sich mit Hämalaun und van GIEson blau färbt. In den Maschen finden sich runde, stark lichtbrechende Kügelchen. Sie bestehen aus Kalk, der durch den Säftekreislauf an die Stellen gebraclit wird, wo er gebraucht wird, wie z. B. an den Mantelrand zum Aufbau neuer Schalenteile. Die Kalkzellen finden sich am häufigsten in den Ecken der Azini. 
An die Endläppchen, die von diesen drei Zellelementen ausgekleidet werden, schließen sich feine Lebergänge an, die sich zu großen vereinigen und schließlich in den für jeden Leberlappen gemeinsamen großen Lebergang übergehen, der dann in den Magenblindsack einmündet. Das Epithel der Lebergänge ist ein zylindrisches mit basalständigen Kernen und einer starken Flimmerung.

Mittel- und Enddarm. Aus dem Magenblindsack steigt nach unten und nach der Columella zu der Mitteldarm hinab. Er zeigt anfangs noch eine ziemliche Dicke. Er geht einmal um die Columella und um den Ösophagus herum, biegt dann scharf nach hinten um, wobei er sich allmählich nach außen durch die Teile des unteren Leberlappens hindurch arbeitet und wird nun an der Oberseite der vierten Windung sichtbar (Textfig. 19, 20). Er grenzt hier an den hintersten Teil der Lungenhöhle und bildet nun eine verkehrt S-förmige Schlinge, inclem er bis fast an den Anfangsteil des Magens wieder nach oben zurückläuft (anf. mttld). Von da kommt er auf die obere Suturlinie der Windungen und steigt nun immer von außen sichtbar abwärts zur Lungenhöhle. Nach Gartenauer sollen sich an der Eintrittstelle des Darmes in die Lungenhöhle bei Landpulmonaten drüsige Elemente finden. Bei Stenogyra sind diese nicht vorhanden. Während seines Verlaufs durch die Lungenhöhle bezeichnen wir den Darm als Enddarm. Infolge der bedeutenden Ausdehnung der Lungenhöhle zeigt auch er die bedeutende Länge von fast ein und einhalb Windungen.

Die innere Reliefbildung und die Histologie des Mitteldarmes haben wir zusammen mit dem Magenblindsack schon kennen gelernt. Der Enddarm bildet Querfalten auf seiner Unterseite. Diese führt allein auch Flimmern, während auf der Oberseite und den Seitenteilen ein schmaler Cuticularsaum auftritt. Etwas oberhalb und hinterwärts vom Atemloch öfnet sich der Enddarm mit dem After nach außen (Taf. 2, Fig. 27). Dieser zeigt an Stelle der Querfalten Längswälste, die nach hinten hin scharf abbrechen, während sie nach außen zu in die glatte Oberfläche des rechten Mantellappens übergehen. In der Region der Längsfalten zeigt der After vollständige Flimmerung. Links neben dem After liegt die Öffnung des sekundären Ureters, der schon während des ganzen Verlaufs durch die Lungenhöhle neben dem Rectum gelegen ist. After und Ureteröffnung vereinigen sich zur Kloake. Bei der Behandlung der Lunge und Niere werden wir auf diese Verhältnisse nochmals ausführlicher zurückkommen. 


\section{Lunge, Niere und Blutkreislanf.}

Lunge. Die Lungenhöhle, welche die letzten Schalenwindungen einnimmt, zeigt eine bedeutende Ausdehnung. Am lebenden Tier sieht man schon durch die dünne Schale das Gefäßnetz des Lungendachs durchschimmern, wobei besonders die in der Mitte verlaufende große Lungenvene auffällt. Präpariert man die Schale ab, so sieht man, daß die Lungenhöhle sich fast durch ein und eine halbe Windung erstreckt. An ausgewachsenen und gut ausgestreckten Tieren fand ich als Längenmaße $3,6-4,2 \mathrm{~cm}$. An ihrem hinteren spitz zulaufenden Ende stößt die Lungenhöhle an den vordersten Teil der verkehrt S-förmigen Schlinge des Mitteldarms (mttld Textfig. 23), während sie nach vorn mit ihrer breiten Seite begrenzt wird durch die Verwachsung des Mantelwulstes mit dem Nackenintegument. Diese Verwachsung wird durchbrochen von dem Atemloch (pnst Textfig. 23), welches so die Kommunikation

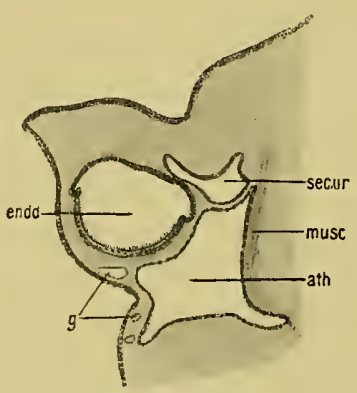

Textfig. 22. Querschnitt durch die Lungenhöhle, sekundären Ureter und Enddarm, kurz hinter dem Atemloch. Vergr. $27: 1$.

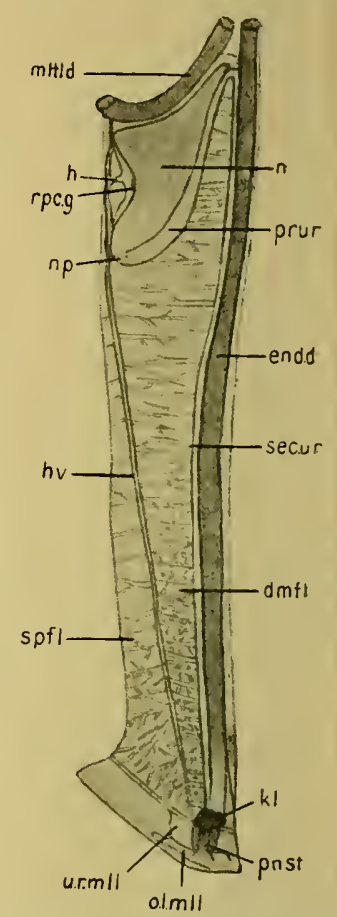

Textfig. 23. Lungendach von unten. Vergr. $2: 1$.

mit der äußeren Luft herstellt. Außen neben dem Atemloch liegen rechts oben und links unten zwei Mantellappen (Taf. 2, Fig. 28), die Ähnlichkeit mit denen von Helix zeigen. Der links oberhalb gelegene $(o . l . m l l)$ ist der größere, er mißt $3,0-3,5 \mathrm{~mm}$. An seinem äußeren linken Ende läuft er zipfelförmig zugespitzt aus (zi) und ragt frei vor dem Mantelwulst vor. Der rechte untere Mantellappen (u.r. mll) dagegen bildet, da er in seiner ganzen Ausdehnung angewachsen ist, eine wulstig vorspringende Leiste. 
Das Epithel dieser Mantellappen ist kubisch mit runden Kernen und zeigt auf den dem Atemgang zugekehrten Seiten deutliche Flimmern. Nach innen zu setzt sich die Flimmerung nur an der Oberseite fort, wo der Enddarm mit dem sekundären Ureter zur Kloake vereinigt, aber gänzlich getrennt von dem Pneumostom und der Lungenhöhle nach außen mit seinem Flimmerepithel mündet. Die Kloakenwand setzt sich also gleichsam auf die Mantellappen fort. Auf der Unterseite des Atemganges schwindet allmählich die Flimmerung, das Epithel wird niedriger und kleidet so das Pneumostom mit einem niedrigen Epithel aus. Nach dem Inneren der Lungenhöhle zu und im Inneren selbst ist das Epithel noch weiter abgeplattet und bedeckt als niedriges Pflasterepithel die Lungenhöhle (Textfig. 22, Taf. 2, Fig. 29, 30). Im Gegensatz zu anderen Pulmonaten zeigt es keine Flimmerung.

Links oben im Atemgang fällt ein Komplex drüsiger Zellen auf, der sich als breites Band nach links hin bis zur Mitte des Mantelwulstes erstreckt. Es ist dies die früher beschriebene Manteldrüse (mtldr Taf. 1, Fig. 1, 2). An dem breiten Streifen, wo die einzelligen Drüsen dieses Komplexes nach außen münden, findet sich an dem Epithel der Mantellappen keine Flimmerung.

Das Respirationsgewebe der Lunge findet sich nur an der Oberseite der Lungenhöhle. Der histologische Aufbau des Gewebes ist folgender (Taf. 2, Fig. 30, 31): Nach außen liegt das kubische Körperepithel $(e p)$, dann folgt eine schmale Lage von Quermuskelfasern (musk) mit spärlichen Kernen. Darunter liegt das respiratorische Gewebe, welches aus zahlreichen spongiösen Bindegewebszellen ( $b d g w)$ mit großen runden Kernen besteht. Zwischen dieses Bindewebe befinden sich die Blutgefäße eingebettet. Die Bindegewebszellen zeigen teilweise einen klaren Inhalt, teilweise finden sich in ihnen starke Anhäufungen von kleinen runden Körnern, die gelb bis braun gefärbt sind. Eine Schichtung konnte ich an den Körnern nicht feststellen. Diese Zellen sind die „Körnchenzellen“ Brocks (kz). Die Blutgefäße sind in ihren ersten Anfängen ganz feine Räume im Bindegewebe ( $g$ Taf. 1, Fig. 31), die aber stets sich durch eine Endothelauskleidung (end) kenntlich machen. Diese ganz feinen Anfangsvenen gehen in größere über ( $g$ Taf. 2, Fig. 30), bei denen die Endothelauskleidung (end) äußerst klar zım Ausdruck kommt. Man sieht hier von den länglichen Kernen des Endothels feine Streifungen seitlich ausgehen, die parallel zur Gefäßwandung angeordnet sind. Deutliche Zellgrenzen sind bei dem Endothel, wie auch sonst bei den 
histologischen Elementen des Lungendaches schwer festzustellen. Die größeren Nebenvenen vereinigen sich schließlich in der Hauptlungenvene, welche ungefähr in der Diagonale von rechts unten nach links oben durch das Lungendach verläuft (hv Textfig. 23). Auch diese Hauptvene zeigt die endotheliale Auskleidung (end), wie ein Schnitt durch die untere Wand dieses weiten Gefäßes zeigt (Taf. 2, Fig. 29). Außerdem treten unter dem Endothel eine Umkleidung mit einer Ringmuskelschicht (musc) und weiter nach außen Längsmuskelfasern (musc) auf. Das Plattenepithel des Lungendaches (ep Taf. 2, Fig. 29) ist in der Gegend der Lungenvene erhöht. Die übrigen Teile der Lungenhöhle aber werden von ganz niedrigem Pflasterepithel (ep Taf. 2, Fig. 30, 31) ausgekleidet, das, wie schon erwähnt, nirgends Flimmerung aufweist.

Im Gegensatz zu Helix treten die Blutgefäße in Lungendach nicht stark leistenartig vor, sondern dieses bildet eine fast plane Fläche, da das Bindegewebe die Gefäße vollkommen umschließt. Nur die in der Mitte verlaufende Hauptvene (hv Textfig. 23) tritt deutlich hervor. Färbt man das Lungendach schwach mit Alaunkarmin, so lassen sich auch die feinen Seitenvenen scharf erkennen. Man erhält so ein klares Bild von der Verteilung und Ausbildung des eigentlichen Atemareals. SEmper führte für die einzelnen Regionen des Lungendachs bestimmte Namen ein. Nach ihm teilt die Hauptvene das ganze Lungendach in eine Spindelfläche (spfl Textfig. 23) und in eine Darmfläche $(d m f l)$. Das Gefäßnetz ist auf beiden Flächen vorn in der Nähe des Pneumostoms (pnst) ein sehr dichtes, während nach hinten an der Niere $(n)$ und am Herzen $(h)$ die dichte Lagerung der Gefäße allmählich abnimmt. Hier sind die Seitenvenen nur noch in geringer Zahl vorhanden, weiter auseinandergelagert und bilden nur spärlich seitliche Anastomosen aus. Auf der Spindelfläche, die im ganzen von geringerer Ausdehnung ist als die Darmfläche, verlieren die Seitengefäße ihre Dichtigkeit schon weiter vorne als auf dieser.

Der Boden der Lungenhöhle, der zugleich die Scheidewand gegen die eigentliche Körperhöhle bildet, zeigt unter dem Pflasterepithel zwei senkrecht zueinander angeordnete Muskelsysteme, eine obere Quer- und eine darunter gelegene Längsmuskellage, wenn wir diese Bezeichnungen auf den ganzen Tierkörper beziehen.

An Tieren, deren untere Schalenwindungen entfernt waren, ließ sich der Atmungsvorgang gut verfolgen. Dieser ist der gleiche, wie wir ihn bei Helix antreffen. Die obere Lungen- 
höhlenwand, die das respiratorische Gewebe bildet, kann sich nicht von der bedeckenden Schale entfernen, sondern vermag nur rückwärts und vorwärts an dieser zu gleiten, allerdings in ausgiebigstem Maße, so daß beim Aufbrechen der Schale das Lungendach sich in unzählige Falten und Fältchen legt. Läßt man nach dem Aufbrechen der Schale das Tier eine Zeit lang in Ruhe, so streckt sich das Lungendach wieder und nimmt die Form an, wie wenn es noch von der Schale bedeckt wäre. Das Atemloch öffnet sich jetzt, der Lungenboden dehnt sich nach dem Körperinnern zu aus, wodurch ein Hohlraum geschaffen wird, in den die frische Luft neu einströmt. Nachden das Atemloch geschlossen ist, dehnt sich der Lungenboden in der entgegengesetzten Richtung, also nach der Lungenhöhle zu aus. Durch das wieder geöffnete Atemloch strömt dann die verbrauchte Luft aus. Dieser AtnungsprozeB wiederholt sich nicht rhythmisch, sondern ganz ungleichmäßig und hängt eng mit dem jeweiligen Kontraktionszustand des ganzen Tieres zusammen.

\section{Niere.}

Am Dach der Lungenhöhle und an ihrem inneren Ende liegt die Niere ( $n$ Textfig. 23). Sie stellt, wie man schon von der Außenseite erkennen kann, ein bräunliches Organ dar, das fast die Gestalt eines Dreiecks hat. Präparieren wir die Lungenhöhle auf und schlagen sie zurück, so erhalten wir ein Bild wie Textfig. 23. Die Niere liegt mit ihrer hinteren kürzesten Seite eng der Mitteldarmwindung $(m t t l d)$ an. Rechts an der Oberseite der Windung verläuft der Enddarm (endd.), ihm gegenüber an der Unterseite liegt das Perikard $(h)$, welches von der Niere umgriffen wird. Während der Herzbeutel eine Länge von 3,0 bis $4,0 \mathrm{~mm}$ hat, mißt die Niere an dieser Seite $6,8-7,6 \mathrm{~mm}$. Somit kann ich Sempers Bemerkung, die Niere sei so kurz wie der Herzbeutel, nicht bestätigen. Die dritte, dem Enddarm zu konvex ckrümmte Seite der Niere mißt 8,7-9,6 mm. Diese Maße zeigen, daß die Niere im Verhältnis zur großen Lungenhöhle die $3,6-4,2 \mathrm{~cm}$ lang ist, eine sehr geringe Ausdehnung besitzt.

Wir wollen uns zunächst mit dem inneren Bau der Niere vertraut machen. Öffnen wir den Nierensack, so finden wir, daß in den hinteren zwei Dritteln der Niere ( $n^{\prime}$ Textfig. 24) starke und zahlreiche Falten lamellenartig in das Lumen vorspringen. Sie sind meist parallel der Längsrichtung angeordnet, doch kommen besonders am hintersten Ende und an den Seiten Falten mit 
anderer Richtung vor. Die größte Höhe und Mächtigkeit zeigen die Lamellen, welche von dem nach innen gelegenen Boden der Niere vorspringen; das steht im Gegensatz zu Helix, wo gerade die Lamellen am mächtigsten am Dach des Nierensackes sich entwickeln. Das vordere Drittel ist dengegenüber ganz anders gestaltet ( $n^{\prime \prime}$ Textfig. 24). Schon äußerlich erkennt man dies an der viel helleren Färbung dieses Teiles der Niere. Es fehlen hier die besonders vom Boden mächtig vorspringenden Falten gänzlich, sie hören ganz plötzlich auf, wie das Textfig. 24 zeigt, die das vordere Drittel $\left(n^{\prime \prime}\right)$ vom Boden her geöffnet zeigt. Vom Boden, wie auch von der Decke erheben sich nur noch kleine

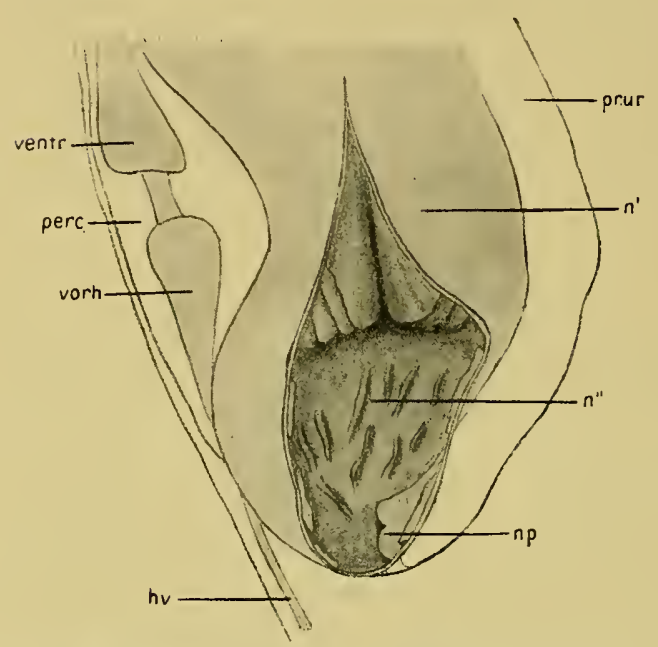

Textfigur 24. Niere im vorderen Teil vom Boden aus geöffnet. Vergr. 10:1. niedrige Wülste, die in ihrer Mehrzahl parallel der Längsrichtung angeordnet sind.

Nach der Lungenhöhle zu wird die Niere von dem PflasterepitheI derselben umgeben, während nach außen das kubische Körperepithel den Abschluß bildet. Im Innern ist der Nierensack mit einem einschichtigen Epithel ausgekleidet, das drüsigenCharakter zeigt. Dieses legt sich zum Zweckeder Oberflächenvergrößerung im oberen Teile in die mächtigen Lamellen. Sie sind in ihrem Innern durch faseriges Bindegewebe mit spärlichen kleinen Kernen gestützt. Stets führen sie an ihrem Scheitel eine Blutlakune, wie sich auch sonst in dem die Niere umhüllenden Parenchym zahlreiche lakunäre Räume finden. Diese bilden das die Niere durchziehende Blutgefäßsystem, welches das Blut in die Nierenlamellen führt und hier den Austausch der Abfallprodukte zu den Nierenzellen bewirkt. Die drüsigen Epithelzellen des Nierensackes haben zylindrische Form und sind am höchsten an den Faltenscheiteln; an den Wandungen und im vorderen Drittel, wo nur kleine wulstige Leisten sich bilden, sind sie am niedrigsten. Der Kern liegt meist basal und zeigt einen Nucleolus, er färbt 
sich stark mit Hämalaun. Das Protoplasma der Drüsenzellen zeigt körnige Struktur und färbt sich bei Hämalaun- van GIESONFärbung gelb. Die besondere Eigentümlichkeit der Nierenzellen besteht in dem Vorhandensein der Harnkonkremente. Sie werden zunächst in Vakuolen als kleine Harnkügelchen gebildet, werden größer und bilden dann bis $17 \mu$ im Durchmesser große Kugeln oder Körner, die von einem zentralen dichteren Kern aus radiäre Streifung und konzentrisch schalige Struktur zeigen. Diese Konkremente liegen im oberen Drittel der Zylinderzellen, sie werden dann und wann und zwar dann immer in großen Massen in das Lumen der Niere entleert. Die Nierenzellen sind dann der Körner beraubt, dagegen sind das Lumen der Niere, besonders das vordere Drittel, und dann auch die beiden Harnleiter stark mit ihnen angefültt. Diese Teile erhalten dann eine dunkelbraune Färbung, die neben dem Vorhandensein von dunkelbraunem Pigment auf die starke Anhäufung des Nierenexkrets zurückzuführen ist. Neben und zwischen den ausgestoßenen Harnkörnern finden sich Protoplasmareste, die durch die gewaltsame Entleerung der Zellen zu erklären sind, wobei Plasmateile beim Platzen der äußeren Zellwand mit herausgerissen werden. Daß ganze Zellen sich ablösen und so die Harnstoffe hinausbefördert werden, habe ich nicht beobachtet.

Da das drüsige Epithel das exkretorisch tätige Gewebe ist und dieses sich nur in den hinteren zwei Dritteln infolge der Oberflächenvergrößerung in den Lamellen zu bedeutender Mächtigkeit entwickelt, so müssen wir diesen Teil der Niere als den hauptsächlich exkretorisch tätigen ansprechen, während der vordere mit seiner niedrigen Wandauskleidung und den kleinen Wülsten nur noch geringeren Anteil an der Exkretion nimmt und schon der Harnleitung zugesprochen werden muß. Dies zeigt sich auch daran, daß er bei manchen Tieren stark mit Harnkonkrementen anलefüllt ist, während er sonst als leerer Hohlraum auftritt. In diesen Raum ragt an seiner vordersten Spitze ein Kanal hinein, der mit ihm durch einen zweilippigen Querschlitz kommuniziert ( $n p$ Textfig. 24). Dieser Kanal ist der primäre Ureter ( $p r . u r$ Textfig. 23), er läuft auf der dem Enddarm zu konvexen Seite der Niere nach hinten in die äußerste Ecke der Lungenhöhle. Hier biegt er in einen spitzen Winkel nach vorn um und folgt nun als sekundärer Ureter (sec. zir Textfig. 23) stets geschlossen dem Enddarm nach vorn. Sekundärer Ureter und Enddarm durchbrechen gemeinsam den Mantelwulst etwas oberhalb des Atem- 
lochs (Taf. 2, Fig. 27), vereinigen sich hier und bilden eine Kloake. Diese Kloake und das Mantelloch werden umgeben von den beiden Mantellappen (Taf. 2, Fig. 28). Die so entstehende breite Rinne am Mantelwulst nennen wir Atemgang. Das nur an der Unterseite flimmernde Rectumepithel (endd Textfig. 22) beginnt allmählich in seiner ganzen Ausdehnung zu flimmern, und auch das niedrige kubische Ureterepithel (sec. ur) nimmt nach der Vereinigung mit dem Enddarn Flimmerung an, so daß also die Kloake als breiter flimmernder Kanal nach außen mündet. Ihre Flimmerung setzt sich noch weiter auf die Mantellappen fort, während die Atemöffnung selbst keine Flimmern trägt.

Das Epithel des primären und sekundären Ureters ist ein kubisches mit rundlichen Kernen, die einen Nukleolus enthalten. Das feingekörnelte Protoplasma zeigt Längsstreifung. Kalottenzellen mit langen Cilien und dazwischen gelegene Zylinderzellen oder sternförmig verästelte Zellen finden sich nicht.

Außer mit dem primären Ureter, mit dem die Niere durch die erwähnte quergeschlitzte Papille in Verbindung steht, kommuniziert sie auch noch mit dem Perikard durch den Renoperikardialgang ( $r p c g$ Textfig. 23). Dieser liegt an der Stelle, wo der Vorhof mit dem Ventrikel sich vereinigt, seitlich nach oben. Er beginnt trichterförmig und richtet sich als runder Kanal nach vorn gegen das Nierenlumen, in welches er allmählich zwischen zwei Lappen übergeht. Dieser Kanal wird ausgekleidet von Zylinderepithel mit runden chromatinreichen mittelständigen Kernen. Besonders ausgezeichnet ist das Epithel durch lange starke Cilien, die stets nach dem Nierenlumen zu gerichtet sind. Nach der Niere zu verliert sich allmählich die Flimmerung, und Drüsennierenzellen treten an Stelle der Epithelzylinderzellen. In gleicher Weise geht im Perikard das flimmernde Zylinderepithel des Herznierenganges in das niedrige Plattenepithel des Herzbeutels über. Es bildet hier jedoch noch eine ziemlich breite trichterförmige, runde Zone, ehe es seine charakteristische Form verliert.

Bisher erwähnten alle Autoren von den Nierenausführgängen von Stenogyra nur, daß der Ureter vollständig geschlossen sei. Auch Beнme, der das Verhalten des Harnleiters bei unserem. Tiere näher untersuchte, sagt, daß „der sekundäre Harnleiter ganz. geschlossen ist, also mit dem von Buliminus Blainvilleanus übereinstimmt". Diese Form beschreibt von JHERING folgendermaßen: „Eine große Öffnung am Mantelrande teilt sich in den Teil, welcher in den Mastdarm führt, und den anderen, durch welchen. 
die Lunge sich öffnet. In letzterer, nicht weit von dem Atemloch entfernt, öffnet sich der Ureter, von dessen Mündung eine Rinne zum Atemloch weiterführt, welche an dessen Rande über und dicht an dem After endet." Dazu gibt voN JHERING noch eine Abbildung, aus der auch klar zu erkennen ist, daß hier weder Kloake noch Atemgang vorliegt, sondern daß hier der Ureter noch in die Lungenhöhle mündet. Wir erkennen hieraus, daß Buliminus Blainvilleanus durchaus von Stenogrya getrennt werden muß.

Ein Schema von den Entwicklungsstadien im Bau des Harnapparates der Bulimusspezies stellte zuerst von JHERING auf. Plate erweiterte dies auf eine große Anzahl anderer Pulmonaten und ВЕск führte dies schließlich noch weiter aus. Wenn wir dieses letzte Schema benutzen, so müssen wir Stenogyra decollata an die letzte Stelle setzen und erhalten dann folgende Reihe:

1. Die Niere öfnet sich nach vorn mit einfacher Papille in die Atemhöhle: Bulimus oblongus, Planorbisspezies.

2. Die Niere öfnet sich mit einem gerade nach vorn verlaufenden, primären Ureter: die meisten Basommatophoren: Limnaea, Physa, Bulimus radiatus, B. purpa. Ferner (nach Beнme) Cionella lubrica, Pupa arenacea, Helix pulchella.

3. Der primäre, zuerst gerade nach vorn verlaufende Ureter biegt an seinem vorderen Ende nach hinten um und mündet in eine nach hinten ziehende Harnfurche: Buliminus detritus, montanus, obscurus.

4. Der primäre Ureter läuft neben der Niere nach hinten und öffnet sich am Grund der Lungenhöhle ohne sekundären Ureter: Testacella, Helix incarnata, strigella, lapicida u. a.

5. Der sekundäre Ureter bildet eine bald offene, bald mehr oder weniger geschlossene Rinne: Bulimus-, Helixspezies.

6. Der sekundäre Uretergang geschlossen, bald allein, bald zusammen mit dem After in die Lungenhöhle ausmündend: Buliminus Blainvilleanus, Helixspezies, Daudebardia rufa, Vitrina, Hyalina, Zonites, Arion usw.

7. Der sekundäre Ureter mündet mit dem After, getrennt von der Lungenhöhle, durch eine besondere Kloake in den Atemgang aus: Stenogyra decollata, Daudebardia saulcyi, Limax, Amalia. 


\section{Blutkreislanf.}

Das Zentralorgan des Gefäßsystems ist das Herz ( $h$ Textfigur 23, 25). Es besteht aus Kammer und Vorkammer und liegt in dem von der Niere umgriffenen Perikard. Die Vorkammer ist mit zahlreichen, lockeren Muskelbündeln, die die verschiedensten Richtungen haben, ausgekleidet. Sie mündet in den linter ihr gelegenen, bedeutend muskelreicheren Ventrikel, dessen Muskelbündel dicht untereinander verflochten sind und so eine dicke Muskelwand bilden. Ein Endothel konnte ich in beiden Abschnitten des Herzens nicht feststellen. Der Ventrikel ist ausgezeichnet durch ein Klappenventil, welches das Blut am Zurückfließen in

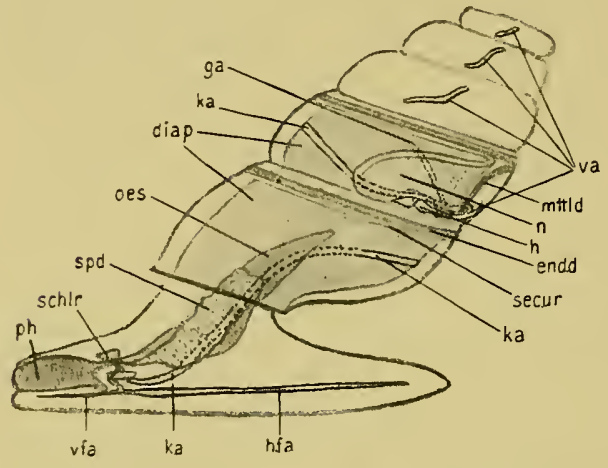

Textfig. 25. Verlauf des Arteriensystems, schematisiert. den Vorhof hindert. Außerdem findet sich ein ebensolches, aus Muskelbündeln bestehendes Ventil am Anfang der Aorta und staut hier das Blut gegen ein Zurückfließen in die Herzkammer. Das Perikard ist mit Plattenepithel ansgebildet, das längliche Kerne führt. Die Zahl der Pulsationen schwankte bei

Tieren, deren Schale über dem Perikard aufgebrochen war, so $\mathrm{da} \beta$ dieses freigelegt wurde, bei gewöhnlicher Temperatur zwischen 23 bis 26 in der Minute.

Aus dem Ventrikel tritt nach hinten die zunächst einheitliche Aorta aus (Textfig. 25), die sich über die der Niere $(n)$ benachbarte Mitteldarmschlinge ( $m$ ttld) hinzieht. Sie teilt sich hier in zwei Äste: die nach oben und hinten gerichtete Visceralarterie $(v a)$ und die nach vorn verlaufende Kopfarterie $(k a)$. Die erstere tritt durch die Lappen der unteren Leber nach innen und nähert sich dabei der Kolumella. Sie gibt nach innen mehrere Äste an die Eiweißdrüse $a b$, nach außen einige an den Magen und den Mitteldarm. Weiterhin folgt die Visceralarterie dem Zwittergang nach oben an der Kolumella entlang und versorgt die Zwitterdrüse und den oberen Leberlappen. 
Die Kopfarterie ( $k a$ Textfig. 25) umgreift nach der Abzweigung von der Visceralarterie in einem scharfen Knick die Mitteldarmschlinge (mttld), welche an der Niere vorbeiläuft, dringt aber nicht in das Körperinnere ein, sondern schließt sich dem Diaphragma (diap), also dem Boden der Lungenhöhle an. Hier läßt sie sich deutlich als weißer Kanal vorspringend, bis zum Ende des zweiten Drittels des Lungenbodens verfolgen. Am Anfang dieses Verlaufes in der Gegend unter der Niere geht von der Kopfarterie ein Ast in das Körperinnere ab. Dieser Ast stellt die Genitalarterie $(g a)$ vor und begibt sich an den Spermovidukt. Im vorderen unteren Teile des Diaphragmas dringt dann die Kopfarterie in das eigentliche Körperinnere ein, steigt rechts neben dem Ösophagus (oes) und den Speicheldrüsen $(s p d)$ nach unten und gelangt unter den Darm. Weiter hin dringt sie unter der Visceralkette durch das von dieser mit den Pedalganglien gebildete Loch nach oben (Textfig. 26). An die Speicheldrüsen gibt die Kopfarterie vorher einige kleine Äste $a b$. Nach dem Durchtritt durch das Loch in der Visceral- und

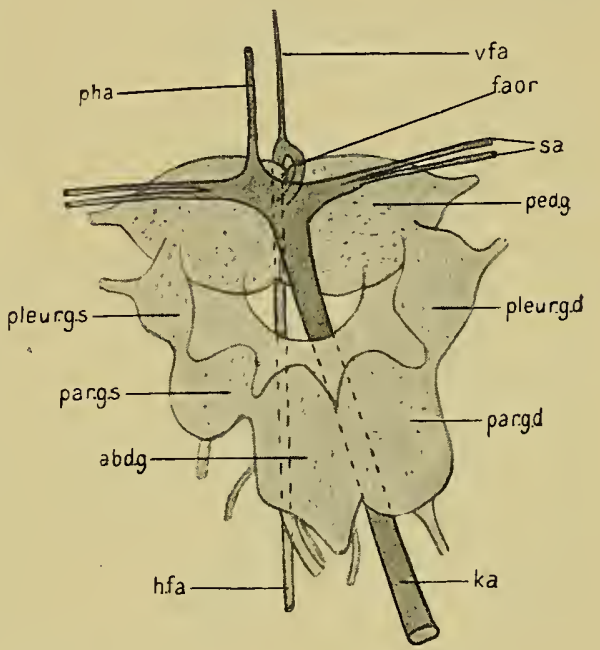

Textfig. 26. Verzweigung der Kopfarterie am Schlundring. Vergr. $20: 1$.

Pedalkette spaltet sich die

Kopfarterie in zahlreiche Stämme. Nach vorn und nach oben geht eine unpaare Arterie aus $(p h a)$, die in clen Pharynx vor der Insertionsstelle der Retraktormuskeln eintritt. Ebenfalls nach vorn aber nach unten verläuft ein starker, zunächst einheitlicher Stamm $(f a)$, die Fußarterie. Sie umgreift zunächst die Pedalganglien $(p e d g)$ an ihrer Vorderseite und entsendet nach vorn an die Ausmündung der Fußdrüse einen schwachen Ast ( $v f a)$, während sich nach hinten der Hauptstamm begibt $(n f a)$, der über der Fußdrüse verläuft und seitlich zahlreiche Ästchen in die Fußmuskulatur abgibt. Zu erwähnen wäre noch ein paariges System von Arterien ( $s a$ ), die jederseits nach oben steigen und in die 
Tentakel und die obere Kopfregion eindringen. Auf der rechten Seite gelit von diesen Arterien ein Stamm an den Penis ab.

Die Arterien sind ausgekleidet mit einem deutlichen Epithel mit runden Kernen. Die Zellgrenzen sind nicht immer an diesem Epithel $\mathrm{zu}$ erkennen.

Alle diese Arterien lösen sich in feinste Kanäle auf und diese sammeln sich wieder in den sogenannten Übergangsgefäßen, welche schließlich in die venösen Blutlakunen führen. Sie entbehren einer epithelialen Auskleidung und zeigen sich nur als große Lïcken in der Muskulatur und im Bindegewebe. Besonders ausgebildet finden sie sich in Fuß zu beiden Seiten der Fußdrüse, im Kopfteil und an den Geschlechtsorganen. Auch die am Magen und an der Eiweißdrüse gelegenen Hohlräume stellen solche venösen Bluträume dar. Aus diesen leiten dann die Venen das Blut der Lungenhöhle zu. Von den hinteren, oberen Partieen führt die Lebervene das Blut neben dem Enddarm nach vorn. Auch das Blut aus den Venenräumen des Fußes und des Kopfes gelangt durch einen venösen Stamm nach dem Vorderrand des Lungendachs. Es bildet sich hier so eine die Lungenhöhle umgreifende Ringvene. Von dieser leiten die zuleitenden Lungengefäße das Blut in das Lungendach, die ableitenden sammeln es wieder und führen es schließlich in die schräg von links vorn nach rechts hinten am Lungendach verlaufende Hauptvene (hv Textfig. 23). Diese führt das arteriell gewordene Blut in den Vorhof.

\section{Geschlechtsorgane.}

Der Geschlechtsapparat von Stenogyra decollata zeigt in den allgemeinen Verhältnissen Ähnlichkeit mit dem von Helix. Charakteristisch für ihn ist, daß er aller Anhangsorgane an den Kopulationswerkzeugen entbehrt. Der allgemeine Verlauf des Geschlschtssystems ist folgender:

Von der im oberen Leberlappen gelegenen Zwitterdrüse (zwdr Textfig. 27) steigt der vielfach gewundene Zwittergang $(z w g)$ an der Kolumella abwärts. In seinem mittleren Teile liegt eng mit ihm verbunden eine geknäulte Vesicula seminalis (ves. sem Textfig. 27, 28), welche im unteren Drittel sich mit ihm vereinigt. Am Ende mündet in den Zwittergang noch der Ausfuhr- 
gang einer bläschenförmigen Drüse ein (bl. $d \dot{r}$ Textfig. 27, 28). Zusammen mit dem Ausführgang der großen Eiweißdrüse (eiz $d r$ Textfig. 27), welche am oberen Ende des Spermovidukts gelegen ist, geht dann der Zwittergang in diesen über. Am Spermovidukt (spov Textfig. 27) unterscheiden wir den Uterusteil $(u . d r)$ mit weißlichem, blätterig gefaltetem Drüsenmantel und die Samenleiterrinne (prst. $d r$ ) mit gelb gefärbten, feiner gefälteten Drüsenanhängen, der Prostata. Neben der Prostatarinne findet sich noch eine dritte Rinne ohne besondere Drüsenanhänge. Im vorderen Teile sondern sich die Teile des Spermovidukts: die Prostatadrüse schwindet und es spaltet sich vom Uterus das Vas deferens (z'as def Textfig. 27) ab, welches, bis zum Atrium genitale hinablaufend, am Penis wieder in die Höhe steigt und in dessem hinteren Ende einmündet. Der Uterus nimmt nach der Abtrennung des Vas deferens den kurzen Stiel des Receptaculum seminis (st.rec) auf, welches als birnförmige Blase dem Stiel oben aufsitzt (rec.sem Textfig.27). Von da an bezeichnen wir den Uterus als Vagina ( $v a g)$. Durch das von rechts am Kopf gelegene Atrium genitale (atr.gen) mündet die Vagina nach außen. In dieses Atrium genitale mündet auch der kurze, aller An-

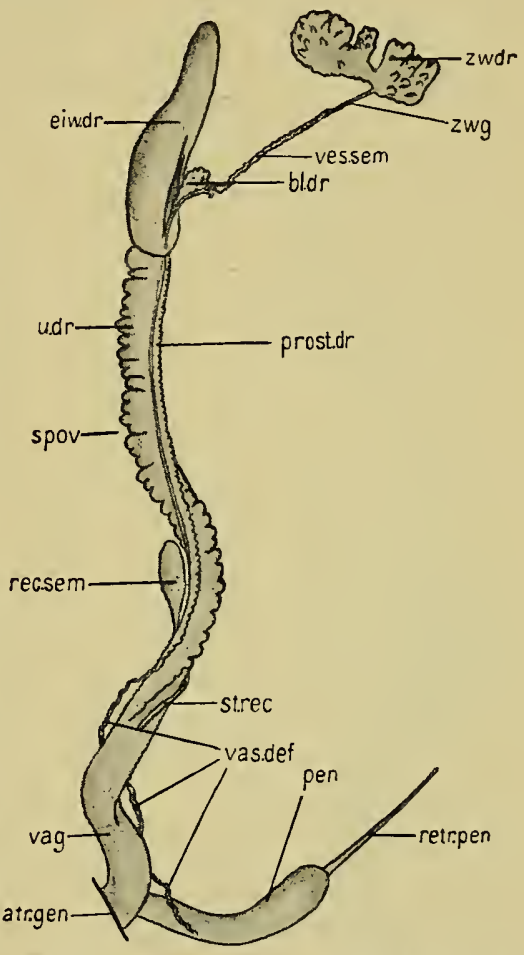

Textfig. 27. Totalbild der Geschlechtsorgane. Vergr. $2: 1$. hangsorgane entbehrende Penis (pen) ein. Der Penis hat einen Retraktormuskel (retr. pen).

Zwitterdrüse. Die Zwitterdrüse liegt in der zweiten oberen Windung des Schneckenkörpers, eingebettet in Bindegewebe und Lebergewebe des oberen Lappens. Sie nimmt hier den der Kolumella zugekehrten Abschnitt der Windung ein und bildet zahlreiche Lappen, die radial nach der Kolumella zu sich vereinigen. Aus dieser Vereinigungsstelle führt der Zwittergang die reifen Geschlechtsprodukte, Spermien und Eier, ab, die in der 
Zwitterdrüse nebeneinander gebildet werden. Bei meinen sämtlichen Tieren war die Zwitterdrüse gleichzeitig mit männlichen, wie weiblichen Elementen angefüllt. Die Eier waren jedoch in viel geringerer Zahl vorhanden als die männlichen Produkte. Soweit meine Untersuchungen reichten, fanden sich bei der Entwicklung der Eier und Samenfäden keine Unterschiede von dem

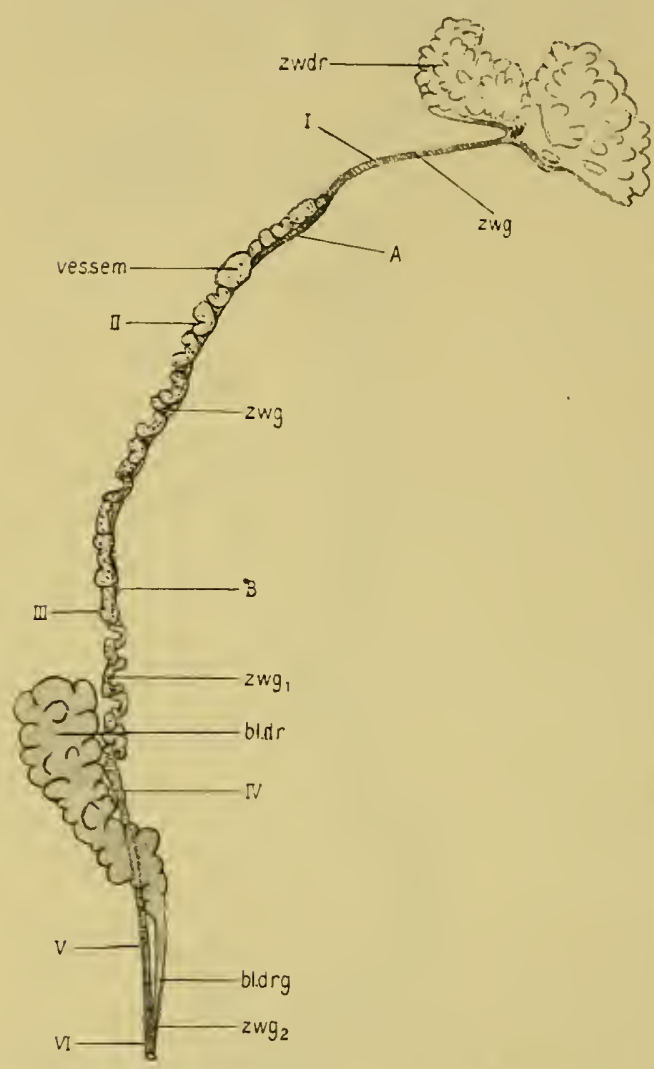

Textfig. 28. Zwitterdrüse und Zwittergang, Vesicula seminalis mit blasiger Drüse. Vergr. $8: 1$. bekannten Entwicklungsgang bei Helix.

Zwittergang. Der Zwittergang steigt in einer ganzen Windung, die Kolumella umschlingend, nach unten. Er zeigt ganz besondere Verhältnisse, die an Totalpräparaten, die mit Alaunkarmin leicht gefärbt wurden, am besten zu studieren sind (Textfig. 28). Der eigentliche Ausführgang der Zwitterdrüse ist ein einfaches Rohr von geringer Dicke - der Durchmesser beträgt ungefähr $35 \mu-$, welches von der Zwitterdrüse bis zur Mündung in den Spermovidukt gleichmäßig, teils gerade, teils unter Knäuelbildung verläuft, allerdings auf diesem Wege die

Mündung eines stark verschlungenen, langen, blasigen Ganges, der Vesicula seminalis (ves. sem) und eines blasenförmigen, hellen Drüsensacks (bl.dr Textfig. 28) in sich aufnimmt. Dieser eigentliche Zwittergang (zwg Textfig. 28, Taf. 2, Fig. 32-37) zeigt in Querschnitt leicht vorspringende Längsfalten und ist mit einer Ringmuskelschicht außen umgeben. Das Protoplasma der flimmernden hohen Epithelzellen ist hell und homogen; die Kerne sind rund und chromatinreich und zeigen einen Nucleolus. Im 
obersten Fünftel des ganzen ausführenden Systems der Zwitterdrüse finden wir diesen Gang allein vor (Textfig. 28I, Taf. 2, Fig. 32). Weiter unten tritt dann aber neben dem eigentlichen Zwittergang die Vesicula seminalis auf (ves. sem Textfig. $28 I I$ Taf. 2, Fig. 33, 38). Diese ist ein oben blind endigender, langer, stark geknäulter Gang, der in seinem ganzen Verlauf keine Kommunikation mit dem Zwittergang hat und erst weit unten, ungefähr. im vierten Fünftel, in diesen einmündet (Textfig. 28III). Die beiden Bilder, Taf. 2, Fig. 38, 39, geben das blinde Ende der Vesicula seminalis und ihre Einmündung in den Zwittergang, also die beiden Stellen $A$ und $B$ der Textfig. 28 in stärkerer Vergrößerung wieder. Die Vesicula seminalis liegt dicht neben dem Zwittergang und überdeckt ihn teilweise, da sie bedeutend voluninöser ist als dieser. Eine dünne Ringmuskelschicht und reichliches Bindegewebe umgibt beide Gänge, so daß sie makroskopisch als ein einheitlicher, geknäulter Gang erscheinen, während nur die Vesicula seminalis die Knäuelbildungen zeigt, dagegen der Zwittergang als gerades Rohr daneben nach unten läuft. Die epitheliale Auskleidung der Vesicula seminalis zeigt verschiedenes Verhalten (Taf. 2, Fig. 33). Auf der dem Zwittergang zu gelegenen Seite befindet sich ein hohes Zylinderepithel mit deutlichem Flimmerbesatz. Das Protoplasma dieser hohen Zylinderzellen ist hell und homogen und führt elliptische, chromatinreiche Kerne mit Nucleolus. Während sich also dem Zwittergang benachbart ein flimmernder Epithelstreifen durch die ganze Vesicula seminalis hinzieht, sind die nach außen gelegenen Teile des Ganges, welche besonders die knäuelförmigen Auftreibungen zeigen, von einem niedrigen, nicht flimmernden Epithel ausgekleidet. Diese Epithelzellen haben in einem feingekörnelten Protoplasma große elliptische, chromatinreiche Kerne mit Nucleolus. Das Innere der Vesicula seminalis ist stets stark angefüllt mit Sjermien. Im vierten Fünftel des gesamten ausführenden Systems der Zwitterdrüse mündet dann die Vesicula seminalis in den Zwittergang. Diese Stelle (Textfig. 28 B, Taf. 2, Fig. 34, 39) zeichnet sich dadurch aus, daß die Knäuelbildungen der Vesicula seminalis und die Anfüllung mit Spermien schwinden. Zugleich gewiunt der flimmernde Epithelstreifen an Raum, so daß schließlich an der Mündung das ganze Epithel des Ganges Flimmern trägt. Von den ebenfalls flimmernden Zylinderzellen des Zwitterganges unterscheidet sich das Epithel der Vesicula seminalis an der Vereinigungsstelle beider nur durch eine etwas hellere Färbung 
des Protoplasmas (Taf. 2, Fig. 34). Als einheitlicher Gáng geht nun der Zwittergang (zwg Textfig. 28) weiter nach unten und zeigt hier starke Knäuelbildungen. In dieser Gegend finden sich an dem Gang dann und wann kleine seitliche Aussackungen (auss Taf. 2, Fig. 35). In diesen liegen häufig Anhäufungen von Spermien. Diese kleinen Aussackungen stellen also gleichsam eine Vorstufe der Vesicula seminalis dar. Der Zwittergang nähert sich immer mehr in seinem weiteren Verlauf der großen Eiweißdrüse (ciz. $d r$ Textfig. 27) und zugleich einem hellen traubigen Sack (bl. $d r$ Textfig. 27, 28). Dieses Gebilde liegt in einer Einsenkung, welche die Eiweißdrüse auf ihrer der Kolumella benachbarten Seite bildet. Der Zwittergang läuft nun dicht neben der hellen traubigen Drüse her und wird, wie diese, stark von dem Gewebe der Eiweißdrüse umgeben, so daß er schließlich äußerlich nicht mehr wahrnehmbar ist. Veränderungen zeigt der Zwittergang während dieses Verlaufes nicht. Die blasige Drüse (bl.dr Textfig. 28) erscheint, makroskopisch betrachtet, hell und mit zahlreichen traubigen Aussackungen besetzt. Ihr hinteres blindgeschlossenes Ende ist breit und voluminös, nach vorn wird dann das Gebilde schmäler, um schließlich durch einen feinen Ausführgang sich mit dem Zwittergang zu vereinigen. Die Wandung der Drüse (Taf. 2, Fig. 35) wird außen gebildet von einer bindegewebigen Faserschicht. Nach innen folgt dann eine Schicht von hohen Zylinderepithelzellen. Diese können niedriger werden, wenn die Drüse stark von Sekret angefüllt und dadurch stark ausgedehnt ist. Das Protoplasma der Zylinderzellen ist gekörnelt, die elliptischen Kerne sind chromatinreich und liegen im basalen Drittel der Zelle. Das Innere des traubigen Sacks ist stets angefüllt mit Sekretklumpen, die sich mit Hämalaun und vaN Greson-Färbung gelb bis violett färben. Aus dem Vorhandensein des Sekrets im Innern geht hervor, daß die Epithelzylinderzellen drüsige Funktion besitzen. Die Drüse verengert sich allmählich zu dem Ausführgang, der einen runden Querschnitt hat und anfangs noch ähnliche Zellen wie die Drüse selbst zeigt (Taf. 2, Fig. 36). Später aber wird das Protoplasma der Epithelzellen heller, verliert die Körnelung und zuletzt tritt dann Flimmerbesatz auf. So vereinigt sich dann der Ausführgang der traubigen Drüse mit dem Zwittergang zu einem einheitlichen Gange (Textfig. 28VI, Taf. 2, Fig. 37). Dieser gemeinsame Gang ( $\left.z w g_{2}\right)$ führt flimmerndes Zylinderepithel mit hellem Inhalt; er ist außen umgeben von einer Ringmuskelschicht. 
In der Literatur werden drüsige Anhänge des Zwittergangs einmal erwähnt. DuBRUeIL stellt ihr Vorhandensein bei Bulimus decollatus und Leucochroa candidissima fest, und gibt für unser Tier an, daß jede drüsige Blase mit einem gesonderten Kanal in den Zwittergang münde, ,comme les glandes de la prostate proprement dite". Diese Verhältnisse liegen, wie wir sahen, nicht vor.

Der Gang $z w g_{2}$, der die Vereinigung von Zwittergang $\left(z w g_{1}\right)$ und Ausführgang der blasigen Drüse (bl.dr) darstellt, setzt sich weiterhin direkt fort in den Spermovidukt, und zwar in die Prostatarinne und die oben erwähnte dritte Rinne und vereinigt sich mit dem Ausführgang der Eiweißdrüse. Bevor wir aber auf diese Verhältnisse eingehen, wollen wir erst den Bau der Eiweißdrüse näher kennen lernen.

Eiweißdrüse. Die Eiweißdrüse stellt ein längliches, einheitliches, weißliches Gebilde dar, welches auf der einen Seite fast eben, auf der anderen Seite stark konvex gekrümmt ist (eizw. $d r$ Textfig. 27). Die ebene Seite liegt der Kolumella zu genähert und zeigt die kleine, oben erwähnte Einbuchtung für die blasige Drüse $(b l . d r)$, welche, wie wir sahen, ein Anhangsorgan des Zwittergangs ist. Die Eiweißdrüse wird durch den Darm nicht in Zipfel geteilt, ebensowenig finden sich Einbuchtungen oder Furchen, die von dem gewundenen Laufe des Darmes herrührten. Nach hinten stößt die Drüse an den Anfangsteil des Magens, nach vorn liegt ihre Begrenzung in der Gegend des Lungenhöhlenanfangs. Die Außenseite wird überdeckt von den Mitteldarınwindungen und Teilen des unteren Leberlappens. Im Innern verläuft von der Spitze bis zum Ende als ausleitender Kanal ein Hauptgang, der der planen Seite der Eiweißdrüse genähert ist und auf Querschnitten als schlitzförmige Spalte erscheint (hk Textfig. $29 a, 30 a, b$ ). Dieser Kanal erweitert sich etwas kurz 7or der Einmündung in den Spermovidukt (Textfig. 29a-d) und geht dann in diesen über unter Verhältnissen, die uns später noch beschäftigen werden. In den zentralen Hauptkanal ergießen sich nach einem verschlungenen Verlauf zahlreiche feine Nebenkanälchen ( $n k$ Textfig. 30), die die drüsigen Blindsäcke darstellen. Die Eiweißdrüse ist also als eine zusammengesetzte tubulöse Drüse aufzufassen.

Die Größe der gesamten Drüse, besonders aber ihre histologische Struktur ist verschieden, je nachdem die Drüse sich in Sekretion befindet oder nicht. Die beiden Übersichtsbilder Textfig. 30 zeigen im Querschnitt bei gleicher Vergrößerung eine Eiweißdrüse 
im Sommer und eine solche im Winter. Die letztere hat eine ungefähr zehnmal geringere Fläche im Querschnitt als die in Sekretion begriffene Eiweißdrüse des Sommers. Hand in Hand mit diesem bedentenden V'olumenunterschied geht ein verschiedenartiger histologischer Bau.

Betrachten wir zunächst den histologischen Bau einer Eiweißdrüse, die sich in Sekretion befindet, und zwar zunächst einen
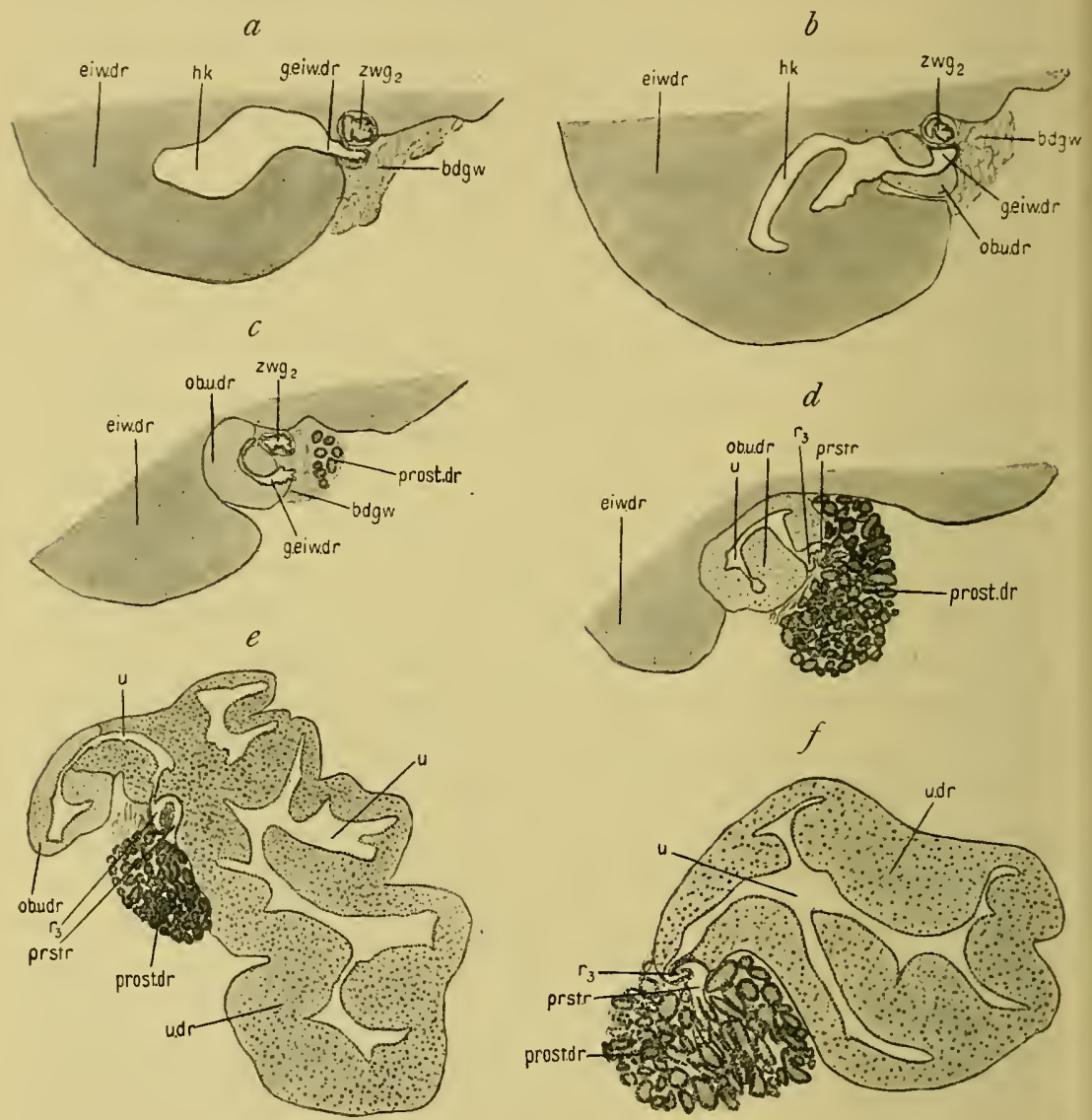

Textfig. 29. Querschnitte durch den oberen Teil des Spermovidukts und durch den unteren Teil der Eiweißdrüse. Vergr' $19: 1$.

drüsigen Blindsack (Textfig. 32). Dieser ist außen umgeben von einer dünnen bindegewebigen Faserschicht ( $b d g$ w), welche spärlich Kerne enthält. Diese Bindegewebsfasern umschließen fest alle einzelnen Tubuli, und so kommt der geschlossene, kompakte Charakter der ganzen Eiweißdrüse zustande. Es folgt nach innen 
das eigentliche drüsige Epithel. Dieses besteht aus sehr großen zylindrischen oder prismatischen Zellen, die mit ihrer freien Seite nach dem Lumen des Ganges zu gerichtet sind $(d r z)$. Das Protoplasma dieser Zellen bildet ein feingekörneltes Netzwerk. Zwischen diesem Protoplasmanetz liegen gleichmäßig in der ganzen Zelle verteilt homogene Sekrete. Krahelska fand an diesen Sekretkörnern bei Helix einen zusammengesetzten Bau nach dem
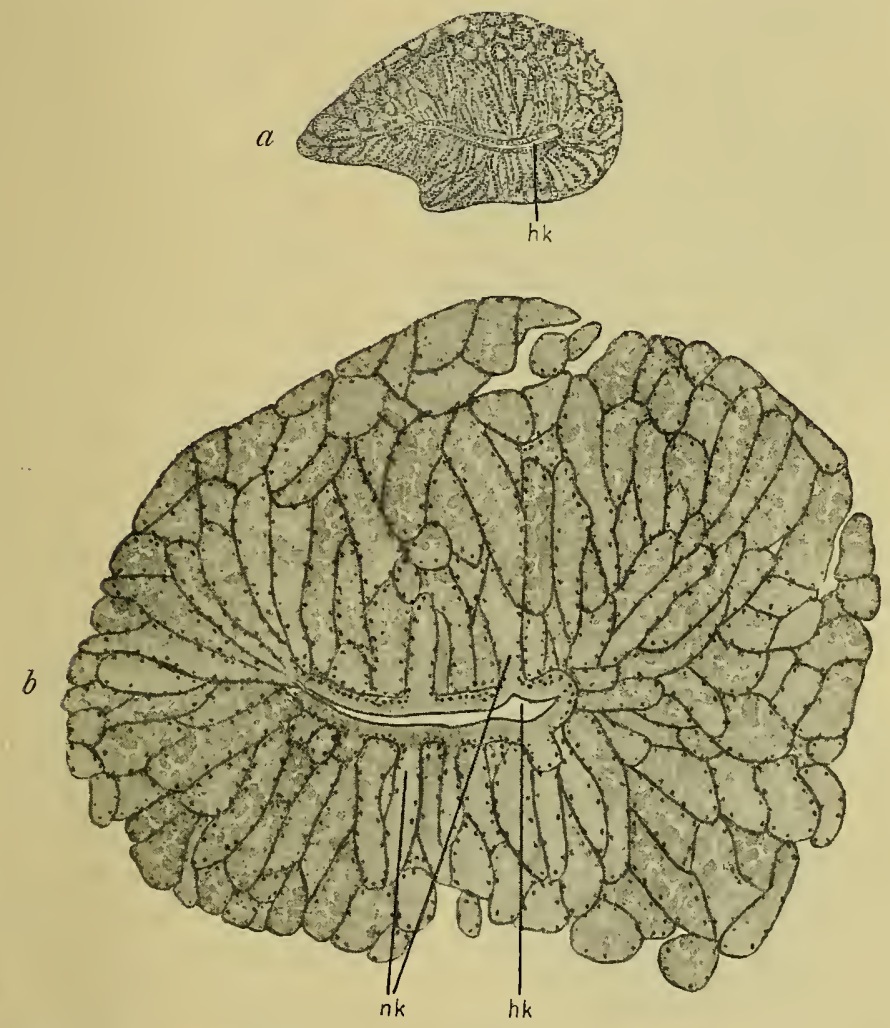

Textfig. 30. Querschnitt durch die Eiweißdrüse. Bei a ohne Sekretion, bei $b$ in Sekretion. Vergr. 28: 1 .

Typus der „HaIdenhainschen Halbmondkörperchen“. Einen solchen Bau konnte ich bei Stenogyra trotz Anwendung der von KRAHELSKA angegebenen Färbemethode nicht nachweisen. Der große Kern der Drüsenzellen färbt sich intensiv und liegt basal in der Zelle; er ist chromatinreich und hat einen Nucleolus. Der Kern ist nicht von einem hellen Protoplasmahof umgeben. wie Cavalié für Helix angibt, sondern die Fasern des Protoplasmanetzes treten 
an den Kern heran, ohne Besonderheiten zu zeigen. Die innerste Auskleidung des Blindsackes bilden schließlich kleine spindelförmige Zellelemente, die sich durch einen hellen kleinen Kern und faserige Struktur auszeichnen. Sie stellen die ,zentrotubulösen Zellen" dar (ctbl.z). Diese liegen als abgeplattete Zellen den großen Drüsenzellen auf, vor allem nehmen sie hier die Stelle ein, wo zwei Drüsenzellen mit ihren seitlichen Wänden aneinander

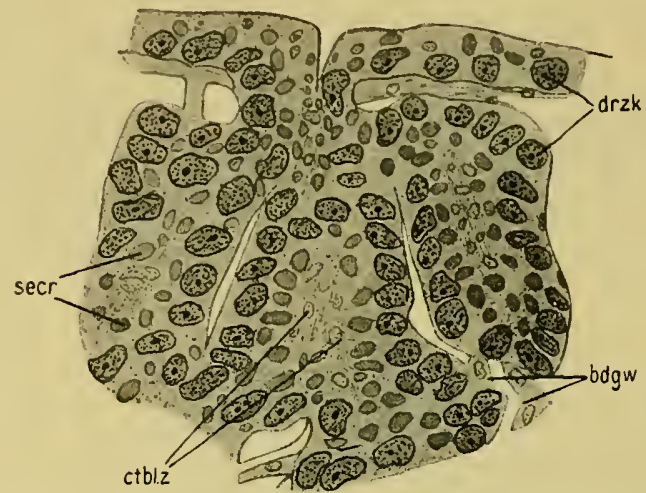

Textfig. 31. Zellen der Eiweißdrüse, nicht sezernierend. Vergr. $451: 1$.

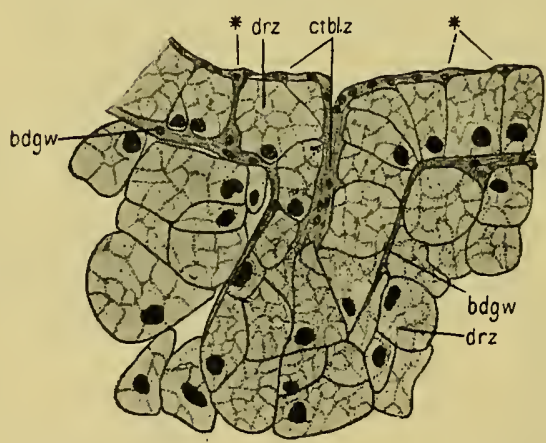

Textfig. 32. Zellen der Eiweißdrüse in der Sekretionsperiode. Vergr. 196: 1 . stoßen und dringen hier Zwischen diese $W$ ände etwas ein (* Textfigur 32). Das Epithel des Hauptkanals der Eiweißdrüse zeigt die gleichen Verhältnisse wie das eben beschriebene der einzelnen blindgeschlossenen Tubuli. Öffnetsich nun ein Blindsack in den Hauptkanal, so geht die äußere Bindegewebsschicht (bdgzw Textfig. 32) des einen in die des anderen über.Die großenDrüsenzellen sind in gleicher Form im Hauptkanal wie in den Tubuli vorhanden.-- Ebenfalls erhalten sich die zentrotubulösen Zellen; sie sind im Hauptkanal in reichlicherer Menge anzutreffen und bilden eine schmale Lage flacher Zellen, die gleichsam die innerste Auskleidung des Hauptkanals darstellt, ohne jedoch den Charakter einer epithelialen Schicht anzunehmen.

Die Eiweißdrüse im Winter, also zu einer Zeit, wo die sezernierende Tätigkeit sistiert ist, zeigt einen etwas anderen Bau (Textfig. 31). Zunächst ist sie schon äußerlich stark zusammengeschrumpft und hat eine ziemlich unscheinbare Gestalt ange- 
nommen. Die einzelnen Zellelemente sind in den Grundzügen die gleichen geblieben. Auch hier finden wir um die einzelnen Tubuli außen eine bindegewebige Faserschicht mit wenigen kleinen Kernen $(b d g w)$. Die Drüsenzellen sind bedeutend kleiner als in der Eiweißdrüse des Sommers. Zwischen den einzelnen Drüsenzellen treten keine deutlichen Zellgrenzen auf, so daß die Kerne $(d r z k)$ in einer gleichmäßig verteilten Schicht körnigen Protoplasmas zu liegen scheinen. Diese chromatinreichen großen runden Kerne, die einen Nucleolus führen, sind an den Außenseiten der Tubuli basal angeordnet. Im Protoplasma der Drüsenzellen liegen meist in der Nähe der basalen Kerne nach innen zu homogene Sekretklumpen (secr), die aber im Vergleich zu denen des Sommers winzig klein erscheinen. Wenn sich diese einzelnen Sekretklumpen stark vermehren, so wird sich das Protoplasma netzförmig um sie anordnen, und wir haben dann die Verhältnisse, wie wir sie bei der Eiweißdrüse des Sommers antrafen. Im Zentrum der Drüsentubuli finden sich im körnigen Protoplasma feine Streifungen und die hellen Kerne der zentrotubulösen Zellen (ctbl.z). Die Kerne dieser Zellen liegen auch in den Drüsenzellen, welche den Zentralkanal epithelartig auskleiden, ohne daß hier wie dort eine Differenzierung des Protoplasmas beider Zellsorten nachzuweisen wäre. Mit der lebhaften Bildung der Sekrete scheint also erst eine Scheidung der großen Drüsenzellen von den spindelförmigen, zentrotubulösen Zellen einzutreten.

Spermovidukt. Aus der Eiweißdrüse führt der Hauptkanal ( $h k$ Textfig. 29a,b) die Sekrete in den Spermovidukt. Auf diesem Wege tritt der Gang an der planen Fläche der Eiweißdrüse nach außen und schnürt sich auf diese Weise von ihr ab (Textfig. 29a-d). Zugleich verliert das Epithel seinen drüsigen Charakter und wird " einem kubischen Epithel, welches auf dieser kurzen Strecke, wo der Gang allein verläuft, Flimmern trägt. Dicht neben diesem ausführenden Kanal der Eiweißdrüse verläuft der Gang (zw $g_{2}$ Textfig. 29a), welcher aus der Vereinigung von Zwittergang (zwg $g_{1}$ Textfig. 28) und blasiger Drüse $(b l . d r)$ hervorgegangen ist. Neben und um den Ausführgang der Eiweißdrüse tritt eine Umkleidung von hellen Drüsenzellen auf (obudr. Textfig. 29b-d). Zugleich erscheinen in der Umgebung des Ganges $z w g_{2}$ die Schläuche der Prostatadrüse (prost.dr. Textfig. 29c, d). Jetzt erst tritt die Vereinigung der beiden Gänge, des Eiweißdrüsenkanals und des Zwitterganges ein (Textfig. 29d). Während der erstere, den wir als Uterusrinne $(u)$ bezeichnen, einheitlich von dem hellen Drüsen- 
mantel $(o b u d r)$ umgeben wird, bildet der andere zwei Rinnen, die Rinne $r_{3}$, die gänzlich frei von irgendeinem Drüsenmantel bleibt und die Prostatarinne (prst.r), die in Verbindung mit den Prostatadrüsenschläuchen tritt. Es geht daraus hervor, wie es sich deutlich auch auf rler Serie Textfig. $29 a-d$ erkennen läßt, daß die Fortsetzung des Zwitterganges in der Prostatarinne und der Rinne $r_{3}$, die des Eiweißdrüsenkanals in der Uterusrinne $(u) z u$ suchen ist. Wir haben also jetzt den Spermovidukt vor uns. an dem sich, wie wir oben sahen, auch äuBerlich die Scheidung in Uterus- und Prostatadrüsenteil erkennen läßt. In dieser Gestalt verläuft num der Spermovidukt äußerlich gleichmäßig unter der Lungenhöhle nach vorn.

Die epitheliale Auskleidung des Spermovidukts ist in den einzelnen Teilen eine verschiedene. Die Uterusrinne (u Taf. 2, Fig. 40) führt ein Zylinderepithel mit elliptischen Kernen und klarem Protoplasma. Eine Flimmerung läßt sich in diesem Teile des Spermovidukts nicht nachweisen. Wie wir schon sahen, ist der oberste Teil der Uterusrinne von einem Mantel heller Drüsen, den oberen Uterusdrüsenzellen (obudr Textfig. 29b-e) umkleidet, welche sich nach oben auch noch an dem Ausführgang der Eiweißdrüse hinaufziehen. Diese unregelmäßig gestalteten Drüsenzellen färben sich ganz schwach bläulich; sie zeigen sehr deutliche Zellgrenzen und einen sehr kleinen rundlichen Kern, der verschiedene Lagen in der Zelle einnimmt. Zwischen die einzelnen Drüsenzellen dringen ganz feine bindegewebige Faserstränge (Textfig. $33 b d w g$ ) ein, so daß die Zellen zu größeren Komplexen vereinigt erscheinen. Durch interzelluläre ganz feine Lücken des Epithels entleeren die Drüsenzellen ihr Sekret (secr) in den Uterusgang. Diese obere Uterusdrüse nimmt einen verhältnismäßig geringen Raum ein: nur die obersten zwei oder drei Lappen des Drüsenmantels sind von dieser Struktur. Im Bereich der oberen Uterusdrüse ist der Querschnitt der Uterusrinne ein schmaler Gang, der keine Aussackungen oder Nebenkanäle zeigt (Textfig. 29d). An Stelle der eben beschriebenen Zellart treten aber weiterhin Drüsenelemente, welche in viel größerer Mächtigkeit entwickelt sind (u. dr Textfig $29 e, f)$. Zugleich ändert sich damit auch der Querschnitt der Uterusrinne: sie wird breiter und treibt seitlich tief in den Drüsenmantel eindringende Aussackungen und Nebengänge. Die einzelnen Drüsenzellen sind viel größer als die Zellen der oberen Uterusdrüse und zeigen flaschenförmige Form (u. $d r$ Taf. 2, Fig. 40). Diese Zellen färben sich mit 
Hämalaun und van Gieson braun bis violett. Ihr Protoplasma ist fein granuliert und hat einen großen, rundlichen, zentral gelegenen Kern mit einem Kernkörperchen. Die Zellen sind nicht in so vielen Schichten übereinandergelagert, wie die kleineren Drüsenelemente der oberen Uterusdrüse. Zuweilen sind die dem Lumen der Rinne zunächst gelegenen Zellen heller gefärbt, was wohl anf die Entleerung des Sekrets durch Interzellularen des Epithels zurückzuführen ist. Diese Art von Drüsenzellen begleitet den längsten Teil der Uterusrinne. Ungefähr in der Gegend, wo das Receptaculum seminis (rec. sem Textfig. 27) mit seiner birnförmigen Blase dem Spermovidukt anliegt, geht äußerlich die weiße Farbe der Uterusdrüsen in eine braune über, die bis zum gänzlichen Schwinden des Drüsenmantels anhält. Diesem äußeren Unterschied in der Farbe entspricht ein innerer

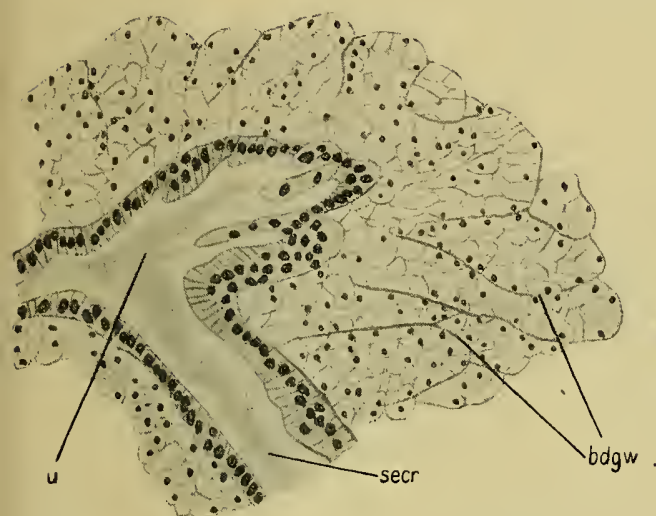

Textfig. 33. Schnitt durch die obere Uterusdrüse. V'ergr. $192: 1$.

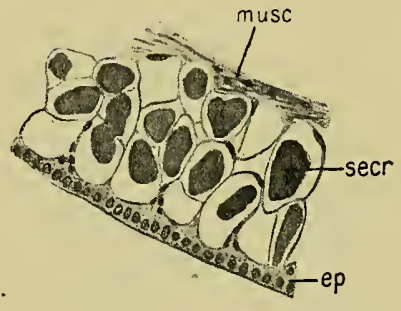

Textfig. 34. Schnitt durch die untere Uterusdrüse. Vergr. 225:1.

histologisch veränderter Bau der Drüsenzellen. Zunächst hat sich aber auch das Epithel der Uterusrinne verändert: aus dem Zylinderepithel ist ein flaches kubisches Epithel geworden, welches in einem feinkörnigen Protoplasma runde Kerne führt (Textfig. 34). Hinter diesem Epithel liegen nun große blasen- und birnförmige Zellen, deren spärliches Protoplasma sich um den wandständigen Kern zusammengezogen hat. Der chromatinreiche Kern dieser Drüsenzellen hat eine schmale längliche Form. Das Lumen der Zelle erscheint entweder ganz hell und leer, oder es wird eingenommen von einem sich stark blau färbenden Sekretklumpen $($ secr $)$. Diese Drüsenzellen, die wir als untere Uterusdrüse bezeichnen wollen $(u, u . d r)$, liegen meist nur in zwei oder drei 
Schichten hintereinander. Zwischen die Drüsenpakete drängen sich allmählich Muskelfasern (musc Textfig. 34) ein, die dann inmer melı an Raum gewinnen, bis sie die untere Uterusdrüse nach Abzweigung des männlichen Ganges, des Vas deferens, gänzlich vom Uterus verdrängen und seine alleinige Umkleidung bilden.

Während der eben beschriebene Verlauf des weiblichen Teils des Spermovidulsts, der Uterusrinne, verschiedene Veränderungen aufwies, sind die beiden anderen Rinnen, die Rinne $r_{3}$ und die Samenrinne mit ihren Prostataschläuchen, in ihrem Verlaufe von oben nach unten ganz gleichmäßig gebaut.

Die Rinne $r_{3}$ (Taf. 2, Fig. 40) liegt dicht neben der Prostatarinne, zeigt aber keine drüsigen Anhänge, sondern als äußere Begrenzung einige Muskelfasern. Sie stellt, wie wir oben sahen, eine Abzweigung und Fortsetzung des Zwittergangs (zwg Textfig. 29a-d) dar. Die innere Auskleidung besteht in einem hohen Zylinderepithel mit starkem Flimmerbesatz (Taf. 2, Fig. 40). Das Protoplasma der Zellen erscheint dunkel uud homogen; die Zellkerne sind elliptisch und chromatinreich und liegen in der Mitte der Zelle. Nach unten geht die Rinne $r_{3}$, nachdem sich das Vas deferens vom Uterus abgetrennt hat, allmählich in diesen über. Sie muß also zu den weiblichen Teilen des Spermovidukts gerechnet werden.

Die neben der eben beschriebenen Rinne gelegene Samenoder Prostatarinne (prostr Taf. 2, Fig. 40) ist ausgekleidet von Zylinderepithel mit deutlichen Flimmern. Auf der Seite, wo das Epithel der Samenrinne in das des Uterus übergeht, erniedrigt sich allmählich das Zylinderepithel stark. Das Protoplasma der Epithelzellen ist ganz hell und homogen, und die Kerne sind elliptisch und mittelständig. Außen begleitet die feingelappte Prostatadrüse (prostdr) die Samenrinne. Die Drüse setzt sich aus vielen einzelnen Drüsenschläuchen zusammen, die nach verschlungenem Verlauf jeder einzeln ihr gelbbraun sich färbendes Sekret direkt in die Rinne ergießen. Jeder Drüsenschlauch ist $\mathrm{zu}$ äußerst umgeben von bindegewebigen Fasern, die elliptische Kerne führen. Die innere Auskleidung der Drüsentubuli nehmen selkretorische Epithelzellen ein. Sie färben sich mit Hämalaun und vaN GIEsON rotbraun, haben zylindrische Gestalt und einen runden basalständigen chromatiureichen Kern. Ihr Protoplasma zeigt grobkörnige Struktur. Zwischen diesen Drüsenzellen finden sich schmale Zellen, deren langgestreckter Kern in der Mitte des 
hellen homogenen Protoplasmas liegt. Sie sind als Stützzellen aufzufassen. Kurz bevor die Samenrinne sich zum Vas deferens zusammenschließt und vom Uterus abschnürt, hört die Prostatadrüse auf.

Receptaculum seminis. Dem untersten Teile des Spermovidukts liegt als längliche Blase das Receptaculum seminis an (rec. sem Textfig. 27). Außen wird es umgeben von einer schmalen Ringmuskelschicht (musc Taf.2, Fig. 43, Textfig. 35a,b), während im Innern ein hohes Zylinderepithel die Blase auskleidet. Dieses Epithel, welchem drüsige Funktion zukommt, hat feingekörneltes Protoplasma und elliptische basalständige Kerne. Die Zylinderzellen nehmen an der Seite, wo die Blase dem Spermovidukt anliegt, bedeutend an Höhe ab, so daß sie bei Blasen, die stark ausgedehnt sind, als kubisches Epithel er-
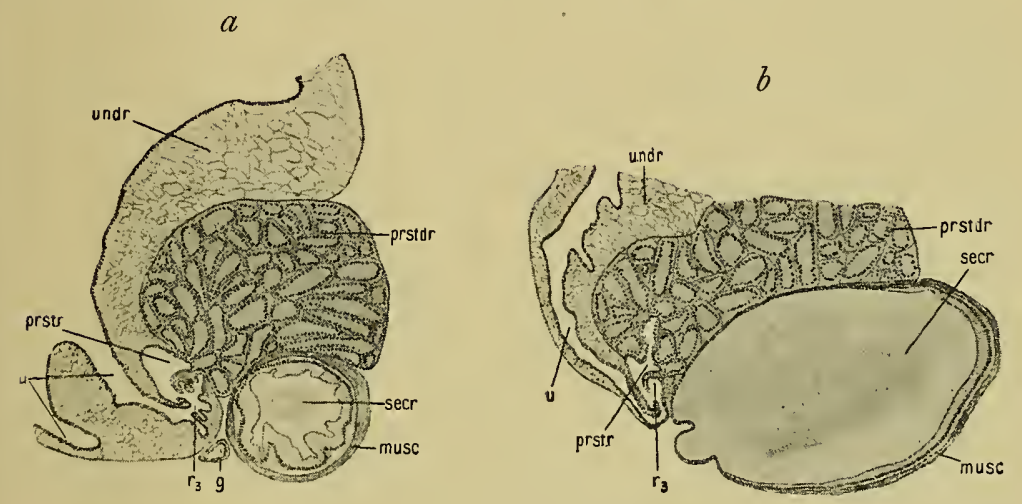

Textfig. 35. Schnitt durch die Blase des Receptakulum seminis, $a$ im Ruhestadium, $b$ in ausgedehntem Zustand. Vergr. $27: 1$.

scheinen (Textfig. 35b). Im Inneren finden sich leicht blaugefärbte Sekrete, die von dem Epithel ausgeschieden werden (secr Taf. 2, Fig. 43, Textfig. 35a, $b$ ).

Nach unten geht das Receptaculum seminis in einen dünnen Stiel ïber (st. rec Textfig. 27), der in seinem oberen Teile von Zylinderepithel mit starkem Flimmerbesatz und basalständigen elliptischen Kernen ausgekleidet ist. Ein Divertikel fehlt dem Receptaculumstiel. Er nähert sich in seinem Verlaufe nach unten immer mehr dem

Uterus. Dieser verliert, nachdem sich die Prostatarinne zum Vas deferens abgeschnürt hat, allmählich den Drüsenmantel der unteren Uterusdrüse und zeigt außen eine starke Ring- 
muskelschicht. Zugleich ändert sich der Clıarakter des Epithels: es wird zu einem Zylinderepithel mit basalständigen Kernen und starkem Flimmerbesatz. Es hat sich also gleichsam das flimmerude Epithel der Rinne $r_{3}$ über den ganzen Uterus ausgedehnt. Uterus und Receptaculumstiel nähern sich einander immer mehr, und hierbei zeigt der Stiel des Receptaculums eine mächtige Größenzunahme des Querschnitts im Gegensatz zum Uterus, dessen Querschnitt kleiner wird. In dem stark erweiterten Receptaculumstiel ragen mächtige Längsfalten vor, deren Zylinderepithel aber jetzt keine Flimmerung mehr zeigt, sondern von einer Cuticula bedeckt wird. Schließlich vereinigen sich Uterus und Receptaculumgang, und wir bezeichnen den nach unten ziehenden gemeinsamen Kanal als

Vagina. Die Vagina ist ziemlich lang (vag Textfig. 27). Sie wird außen umgeben von einer starken Lage Ringmuskelfasern, nach innen springen Längsfalten vor, die in spärlichem Bindegewebe verschieden gerichtete Muskelfasern als Stütze haben. Die innere Auskleidung bildet ein Zylinderepithel mit elliptischen basalständigen Kernen und einer starken Cuticula. Drüsenzellen treten an der Vagina, wie auch am Atrium genitale nicht auf, durch welches die Vagina sich nach außen öffnet.

Vas deferens. Das Vas deferens stellt die Fortsetzung der Prostatarinne des Spermovidukts dar. Von diesem schnürt es sich in der vorderen Körperhälfte nach dem Aufhören der Prostatadrüsenschläuche als' rundlicher Kanal ab (vas. def Textfig. 27). Zunächst verläuft es noch innerhalb der Ringmuskulatur, welche den Uterus umhüllt, dann aber wird es frei und schlingt sich mit zahlreichen Windungen unter der Vagina hindurch bis hinab zum Geschlechtsatrium. Hier biegt es dann nach oben um und folgt dem Verlauf des Penis (Textfig. 27). Im unteren Drittel des Penis tritt das Vas deferens in dessen muskulöse Umhüllung ein und ist von außen nicht mehr als Rohr wahrzunehmen. Infolgedessen findet sich in der Literatur die Angabe, daß die Einmündung des Vas deferens in den Penis in dessen unterem Drittel gelegen sei. Jedoch innerhalb des Muskelmantels steigt das Vas deferens bis an die Spitze des Penis und mündet hier erst in diesen ein. Der runde Querschnitt des Vas deferens zeigt meist mehrere vorspringende Längsfalten. Innerhalb der Muskulatur des Penis ist der Querschnitt bedeutend kleiner als auf der Strecke, wo das Vas deferens als selbständiger Kanal allein verläuft. Das Epithel des Ganges ist hochzylindrisch 
mit länglichen basalgelegenen Kernen und ist mit langen Flimmern ausgestattet. Außen befindet sich eine schwache Ringmuskelschicht; so lange das Vas deferens isoliert und selbständig neben der Vagina herläuft, ist es durch bindegewebige Fasern an dieser befestigt.

Penis. Der Penis in eingestïlptem Zustande ist ein kurzes zylindrisches Gebilde (pen Textfig. 27), welches in seiner Mitte einen stumpfwinkeligen Knick bildet. Während er nach unten in das Geschlechtsatrium übergeht, ist an seinem hintersten Ende der Retraktormuskel befestigt (retr. pen Textfig. 27). Dieser ist stets einheitlich vorhanden, schlingt sich unter dem rechten Augenltentakelretraktor hindurch und strebt nach hinten hin der Mittellinie des Körpers zu. Er befestigt sich hier am Diaphragma an der Stelle, wo dieses von der Kopfarterie durchbrochen wird.

Der genauere Bau des Penis läßt sich am besten an ausgestülpten Exemplaren studieren. Bei einigen Tieren, die längere Zeit in lauwarmes Wasser gelegt waren, stülpte sich der Penis meist sehr schön aus. Er tritt dann als dicker, weißlicher, durchschimmernder Kolben aus dem Geschlechtsatrium aus, wobei dann die Vaginalöffnung oberhalb des Penis nach hinten zu liegen kommt (vag Taf. 2, Fig. 41). An der ausgestülpten Rute (Taf. 2, Fig. 41, 42) können wir einen hinteren Teil von einem dickeren vorderen, die Glans bildenden Abschnitt unterscheiden, ferner an diesem wieder eine Oberseite und eine Unterseite. An den Seitenteilen ist die Glans etwas zusammengepreßt, so daß der Querschnitt (Textfig. 38) annähernd elliptische Gestalt hat. Das ganze kolbige Gebilde ist rechtwinklig eingeknickt, so daß dem unteren Teile des Penis, der senkrecht zur Seitenlinie des Körpers aus dem Geschlechtsatrium austritt, die Glans unter f.nem rechten Winkel nach vorn umgebogen, also dann parallel zur Seite des Körpers aufsitzt (Taf. 2, Fig. 41). Der vordere Abschnitt des Penis zeigt eine leicht gebogene Rückenseite, welche mit kleinen Papillen ( $p a p$ Taf. 2, Fig. 41, 42) besetzt ist. Nach den Seiten zu verliert die Oberseite die Papillen und geht in die Unterseite über, welche zwei stark aufgetriebene Wülste (zwu Taf. 2, Fig. 41, 42) bildet. Diese Wülste stoßen in der Mittellinie der Unterseite zusammen und bilden hier zwischen sich eine Längsfurche (lf). Diese erstreckt sich aber nicht über die ganze Unterseite, sondern vorn und hinten gehen die Wülste ohne Furchenbildung glatt ineinander über. So entsteht eine angenähert sichelförmige Gestalt der Wülste. Die 
Längsfurche endet nach hinten als schmaler, blinder Gang, der sich nach innen hinein abschnïrt und hier noch eine kurze Strecke verläuft ( $l f^{\prime \prime}$ 'Textfig. 36, 38). Nach vorn an der Spitze geht die Längsfurche in einen Kanal über (lf Textfig. 36), der sich gleichfalls nach innen abschnürt und sich dann nach hinten hin in das Vas deferens (vas. def) fortsetzt. In diese Längsfurche wird also der Samen entleert. Vorn an der Spitze des ausgestülpten Penis stoßen die zu einem Wulst ( $\left.w u^{\mathbf{1}}\right)$ vereinigten

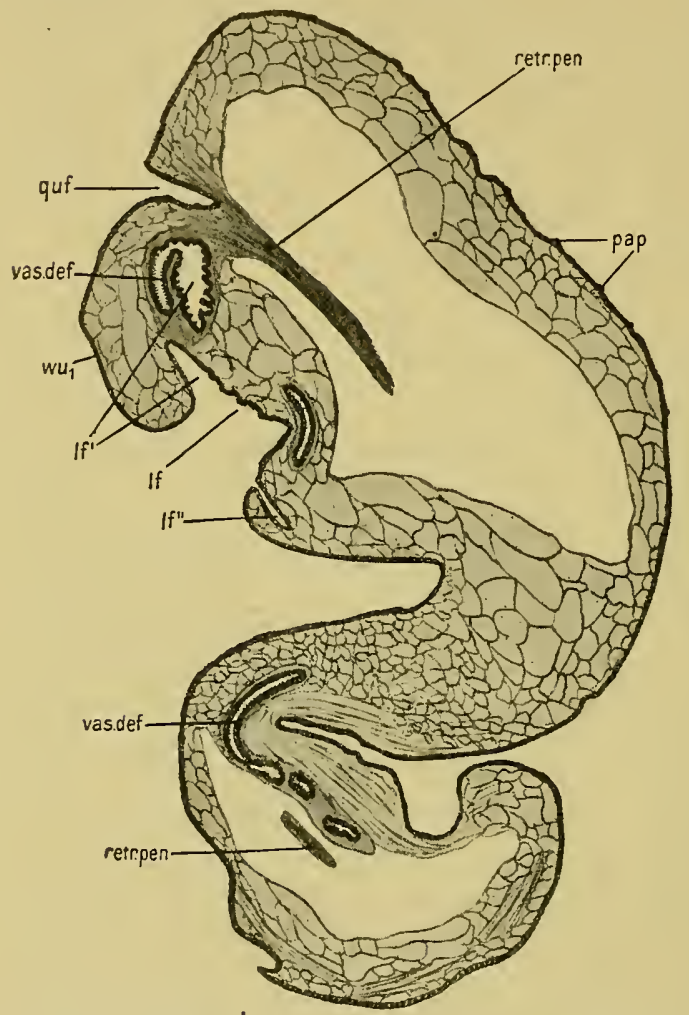

Textfig. 36. Sagittalschnitt durch den ausgestülpten Penis. Vergr. 21:1. Auftreibungen (wu) der Unterseite mit dem Rücken des Daches zusammen und bilden hier zwischen sich eine Querfurche (quf Taf. 2, Fig. 41, 42, Textfig. 36). Falls der Penis noch nicht vollständig ausgestülpt ist, setzt sich diese Querfurche nach hinten noch als blindendigender Spaltraum fort, dagegen bildet sie bei vollständig ausgestülpten Exemplaren nur eine seichte Rinne (Textfig. 36). An dieser Querfurche ist der Retraktormuskel des Penis befestigt (retr. pen). Wird der Penis eingestülpt, so ist diese Querrinne die Stelle, wo zuerst die Einrollung beginnt. Wir haben also hier ganz gleiche Verhältnisse, wie wir sie bei den Tentakeln vorfinden, wo auch die Retraktoren an einer seichten Furche des Tentakelknopfes inserieren. Diese Querrinne hat also mit der Ausleitung des Samens nichts zu tun.

Der Retraktormuskel läuft beim ausgestïlpten Penis von dieser Querfurche nach hinten an das Diaphragma, indem er in 
der Mitte des großen zentralen, von Blutflüssigkeit angefüllten Hohlraumes bleibt (Textfig. 38). Bei diesem Verlauf schimmert es durch den Penis durch (Taf. 2, Fig. 41).

Das Vas deferens tritt, wie wir sahen, im unteren Drittel in die Muskelwandung des eingestülpten Penis ein. Bei der aus-

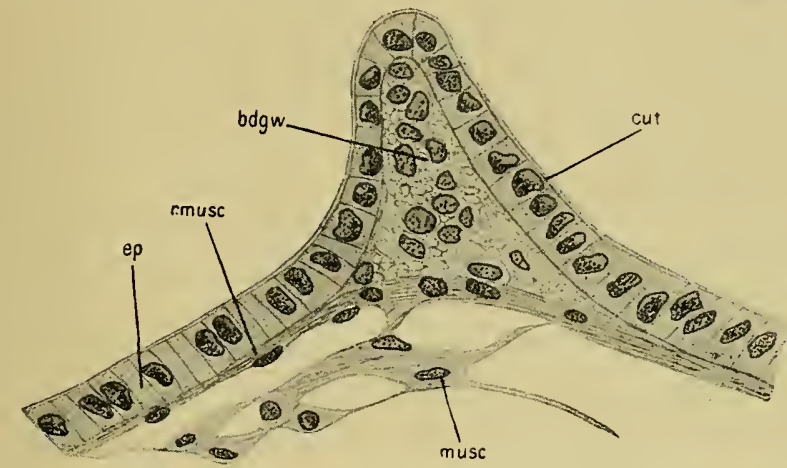

Textfig. 37. Querschnitt durch eine Reizpapille des Penis. Vergr. 805:1.

gestülpten Rute verläuft das Vas deferens im unteren Drittel noch frei im zentralen Hohlraum, dann aber schließt es sich der Muskelwand der Unterseite an und gelangt hier nach oben bis zur Einmündung in die Längsfurche (lf), ohne dabei stets in der Medianlinie der Unterseite $\mathrm{zu}$ verlaufen (Textfig. 36, 38).

Der hintere Abschnitt des ausgestülpten Penisrohres stellt einen einfachen Stiel dar, der höchstens einige Faltungen auf weist (Taf. 2, Fig. 41, 42).

Beim eingestülpten Penis liegen die Verhältnisse nun gerade umgekehrt wie die eben geschilderten, indem durch die Einrollung die äußeren Teile nach innen verlagert sind. Hierbei treten dann

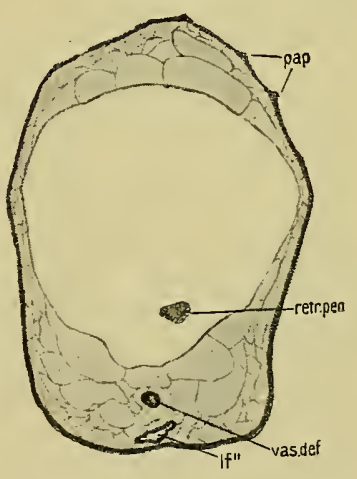

Textfig. 38. Querschnitt durcb den ausgestülpten Penis. vor allem zahlreiche Längsfalten auf.

Das Epithel, welches den ganzen Penisschlauch bedeckt, ist ein zylindrisches mit schwacher Cuticula (cut) und rundlichen chromatinreichen Kernen ( $e p$ Textfig. 37). Das Protoplasma ist fein gekörnelt und zeigt um den Kern herum einen hellen Hof. Am oberen Ende der Längsfurche ( $l f^{\prime}$ Textfig. 36) geht dieses Epithel in das Flimmerepithel des Vas deferens über. Die Pa- 
pillen (pap Taf. 2, Fig. 41, 42; Textfig. 36, 37, 38), welche den Rücken der Glans bedecken, stellen kegelförmige Vorwölbungen dar. Im Inneren findet sich als Stïtze des vorspringenden Epithels ein blasiges Bindegewebe (bdgzw Textfig. 37 ), welches große runde chromatinarme Kerne enthält. Nach innen von diesem Stützgewebe, wie auch unter dem übrigen Epithel des Penisschlauchs liegt eine dünne Ringmuskelschicht (r.musc) mit länglichen Kernen. Diese setzt sich auch auf das Vas deferens fort. Das Innere des ausgestülpten Penis wird ausgefüllt von einem zentralen, mit Blutflüssigkeit erfüllten Hohlraum und von einem diesen umschließenden, ebenfalls durch Blut aufgetriebenen Muskelgewebe (Textfig. 36, 38). Diejenige Muskellage, welche die innerste Auskleidung des zentralen Hohlraumes darstellt, ist dlann beim eingestülpten Penis die äußersteUmkleidung des ganzen Rohres. Während wir bei der eingestülpten Rute eine feste Längs- und Ringnıuskulatur als äußere Bedleckung finden, ist diese Muskulatur beim ausgestülpten Penis nach innen in den Raum zwischen zentralen Hohlraum und äußerem Epithel verlagert. Die vorher kompakte Muskelmasse ist hier in ihre einzelnen Fasern aufgelöst, und zwischen diesen befindet sich Blutflüssigkeit. Auf diese Weise macht die Muskulatur den Eindruck vesikulösen Gewebes. Drüsenzellen finden sich am Penis nicht.

Spermatophoren habe ich bei Stenogyra decollata bei keinem Tiere finden können. Ich glaube daher, daß solche nicht gebildet werden. Diese Annahme läßt sich dadurch stützen, daß Anhangsorgane, die besonders der Spermatophore angepaßt sind, wie Flagellum am Penis und Divertikel am Receptaculumstiel, ferner auch drüsiges Epithel am Penis fehlen. Andererseits ist es wahrscheinlich, daß die erwähnte Erweiterung des Receptaculumstieles an der Mündung in die Vagina es ermöglichen, daß der Penis mit seiner vordersten Spitze bis wenig über die Receptaculumstielmündung in den Uterus eingeführt werden kann und hierbei die Uterusmündung mit seiner Spitze zupreßt und abschließt. Dann kann der Samen durch die Längsfurche des Penis direkt in den Stiel der Samenblase gelangen.

Eine Kopulation habe ich an meinen Tieren nicht beobachten können.

Abnormitäten am Geschlechtsapparat fanden sich an den von mir untersuchten Sclnecken nicht. In der Literatur erwälhnt A. Sснмidr einen Geschlechtsapparat mit drei und einen mit zwei Ruten. 


\section{Zusammenfassung der wichtigsten Ergebnisse.}

1. Der Körper wird von einem einschichtigen Epithel bedeckt, welches an der Fußsohle Flimmern, an den übrigen nicht von der Schale bedeckten Körperteilen eine Cuticula trägt.

2. An dem Mantelwulst liegt im Grunde des von zwei Mantellappen gebildeten Atemganges in der Nähe der Kloake und des Pneumostoms die Manteldrüse. Sie setzt sich aus zwei Sorten einzelliger Drüsen zusammen, die durch das Epithel nach außen münden.

3. In der Fußdrüse sind die einzelligen Drüsenelemente sehr mannigfaltig in Struktur und Farbreaktion. Im hinteren Teile springen vom Dach drei Falten in das Lumen des Ganges vor.

4. Die Schale wird zusammengesetzt vom Periostracum, dem vierschichtigen Ostracum und dem zweischichtigen Hypostracum. Der bei der Dekollation neugebildete Apex besteht aus den beiden Hypostrakalschichten.

5. Die einzelnen Stufen der Dekollation sind: Ansatz neuer Schalensubstanz an der untersten Windung, Hinabgleiten des Tieres in diese, Abscheiden eines neuen Apex, Ábbrechen der oberen leeren Umgänge. - Die Abscheidung des neuen Apex ist ein regeneratorischer Vorgang. - Das Abbrechen der oberen verlassenen Windungen geschieht rein mechanisch.

6. Quergestreifte Muskelfasern fanden sich in keiner Schnittserie.

7. An der Anheftungsstelle des Kolumellarmuskels an die Kolumella liegt ein erhöhtes Körperepithel, darunter stark angehäuftes Bindegewebe. In diesem befestigen sich die Muskelfasern, sie treton nicht bis an die Spindel heran. Eine homogene Membran, die mit der Schalenmuskelanheftung etwas $\mathrm{zu}$ tun hat, existiert nicht.

8. Das Cerebralganglion bildet lappige Regionen. Das rechte Parietalganglion ist bedeutend größer als das linke und mit dem unpaaren Abdominalganglion stark verschmolzen. - Der Penisnerv entspringt nicht allein gesondert, sondern ist eine Abzweigung eines paarigen Nerven, der zur seitlichen Körperwand zieht.

9. Das Epithel der Augenblase besteht im hinteren Teile aus den Retinazellen (Pigment- und Sinneszellen), vorn aus den Zellen der Pellucida interna. In dieser finden sich bis acht besonders große Zellen mit stark färbbarem Protoplasma und blasigem Kern. 
10. In der Statocyste finden sich wenige große Riesenzellen, die seitliche Fortsätze bilden, neben zahlreichen Syncytialzellen.

11. Im hinteren Teile des Pharynx liegt die Subösophagealtasche. Sie hat zwischen zwei Wülsten einen mit starker Chitinlage versehenen Zapfen, der gegen einige an der Ösophagusmündung gelegene Falten gepreßt wird und so ein Widerlager gegen den Rückfluß der zerriebenen Nahrung bildet.

12. Am Scheitel der Zungenstützplatten unter der Radula zeigt das Epithel der Pharynxhöhle eine Differenzierung in ein Plattenepithel mit Einlagerung breiter Partien von Kittsubstanz.

13. Die Radula wird gestützt von paarigen Platten, die mit Knorpelgewebe nichts $\mathrm{zu}$ tun haben. $\mathrm{Zu}$ ihrer Bewegung dient ein kompliziertes Muskelsystem.

14. Die Zähne der Radula werden nicht von einer Reihe von fünf hintereinander gelegenen Zellen abgeschieden. Die vorderste Reihe der Odontoblasten scheidet die Basalmembran ab. An der Bildung des Rhachiszahnes beteiligen sich 16, an der der Lateralzähne 12-13 Odontoblasten. - Die Odontoblasten werden nicht durch neue Zellen von hinten her ersetzt. - Das Epithel der Oberseite ist an der Zahnbildung beteiligt. - Das obere Epithel und eine doppelte Einschnürung der Radula bilden einen Sperrapparat gegen zu starken Zug nach außen.

15. Der Ösophagus zeigt zuweilen eine starke Anschwellung. Sein Epithel enthält Drüsenzellen.

16. An dem Ausfuhrgang der großen Speicheldrüsen finden sich innerhalb der Muskulatur des Pharynx die Nalepaschen Drüsen.

17. Im Magenblindsack und im Mitteldarm ragen zwei Wülste stark in das Lumen vor. Ihnen kommit eine wichtige physiologische Bedeutung zu.

18. Beim Eintritt des Enddarms in die Lungenhöhle finden sich keine Drüsenzellen. - Der Enddarm vereinigt sich mit dem sekundären Ureter zur Kloake, und diese mündet getrennt von der Atemhöhle und dem Pneumostom an dem Mantelwulst nach außen in den Atemgang.

19. Das Plattenepithel der Lungenhöhle und des Pneumostoms trägt keine Flimmern. - Die respiratorisch tätigen Gefäße des Lungendachs haben stets eine Endothelauskleidung. - An der Darmfläche des Lungendachs finden sich die Gefäßstämme dichter und zahlreicher als auf der Spindelfläche. 
20. Die Niere umgreift den Herzbeutel. In ihrem hinteren Teile springen rom Boden Lamellen vor und bilden hier den eigentlich exkretorischen Abschnitt. Der sekundäre Ureter läuft geschlossen nach vorn zur Kloake. Das Epithel des Ureters ist kubisch ohne Flimmern.

21. Aus dem Ventrikel entspringt eine einheitliche Aorta. Sie teilt sich in die nach oben kolumellarwärts laufende Visceralarterie und die nach unten am Diaphragma gelegene Kopfarterie. Diese zeigt nach dem Durchtritt durch die Visceral-Pedalkette starke Verzweigungen.

22. Am Zwittergang liegt eine geknäuelte Vesicula seminalis und eine bläschenförmige Drüse.

23. Die Eiweißdrüse zeigt je nach der Jahreszeit verschiedene Größe und verschiedenes histologisches Aussehen. Die Eiweißdrüse ist eine zusammengesetzte tubulöse Drüse. Ihre histologischen Bestandteile sind: Drüsenzellen, zentrotubulöse Zellen und Bindegewebszellen.

24. Der Spermovidulkt hat drei Rinnen: die Uterusrinne mit den in den einzelnen Regionen verschieden gestalteten Drüsenanhängen, die Samenrinne mit den Prostatadrüsenschläuchen und eine Rinne ohne drüsige Bekleidung.

25. Der Penis hat einen Retraktormuskel, der sich am Diaphragma anheftet. Der ausgestülpte Penis hat eine deutlich abgesetzte Glans. An dieser finden sich eine Längsfurche, in die der Samen entleert wird, und eine Querfurche, an der der Retraktor inseriert. Auf der Rückenseite der Glans liegen Reizpapillen.

\section{Literaturverzeichnis.}

1) Amaudrut, A., La partie antérieure du tube digestif et la torsion chez les Mollusques gastéropodes. Ann. scienc. nat. (8) zool. 1898, Tome VII.

2) Ders., La structure et la circulation dans l'organe de Bojanus de quelques Mollusques pulmonés. Bull. soc. philomath., Paris 1886, 7. sér., Tome $\mathrm{X}$.

3) Ders., Structure et mécanisme du bulbe chez les Mollusques. Compt. rend. acad., Paris 1897, Tome CXXIV.

4) Ders., Sur le système nerveux de quelques Mollusques pulmonés (Achatina, Bulime, Helix, Nanina, Vaginula). Bull. soc. philomath., Paris 1886, 7. sér., Tome $\mathrm{X}$.

5) ANDrÉE, E., Recherches sur la glande pédieuse des Pulmonés. Rev. Suisse zool. 1894, Tome II. 
6) В̈̈скеR, R., Die Augen einiger Gastropoden. Arb. zool. Inst. Wien 1903, Bd. XIV.

7) Barfurth, D., Über den Bau und die Tätigkeit der Gastropodenleber. Arch. f. mikr. Anat., Bd. XXII.

8) Венме, Тн., Beiträge zur Anatomie und Entwicklungsgeschichte des Harnapparates der Lungenschnecken. Arch. f. Naturgesch. $1859, \mathrm{Bd} . \mathrm{LV}$.

9) Веск, K., Anatomie deutscher Buliminus-Arten. Jen. Zeitschr. f. Naturwissensch. 1912, Bd. XLVIII.

10) Bergh, R. S., Beiträge zur vergleichenden Histologie: I. Über die Gefäßwandung der Mollusken. Anat. Hefte 1898, Bd. X.

11) Biedermann, W., Untersuchungen über Bau und Entstehung der Molluskenschalen. Jen. Zeitschr. f. Naturw. 1902, Bd. XXXVI.

12) Ders., Beiträge zur allgemeinen Nerven- und Muskelphysiologie: 14. Über das Herz von Helix pomatia. Sitzungsber. d. k. k. Akad. d. Wissensch., math.-naturwissensch. Klasse, Wien 1884, Bd. LXXXIX.

13) Ders., Die Aufnahme, Verarbeitung und Assinilation der Nahrung. Pflügers Archiv.

14) Ders., Studien zur vergleichenden Physiologie der peristaltischen Bewegungen. II. Die lokomotorischen Wellen der Schneckensohle. III. Lie Innervation der Schneckensoble. Arch. Ges. Physiologie 1905, Bd. CVII, 1906, Bd. CXI.

15) Ders. und Moritz, P., Beiträge zur vergleichenden Physiologie der Verdauung. II. Über ein zelluloselösendes Enzyn im Lebersekret der Schnecke (Helix pomatia). III. Über die Funktion der sogenannten Leber der Mollusken. Arch. Ges. Physiologie 1898, Bd. LXXIII, 1899, Bd. LXXV.

16) BLoch, I., Die embryonale Entwicklung der Radula von Paludina vivipara. Jen. Zeitschr. f. Naturwissensch. 1896, Bd. XXX.

17) Böнмig, Тн., Beiträge zur Kenntnis des Zentralnervensystems einiger pulmonaten Gastropoden. Inaug.-Dissert. Leipzig 1883.

18) ВRоск, I., Untersuchungen über die interstitiellen Bindesubstanzen der Mollusken. Zeitschr. f. wissensch. Zool. 1883, Bd. XXXIX.

19) Buresch, Iw., Untersuchungen über die Zwitterdrüse der Pulmonaten. Arch. f. Zellforschung 1911, Bd. VII.

20) Cavalié, Sur la sécrétion de la glande albuminipare chez l'escargot. Compt. rend. soc. biol. 1902, Tome LIV.

21) Ders. et Berlot, Nature de la glande albuminipare de l'escargot. Compt. rend. soc. biol. 1902, Tome LIV.

22) Dies., Sur la glande albuminipare de l'escargot. Compt. rend. soc. biol. 1902, Tome LIV.

23) CuÉnot, L., Études physiologiques sur les Gastéropodes pulmonés. Arch. de Biol. 1892, Bd. XII.

24) Dubors, R., Sur la physiologie comparée de l'olfaction. Compt. rend. acad. sc., Paris 1898, Tome CXI.

25) Dubruerl, E., Sur la constitution du canal excréteur de l'organe hermaphrodite dans Leucochroa candidissima Beck et dans le Bulimus decollatus L. Compt. rend. 1876, Tome LXXXII. 
26) Ellermann, W., Über die Struktur rler Darmepithelzellen von Helix. Anat. Anz. 1899.

27) Fischer, H., Recherches sur la morphologie du foie des Gastéropodes. Bull. scient. de la France et de la Belg. 1892, Tome XXIV.

28) Gartenauer, H. M., Über den Darmkanal einiger einheimischer Gastropoden. Inaug.-Diss. Straßburg 1875.

29) Heidenharn, M., Beiträge zur Aufklärung des wahren Wesens der faserförmigen Differenzierungen. Anat. Anz. 1899, Bd. XVI.

30) Hesse, R., Über die Retina des Gastropodenauges. Verhandl. d. Deutsch. zool. Ges. 1902.

31) Jhering, H. v., Über den uropneustischen Apparat der Heliceen. Zeitschr. f. wissensch. Zool. 1885, Bd. XLI.

32) Ders., Zur Morphologie und Systematik des Geschlechtsapparates von Helix. Zeitschr. f. wissensch. Zool., Bd. LIV.

33) Ders., Vergleichende Anatomie des Nervensystems und Phylogenie der Mollusken. Leipzig 1877.

34) Jonnston, G., Einleitung in die Conchyliologie. Stuttgart 1853.

35) Korschelt, E., Zum Schalenersatz bei Landschnecken. Arch. f. Entwicklungsmech. 1910, Bd. XXX.

36) Krahelska, M., Über den Einfluß der Winterruhe auf den histologischen Bau einiger Landpulmonaten. Jen. Zeitschr. f. Naturwissensch. 1910, Bd. XLVI.

37) Dies., Drüsenstudien. Histologischer Bau der Schneckeneiweißdrüse und die in ihm durch den Einfluß des Hungers usw. hervorgerufene Veränderung. Arch. f. Zellforschung 1912/13, Bd. IX.

38) Lacaze-Duthiers, H. DE, Otocystes des Mollusques. Arch. de zool. exp. 1872, Tome 1 .

39) Ders., Les ganglions dits palléaux et le stomato-gastrique de quelques Gastéropodes. Arch. de zool. exp. et gén., 3. sér., 1896, Tome VI.

40) Lankester, E. Ray., On the structure and origin of the spermatophores. Quart. Journ. 1871.

41) Lange, A., Über Bau und Funktion der Speicheldrüsen bei den Gastropoden. Anat. Hefte 1902, Bd. XIX.

42) Lang, A., Lehrbuch der vergleichenden Anatomie der Wirbellosen, Teil III, 1, Mollusca, 1907.

43) Leydig, Fr., Zur Anatomie und Physiologie der Lungenschnecken. Arch. f. mikr. Anat. 1865, Bd. I.

44) Ders., Die Hautdecke und Schale der Gastropoden, nebst einer Übersicht der einheimischen Limacinen. Arch. f. Naturg. 1876.

45) Loisel, G., Les cartilages linguaux des Mollusques (structure et développement histogénique). Journ. anat. et physiol. 1893, Ann. 29.

46) Ders., Sur l'appareil musculaire de la radula chez les Helix. Journ. anat. et physiol. 1892, Ann. 28.

47) Marceau, F., Recherches sur la structure du coeur chez les Mollusques. Arch. anat. microsc. 1905, Tome VII.

48) Meisenheimer, J., Biologie, Morphologie und Physiologie des Begattungsvorganges und der Eiablage von Helix pomatia. Zool. Jahrb. System. 1907, Bd. XXV.

49) Ders., Die Weinbergschnecke. Leipzig 1912. 
50) Merton, H., Quergestreifte Muskulatur und vesikulöses Gewebe hei Gastropoden. Zool. Auz., Bd. XXXVII, Nr. 26.

51) Moquin-Taudon, M. A., Histoire naturelle des Mollusques terrestres et fluviatiles de France. 1855.

52) Ders., Remarques critiques sur le genre Bulimus. Rer. et Magas. de Zool. 1855, Tome VII.

53) Nabias, B. DE, Recherches histologiques et organologiques sur les centres nerveux des Gastéropodes. Bordeaux 1894.

54) Ders., Structure de systéme nerveux des Gastéropodes. Compt. rend. soc. biol., 9. sér., 1893, Tome V.

55) Ders., Cerveau et nerfs cérébraux chez Bulimus decollatus L. Act. de la soc. lin. de Bordeaux, 1896.

56) Nalepa, A., Beiträge zur Anatomie der Stylommatophoren. Sitzungsber. d. k. k. Akad. d. Wissensch., Wien 1883, Bd. LXXXVII, I. Abt.

57) Ders., Die Interzellularräume des Epithels und ihre physiologische Bedeutung bei den Pulmonaten. Sitzungsber. d. k. k. Akad. d. Wissensch., Wien 1883, Bd. LXXXVIII, I. Abt.

58) Nowikoff, M., Studien über das Knorpelgewebe von Wirbellosen. Zeitschr. f. wissensch. Zool. 1912, Bd. CIII.

59) Nüsslin, O., Beiträge zur Anatomie und Physiologie der Pulmonaten. Tübingen 1879 .

60) Nyst, H., Notice sur deux coquilles mexicaines, appartenant deux genres Pupa et Helix. Bull. de l'Acad. royale des scienc. de Bruxelles, 1841.

61) Paravicini, G., Nota istologica sull' inserzione del muscolo columellare nell' Helix pomatia L. Atti Soc. Ital. sc. nat. 1898, Tome XXXVII.

62) Pacaut et Vigier, Les glandes salivaires de l'escargot (Helix pomatia). Arch. de l'anat. microscop. 1906, Tome VIII.

63) Pelseneer, P., Mollusca. London 1906.

64) Plate, L., Bemerkungen über die Phylogenie und die Entstehung der Asymmetrie der Mollusken. Zool. Jahrb., Anat. u. Ontog. 1895, Bd. IX.

65) Ders., Beiträge zur Anatomie und Systematik der Janelliden. Zool. Jahrb., Morph. 1898, Bd. XI.

66) Rassbach, R., Beiträge zur Kenntnis der Schale und Schalenregeneration von Anodonta cellensis Schröt. Zeitschr. f. wissensch. Zool. 1912, Bd. CIII.

67) Rössler, R., Die Bildung der Radula bei den cephalophoren Mollusken. Zeitschr. f. wissensch. Zool. 1885, Bd. XLI.

68) RÜckeR, A., Über die Bildung der Radula bei Helix pomatia. 22. Ber. Oberhess. Ges. f. Natur- u. Heilkunde, 1899.

69) Samassa, P., Über die Nerven des augentragenden Fühlers von Helix pomatia. Zool. Jahrb., Abt. f. Morphol. 1894, Bd. VII.

70) Sarasin, P. B., Über die Sinnesorgane und die Fußdrüse einiger Gastropoden. Arb. zool. Inst. Würzburg 1883, Bd. VI.

71) Schmidt, W., Untersuchungen über die Statocyste unserer einheimischen Schnecken. Jen. Zeitschr. f. Naturwissensch. 1912, Bd. XLVIII. 
72) Schuid, A., Der Geschlechtsapparat der Stylommatophoren. Berlin 1855.

73) Schnabel, H., Über die Embryonalentwicklung der Radula bei den Mollusken. Zeitschr. f. wissensch. Zool. 1903, Bd. LXXIV.

74) Schneider, K. C., Lehrbuch der vergleichenden Histologie der Tiere. Jena 1902.

75) Semper, C., Beiträge zur Anatomie und Physiologie der Pulmonaten. Zeitschr. f. wissensch. Zool. 1857, Bd. VIII.

76) Ders., Reisen im Archipel der Philippinen, Bd. III. Wiesbaden 1870.

77) Simroth, H., Mollusea, Bronns Klassen und Ordnungen des Tierreichs. Leipzig 1908.

78) Ders., Über die Sinnesorgane einheimischer Weichtiere. Zeitschr. f. wissensch. Zool. 1876, Bd. XXVI.

79) Ders., Über das Nervensystem und die Bewegung der deutschen Binnenschnecken. Programm der Realschule II. Ordnung. Leipzig 1882.

80) Ders., Ubber die Niere der Pulmonaten. Aus Sempers Nachlaß: Semper, Reisen im Archipel der Philippinen, 1894, Bd. III.

81) Sollas, J., The Molluscan Radula. Anat. Journ. of micr. sc. 1907, Vol. LI.

82) SpIRo, J., Recherches sur la structure histologique du tube digestif de l'Helix pomatia L. Rev. suisse de zool. 1911, Vol. XIX, No. 12.

83) Stiasny, G., Die Niere der Weinbergschnecke. Zool. Anz. 1903, Bd. XXVI.

84) Techow, G., Zur Kenntnis der Schalenregeneration bei den Gastropoden. Arch. f. Entwicklungsmech. 1910, Bd. XXXI.

85) Threle, J., Beiträge zur Kenntnis der Mollusken: II. Über die Molluskenschale. III. Über Hautdrüsen und ihre Derivate. Zeitschr. f. wissensch. Zool., Bd. LV, LXII.

86) Villepoix, R. Moynier DE, Recherches sur la formation et l'accroissement de la coquille des Mollusques. Journ. Anat. et Physiol., 28. année, 1892.

87) Wiegmann, Fr., Beiträge zur Anatomie der Landschnecken des indischen Archipels. Zool. Ergebnisse einer Reise in Niederländisch-Ostindien von Dr. M. Weber.

88) Yung, E., Anatomie et malformations du grand tentacule de l'escargot. Rev. suisse de zool. 1911, Tome XIX.

\section{Tafelerklärungen.}

Tafel 1.

Fig. 1. Schnitt durch den Mantelrand und die Mantellappen. $28: 1$. Fig. 2. Schnitt durch die Manteldrüse. 225:1.

Fig. 3. Drüsenzellen des vorderen Teiles der Oberseite der Fußdrüse. 225:1.

Fig. 4. Drüsenzellen des hinteren Teiles der Oberseite der Fußdrüse. $225: 1$. 
Fig. Ђ. Drüsenzellen der Unterseite der Fußdrüse. 225:1.

Fig. 6. Drüsenzellen vom Mantelrande. $225: 1$.

Fig. 7. Schale a) eines jungen, nicht dekollierten, b) eines älteren dekollierten Tieres. Nat. Gr.

Fig. 8. Schliff parallel der Kolumella durch ein Gehäuse, schematisch. Nat. Gr.

Fig. 9. Schalen älterer dekollierter Tiere mit beginnender Bildung des Spaltes. Nat. Gr.

Fig. 10. Schliff durch die Schale senkrecht zur Außenseite und senkrecht zu den Anwachsstreifen. 225:1.

Fig. 11. Schliff durch den neugebildeten Apex. 225:1.

Fig. 12. Der neugebildete Apex von oben gesehen. 8:1.

Fig. 13. Schnitt durch die Anheftungsstelle des Kolumellarmuskels an die Spindel. $225: 1$.

Fig. 14. Anheftungsstelle des Kolumellarmuskels an die Spindel. $515: 1$.

Fig. 15. Faseriges Bindegewebe aus dem Radulapfropf. $515: 1$.

Fig. 16. Kalkzelle in der Muskulatur. 920:1.

Fig. 17. Kalkzelle im Bindegewebe des Eingeweidesacks. $515: 1$.

Fig. 18. Schnitt durch den Hautmuskelschlauch. 225:1.

Fig. 19. Kopf mit Mundöffnung von vorn. 5:1.

Fig. 20. Mundöffnung und Pharynx durch Sagittalschnitt geöffnet. $12: 1$.

Fig. 21. Pharynxepithel am Scheitel der Radulastützplatte unter der Radula von der Fläche. 515:1.

\section{Tafel 2.}

Fig. 22. Pharynx von oben durch einen Medianschnitt geöffnet. $12: 1$.

Fig. 23. Dass., Dach der Subösophagealtasche und Ösophagus abpräpariert. $12: 1$.

Fig. 24. Schnitt durch die Nalepasche Drüse. 225:1.

Fig. 25. Schnitt durch das Ösophagusepithel. 515:1.

Fig. 26. Magen und Mitteldarm seitlich aufgeschnitten. 3:1.

Fig. 27. Kloake und Atemloch. Rectum und Mantelrand durchschitten. $5: 1$.

Fig. 28. Pneumostom, Kloake und Mantellappen von vorn. 5:1.

Fig. 29. Schnitt durch die untere Wandung der Hauptlungenvene. $405: 1$. $405: 1$.

Fig. 30. Schnitt durch ein größeres Gefäß des Lungendachs. $515: 1$.

Fig. 31. Schnitt durch die feinsten Gefäße des Lungendachs.

Fig. 32. Schnitt durch den Zwittergang bei I. v. Textfig. 29. 97:1. Fig. 33. " " " $" \quad$ bei II.v. Textfig. 29. 97:1.

Fig. 34. " " " " " $\quad " \quad$ beiIII. v. Textfig. 29. $97: 1$.

Fig. 35. " " " " $\quad$ " bei IV.v.Textfig. 29. $97: 1$.

Fig. 36. " " " $" \quad$ bei V.v. Textfig. 29. $97: 1$.

Fig. 37. " " " $\quad$ " bei VI. v. Textfig. 29. 97:1. 
Fig. 38. Die Stelle $A$ des Zwittergangs von Textfig. 29. 54:1.

Fig. 39. Die Stelle $B$ des Zwittergangs von Textfig. 29. $54: 1$.

Fig. 40. Schnitt durch die Prostatarinne, Rinne $r_{3}$ und die Uterusrinne mit ihren Drüsen. 97:1.

Fig. 41. Penis ausgestülpt von der Seite. 5:1.

Fig. 42. Penis ausgestülpt von unten. $5: 1$.

Fig. 43. Schnitt durch das Receptaculum seminis-Epithel. $225: 1$.

\section{Figurenbezeichnung.}

\begin{tabular}{|c|c|c|c|}
\hline 20 & & f.aor & rta \\
\hline$a b d . g$ & dominalganglion & Astr & Flimmerstreifen \\
\hline & Ausführgang & fs & Fußsohle \\
\hline.$l i$ & äußere Lippe & $f u$ & che \\
\hline$h$ & A & $g$ & larterie \\
\hline $\operatorname{th}$ & $\begin{array}{l}\text { A } \\
\text { A }\end{array}$ & $\begin{array}{l}g a \\
\text { g.eizw. } d r\end{array}$ & $\begin{array}{l}\text { larterie } \\
\text { drüsengang }\end{array}$ \\
\hline trg & genitale & $\begin{array}{l}g \cdot e 2 w \cdot d r \\
h\end{array}$ & igang \\
\hline uff & & $h . d . d r z$ & $\begin{array}{l}\text { hintere dunkle Drüsen- } \\
\text { zellen }\end{array}$ \\
\hline $\begin{array}{l}\text { iss } \\
c . c\end{array}$ & & & $\begin{array}{l}\text { zellen } \\
\text { helle Drüsenzelle }\end{array}$ \\
\hline .0 & & $\begin{array}{l}h . f a \\
h k\end{array}$ & ie \\
\hline 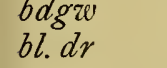 & $\begin{array}{l}\mathrm{B} \\
\mathrm{b}\end{array}$ & $\begin{array}{l}h k \\
h v\end{array}$ & $\mathrm{Ha}$ \\
\hline & ler blasi- & $\begin{array}{l}\text { hv } \\
\text { hypostr }\end{array}$ & um \\
\hline & & i. $l i$ & \\
\hline & B & $k a$ & rie \\
\hline$p l$ & & $k e, k e^{\prime}$ & \\
\hline & missur & k. $d r z$ & elle \\
\hline & ektiv & $k i$ & \\
\hline & alkonnektiv & $k . k z$ & örnerzelle \\
\hline & leuralkon- & $\begin{array}{l}k k v \cdot w \\
k l\end{array}$ & ve Scheidewand \\
\hline$r b$. & ganglion & $k l . t$ & er Tentakel \\
\hline$o l$ & K & $k p w$ & $\mathrm{~K}$ \\
\hline$t b l . z$ & tubulöse Zelle & & $\mathrm{K}$ \\
\hline$u t$ & C & lf $, l f^{\prime}, l$ & $\mathrm{Ls}$ \\
\hline$d r z$ & $\begin{array}{l}\text { Drüsenzellen } \\
\text { zelle }\end{array}$ & & $\mathrm{L}$ \\
\hline$\theta r$ & $\begin{array}{l}\text { zelle } \\
\text { polster }\end{array}$ & $m a$ & Magen \\
\hline $\begin{array}{l}r p \\
i a p \\
i a p\end{array}$ & $\begin{array}{l}\mathrm{D} \\
\mathrm{D}\end{array}$ & $m d . f d r$ & $\begin{array}{c}\text { Mündung der Fuß- } \\
\text { drüse }\end{array}$ \\
\hline$m f l$ & läche & $m d . u r$ & Mündung des Ureters \\
\hline d & drüsenzel & $m t l . d r$ & drüse \\
\hline $\operatorname{ch} n$ & nürung & mttld & \\
\hline & drüse & mupl & M \\
\hline & & musc & culatur \\
\hline & & & Niere \\
\hline & & nal.dr & NaLEGasche Drüsen \\
\hline & & ne & \\
\hline
\end{tabular}




\section{- 88}

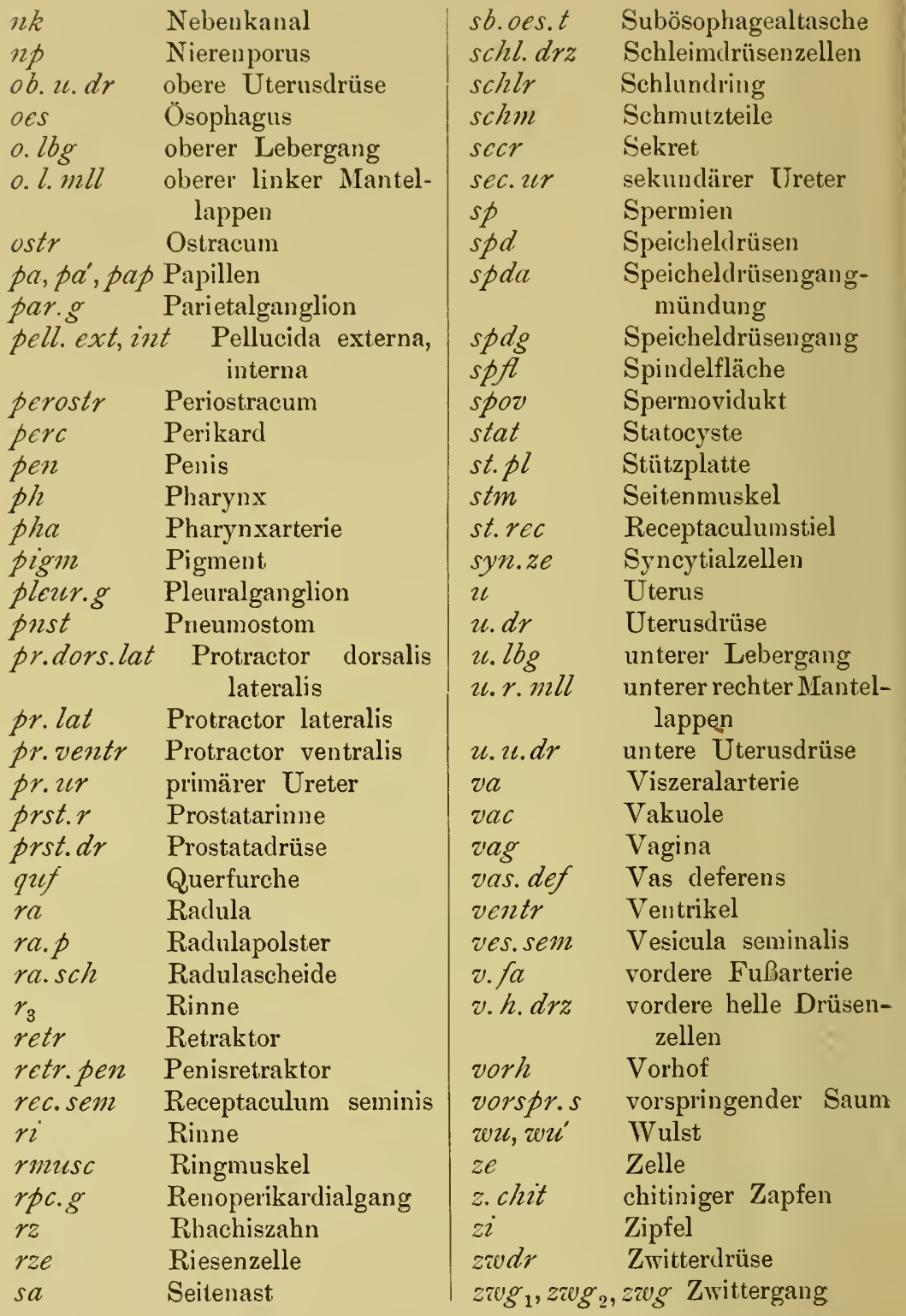




\section{Lebenslauf.}

Johannes Wille wurde am 5. Mai 1892 als Sohn des Lehrers Johannes Wille in Gera-Reuß geboren. Nach 2jährigem Besuch der Bürgerschule trat er Ostern 1900 in die Vorschule des Fürstlichen Gymnasiums ein, der er ein Jahr angehörte. Von Ostern 1901 an besuchte er das Fürstliche Gymnasium zu Gera, das er Ostern 1910 mit dem Zeugnis der Reife verließ. Er bezog zuerst die Universität Marburg und widmete sich dem Studium der Mathematik, Physik, Zoologie und Botanik. Nach viersemestrigem Studium wandte er sich nach Jena. Hier war er hauptsächlich mit der Abfassung seiner Arbeit beschäftigt und bestand am.23. Februar 1914 die mündliche Doktorprüfung.

Seine Lehrer waren die Herren Professoren und Dozenten: in Marburg: Korschelt, Harms, Tönniges, A. Meyer, Diels, Richarz, Schulze, Hensel, von Dalwigk, Mannkopf, Tuczek, Mirbt; in Jena: Plate, Meisenheimer, Hase, Stahl, Dettmer, Wien, Auerbach, Baedecker, Thomae, Haussner, Frege, Wilckens, von Eggeling, von Zahn, Eucken, Bauch, Weinel, Thümmel, Lietzmann, Michels, Wilhelm, Stoy. 



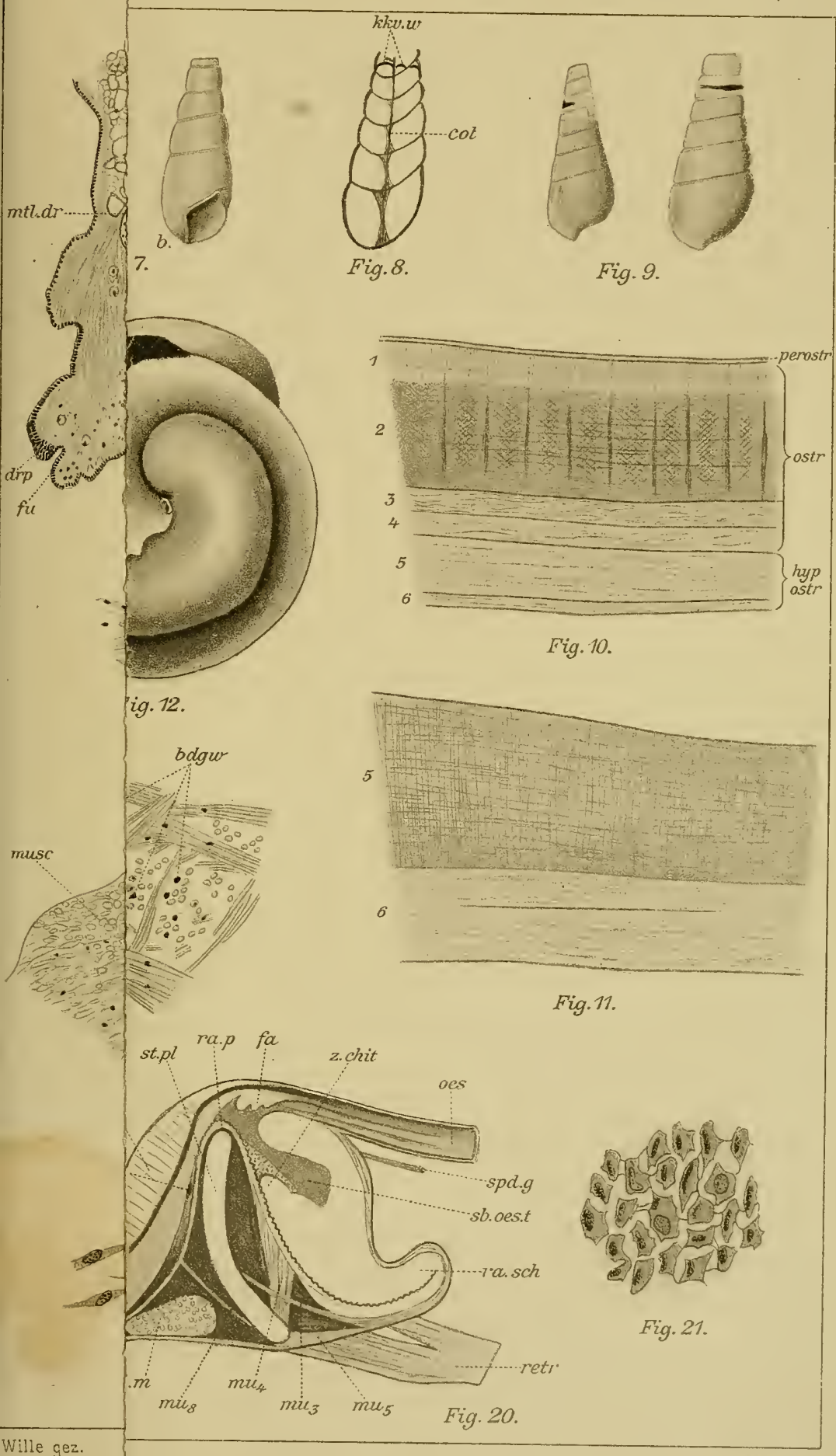

Wille gez. 


Taf. 2.

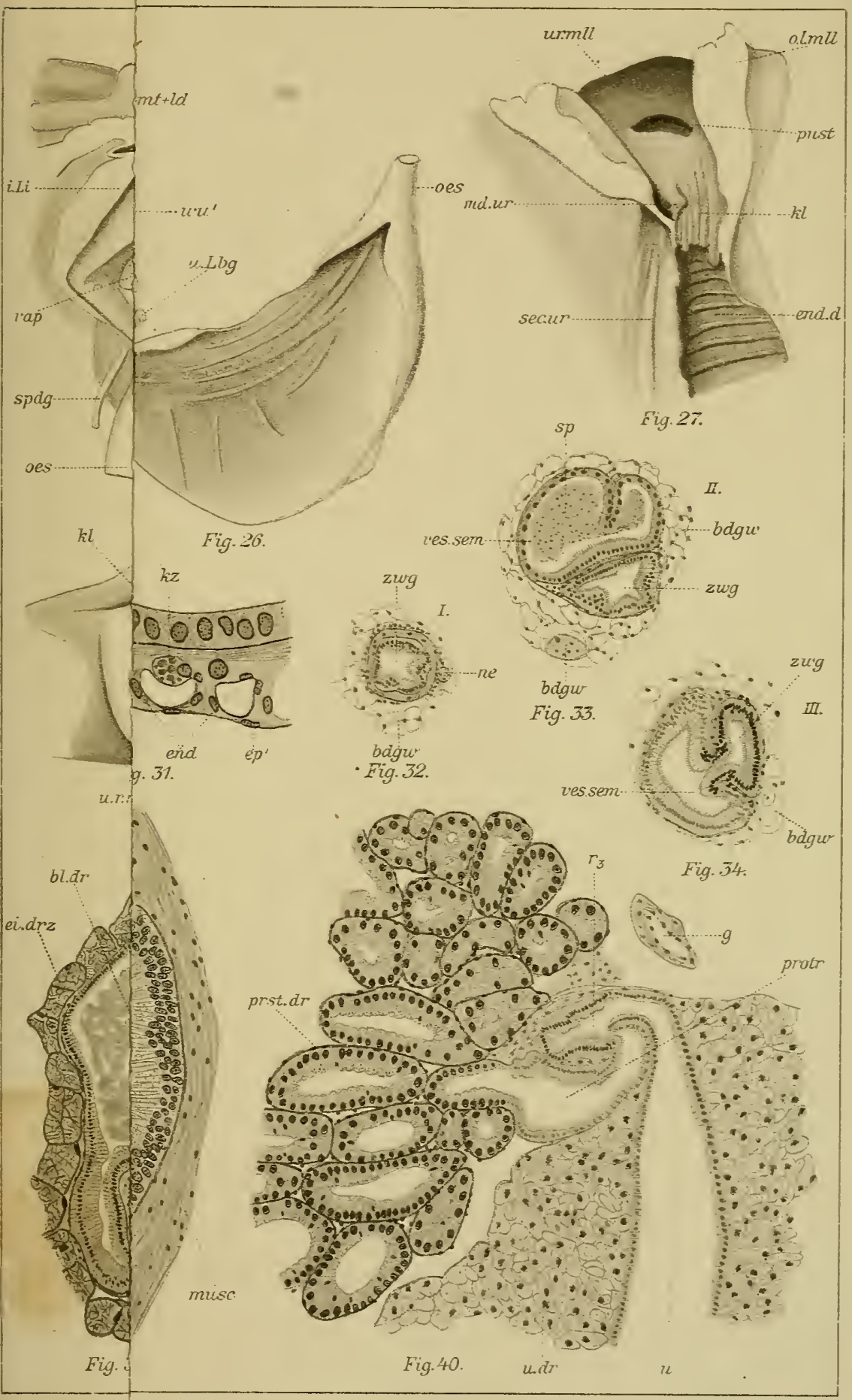





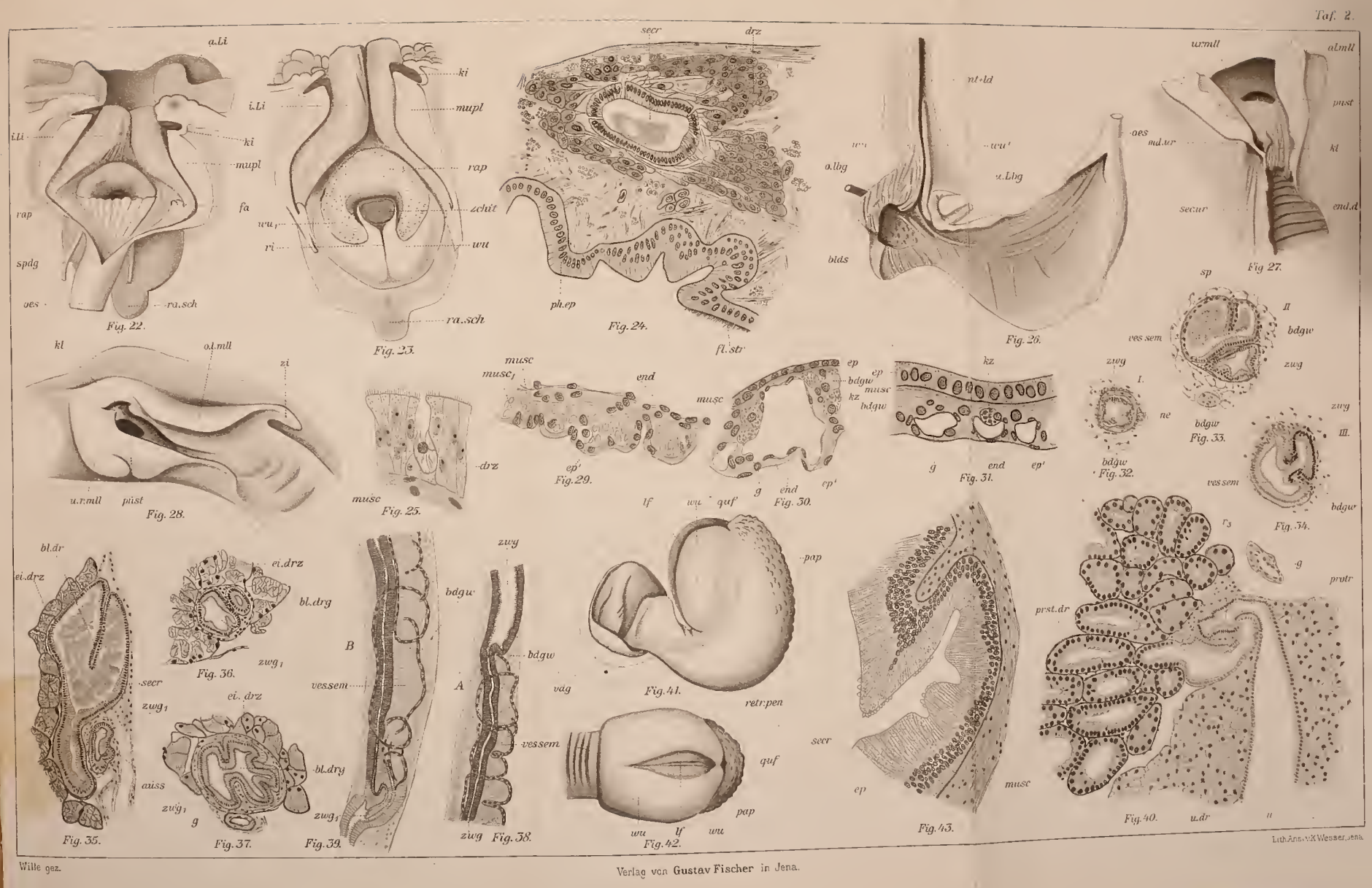







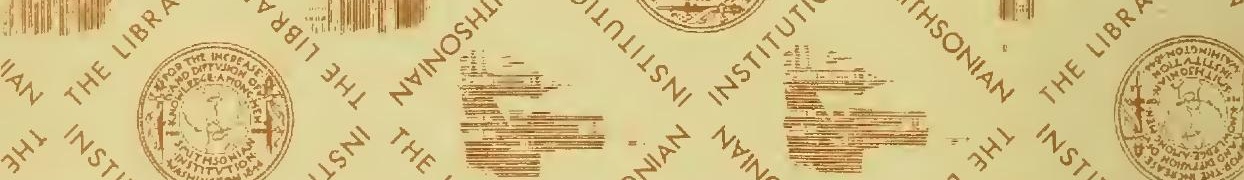

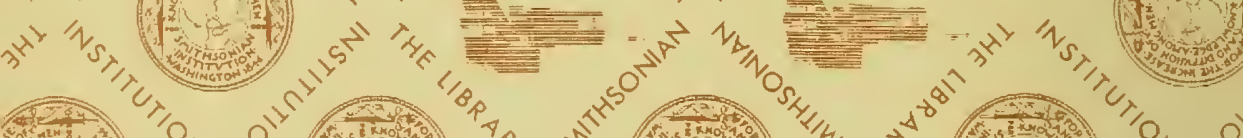

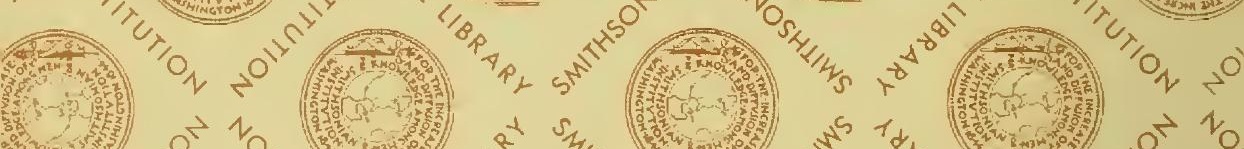

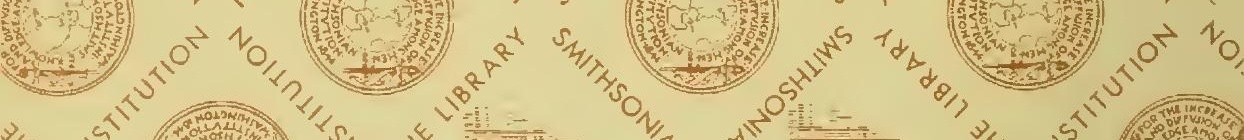

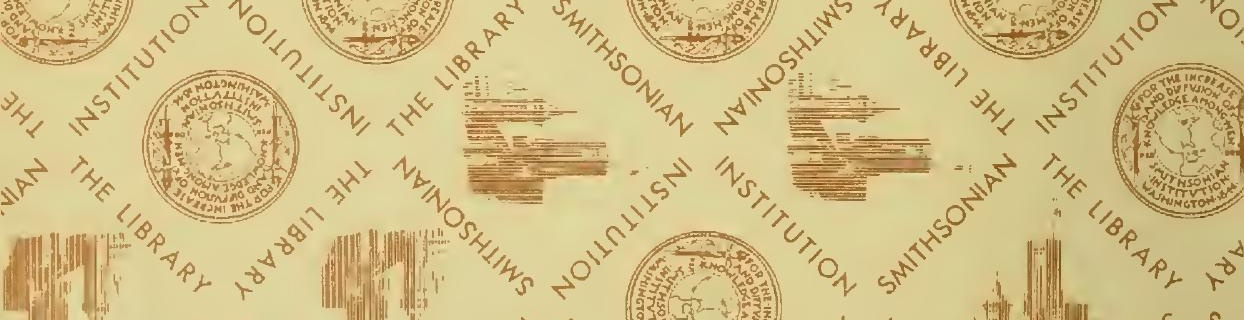

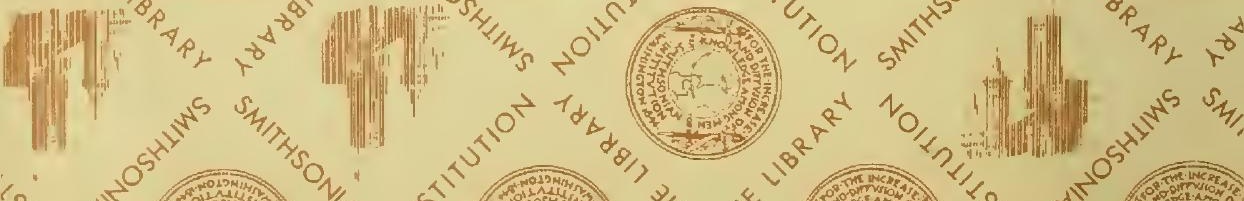

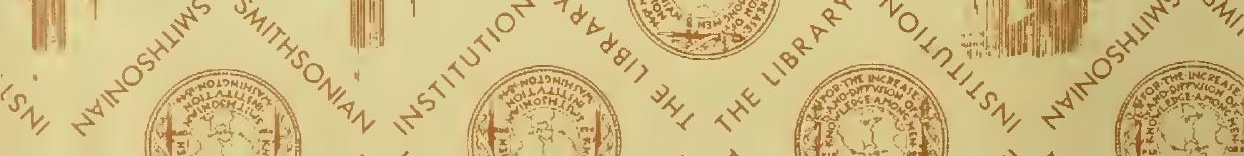




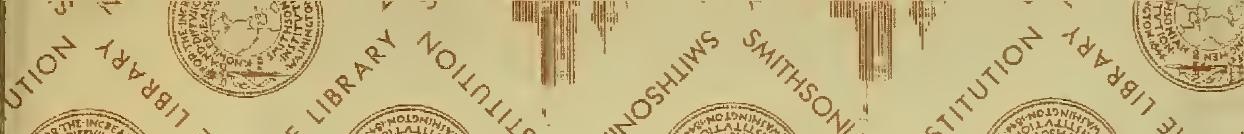

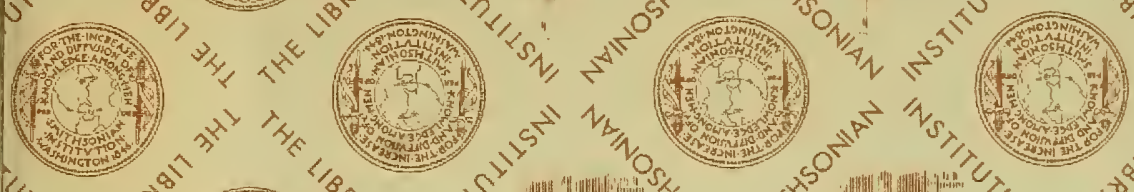

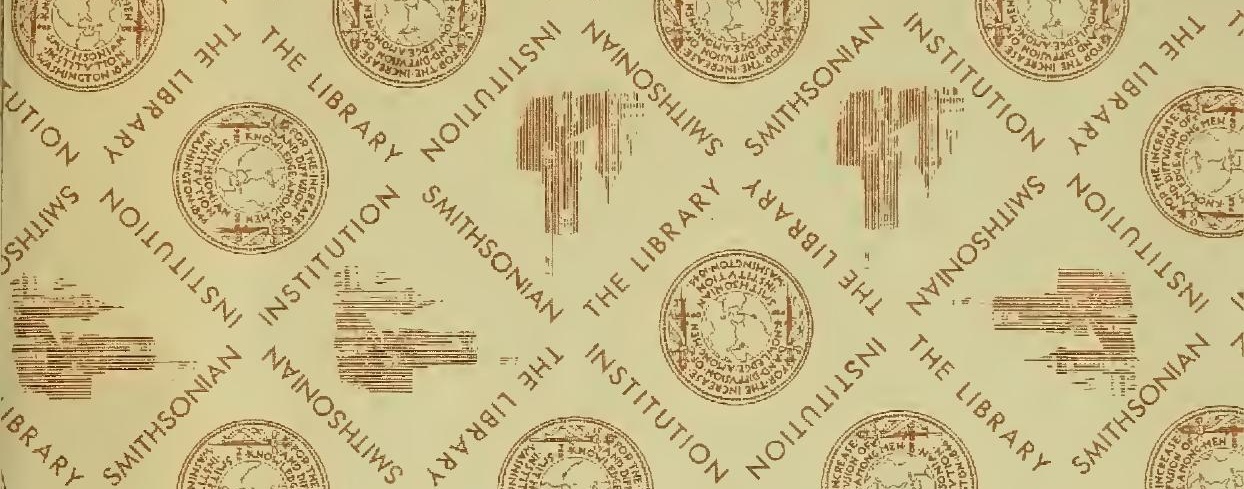
(1)

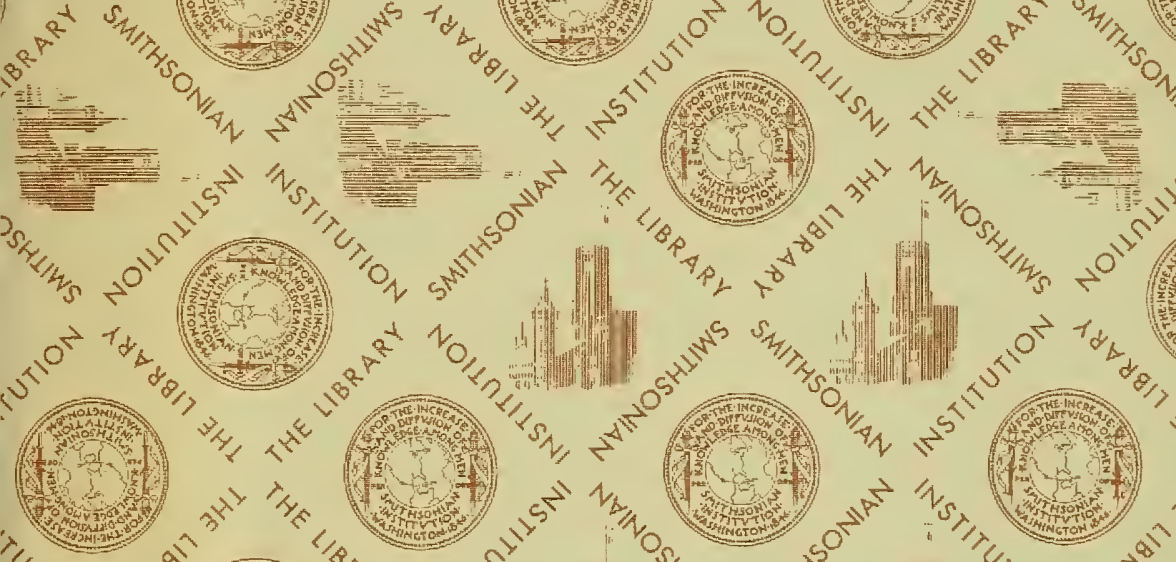

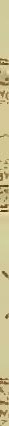

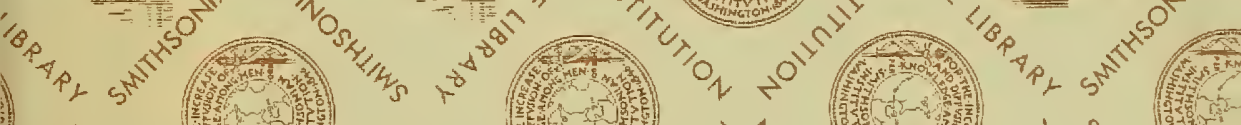
\%

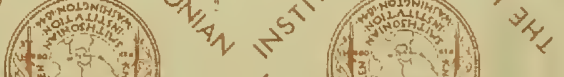


